\title{
An Ethnographic examination of Head Start Nursery School Programs in Ottawa: Past, Present and Future
} by SYLVETTE BRUNEAU, BSW Carleton University

\begin{abstract}
A thesis submitted to the Faculty of Graduate and Postdoctoral Affairs in partial fulfillment of the requirements for the degree of Master of Social Work
\end{abstract}

Carleton University Ottawa, Ontario

(C) 2013 
Library and Archives

Canada

Published Heritage

Branch

395 Wellington Street

Ottawa ON K1A ON4

Canada
Bibliothèque et

Archives Canada

Direction du

Patrimoine de l'édition

395 , rue Wellington

Ottawa ON K1A ON4

Canada
Your file Votre référence

ISBN: 978-0-494-94574-2

Our file Notre référence

ISBN: $978-0-494-94574-2$
NOTICE:

The author has granted a nonexclusive license allowing Library and Archives Canada to reproduce, publish, archive, preserve, conserve, communicate to the public by telecommunication or on the Internet, loan, distrbute and sell theses worldwide, for commercial or noncommercial purposes, in microform, paper, electronic and/or any other formats.

The author retains copyright ownership and moral rights in this thesis. Neither the thesis nor substantial extracts from it may be printed or otherwise reproduced without the author's permission.
AVIS:

L'auteur a accordé une licence non exclusive permettant à la Bibliothèque et Archives Canada de reproduire, publier, archiver, sauvegarder, conserver, transmettre au public par télécommunication ou par l'Internet, prêter, distribuer et vendre des thèses partout dans le monde, à des fins commerciales ou autres, sur support microforme, papier, électronique et/ou autres formats.

L'auteur conserve la propriété du droit d'auteur et des droits moraux qui protege cette thèse. $\mathrm{Ni}$ la thèse ni des extraits substantiels de celle-ci ne doivent être imprimés ou autrement reproduits sans son autorisation.
In compliance with the Canadian Privacy Act some supporting forms may have been removed from this thesis.

While these forms may be included in the document page count, their removal does not represent any loss of content from the thesis.
Conformément à la loi canadienne sur la protection de la vie privée, quelques formulaires secondaires ont été enlevés de cette thèse.

Bien que ces formulaires aient inclus dans la pagination, il n'y aura aucun contenu manquant. 


\begin{abstract}
This study explores the history, the sustenance and the basic operations of Head Start in the Ottawa Carleton Region. Head Start is a specialized form of nursery school designed to raise children of low income and marginalized groups out of poverty by lavishing their 'early years' with stimulating and enriching experiences. Through the use of various research methods including, interviews, focus group and minute reviews the paper explores the foundations of Head Start in Ottawa, the guiding theories of the Head Start Model, the objectives of the program and to what extent the goals are being fulfilled. In this thesis I also identify and discuss some of the structural barriers encountered in the delivery of the Head Start services. A lack of funding commitment underscored the struggles which restrict the potential of the marginalized from becoming empowered and self-sustaining. The disconnection between providers and families using Head Start was also a major area of concern as the involvement of the entire family is critical in capitalizing on the efforts made during the preschool hours.
\end{abstract}




\section{Acknowledgements}

The success and completion of this thesis was built on the overwhelming support and contributions of many individuals. My sincerest gratitude goes to my thesis supervisor, Professor Gerald deMontigny, my second reader professor Shelley Parlow for the many suggestions and recommendations made throughout this process. I also extend special thanks to my editor Charith Wijayawardana who took time to review the paper in its entirety. Heart felt thank you to my partner and best friend, Kelvin Neil Garrette who remained positive, encouraging, supportive and patient through this extremely busy year of writing and graduate school.

Thank you to the members of the Head Start Community of Ottawa (past and present) who welcomed me and were accommodating of my research work!

Sylvette Bruneau 


\section{Table of Content}

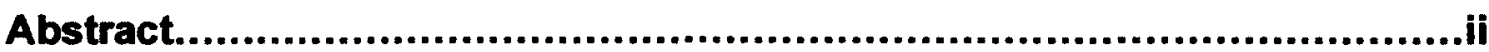

Acknowledgements........................................................................

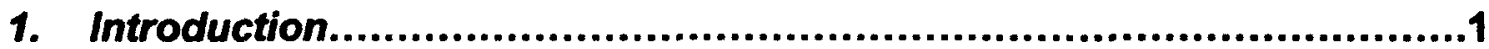

My experience as a Head Start Teacher ...................................................... 1

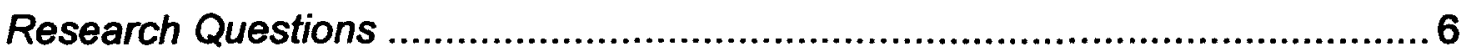

Summary of Research Questions ........................................................... 9

2. Description of Head Start.......................................................13

The Application Process-Ottawa ............................................................... 17

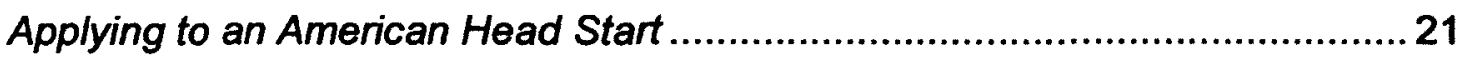

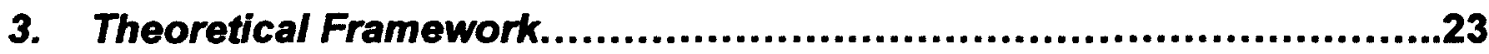

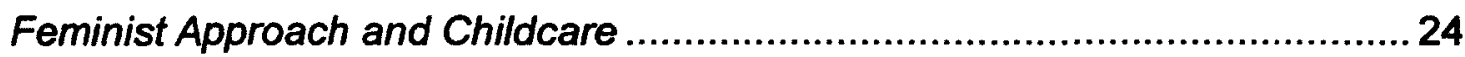

Does a Feminist Approach Suffice? ............................................................. 29

A Structural Approach to understanding Head Start ....................................... 31

Anti-Oppressive Practice (AOP) and Head Start........................................... 33

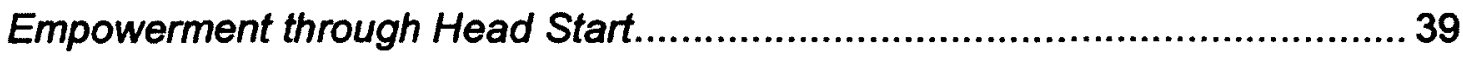

Ecological System Theory and Head Start ....................................................43 43

The Ypsilanti Perry Preschool Project ...........................................................45

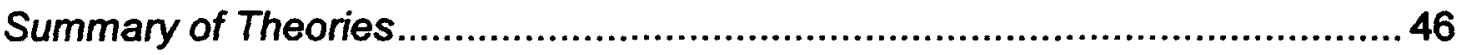

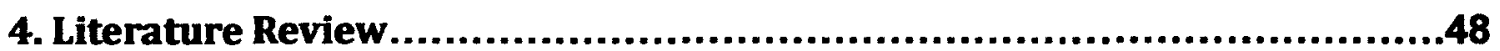

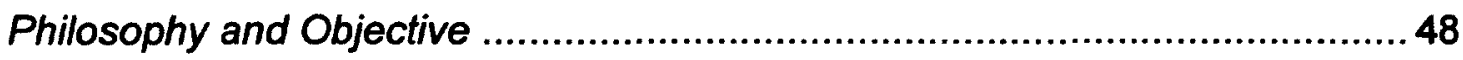

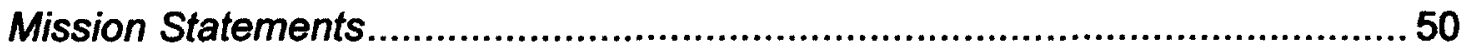

History of Head Start in the United States ..................................................52

History of Head Start in Ottawa......................................................................56

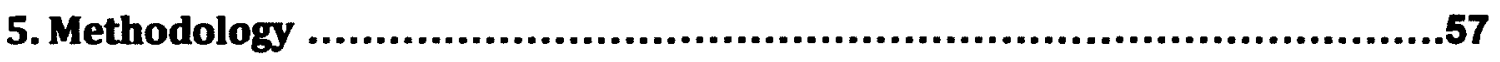

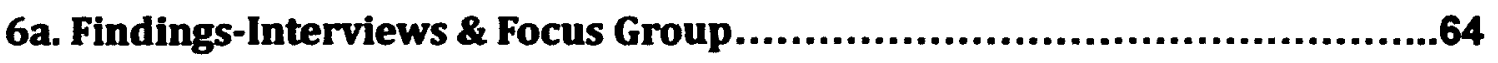

Founders' Interviews \& Focus Group Findings..............................................64

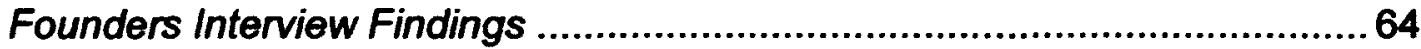

History before OCHAP ............................................................................64

How Head Start got a Start..................................................................... 71

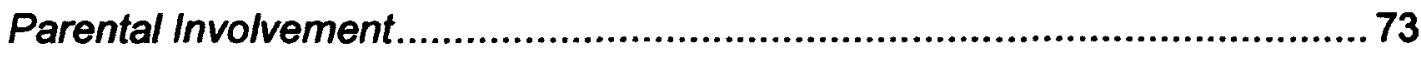




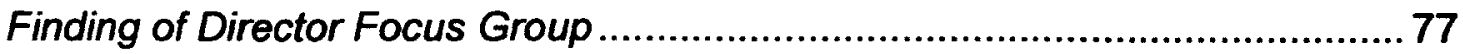

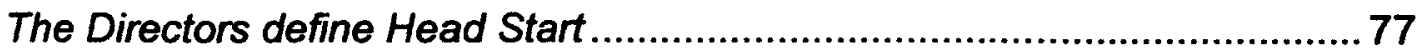

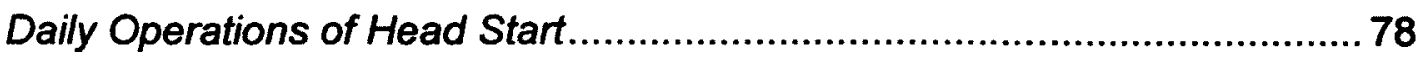

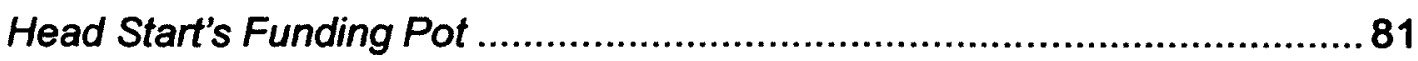

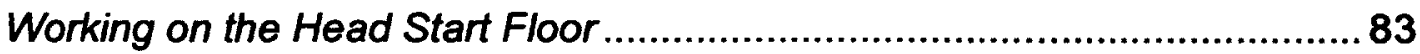

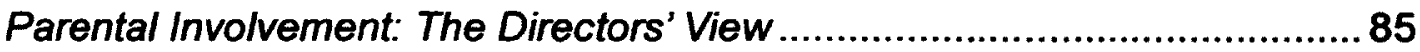

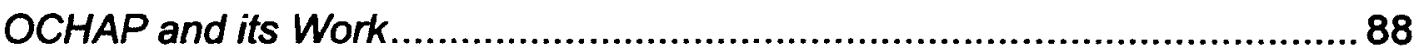

Summarizing Founders Interviews and Directors' Focus............................ 90

6b. Findings/Reviews of Records..............................................91

An Archival view of Head Start's History ....................................................... 91

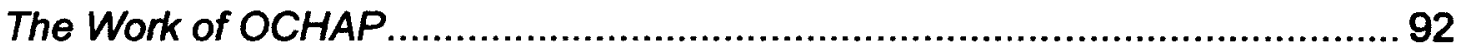

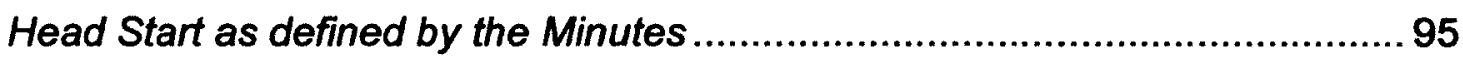

Funding Woes since the Inception ................................................................98

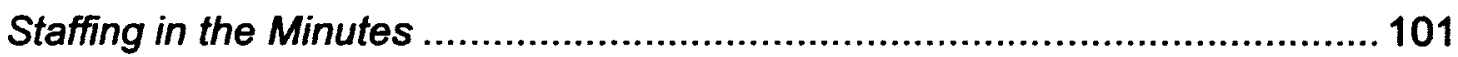

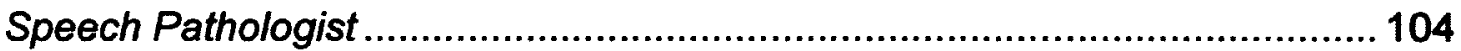

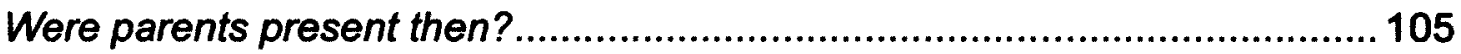

7. Analysis and Discussion..........................................................108

What does the program do? How it works? ............................................... 108

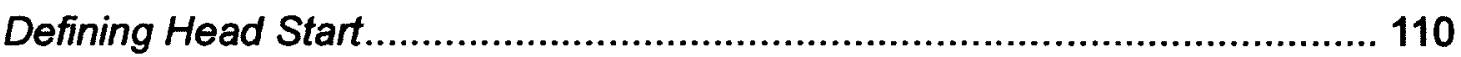

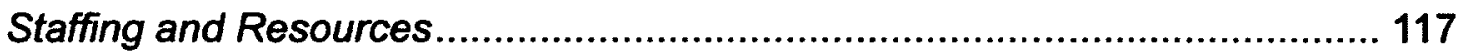

The Roots of Head Start Ottawa ............................................................. 121

Bridging the Gap: Getting Parents More Involved ...................................... 124

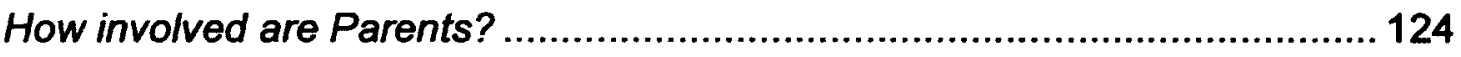

Why should parents be involved? .............................................................. 126

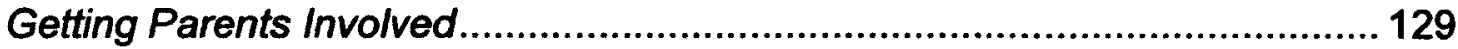

The role of Ottawa Carleton Head Start Association for Pre-Schools (OCHAP)

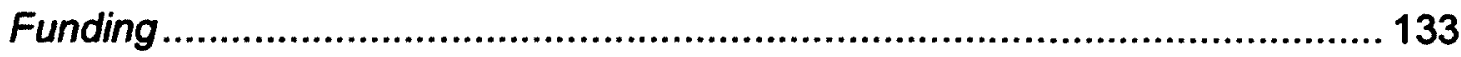

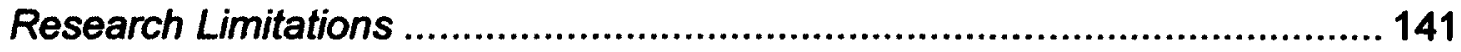

8. Conclusion..........................................................................143

The roots of Head Start in Ottawa............................................................... 143 
Pulling the Defining Pieces Together ....................................................... 143

Head Start's place in the current childcare system ...................................... 144

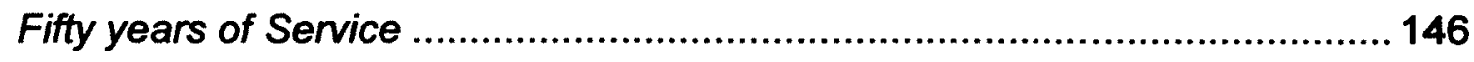

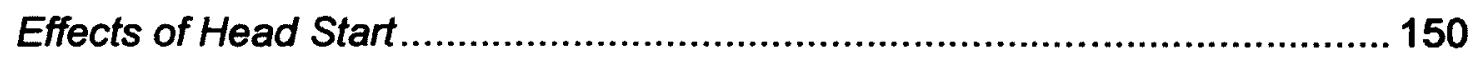

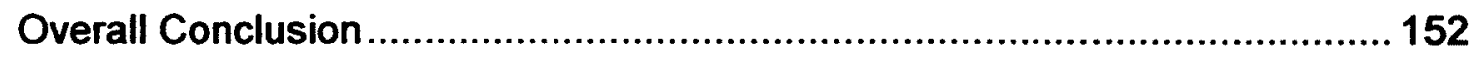

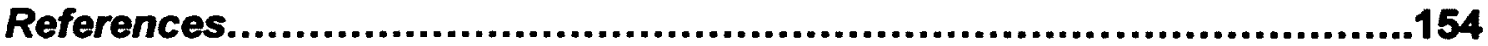

Append. 1 -Semi-Structured Interview for Head Start Founders......................... 158

Append. 2a. -Semi-Structured Interview for Head Start Directors ........................ 159

Append.2b- The Head Start Model ........................................................... 160

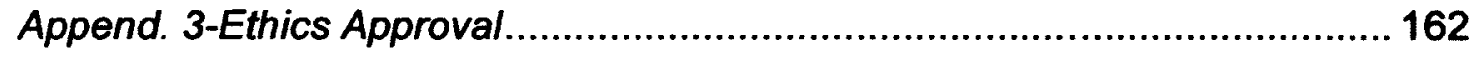

Append. 4 -Consent Form for the Founder of Head Start ........................... 163

Append. 5 -Letter and Consent Form for the Directors of Head Start ........... 166 


\section{Introduction}

My experience as a Head Start Teacher

This section is a reflection of how I understood Head Start from my position as a teacher. I will touch on my role and involvement in the everyday operations of the program, the parental involvement, and my overall understanding of Head Start. It must be noted however that I came into the position during the last four months of the program's existence at the centre so the dynamics might have been somewhat different from the norm.

After completing my first year of undergraduate studies in 2008 , I secured a job with a childcare centre in Ottawa. Within this centre was a Head Start nursery school program. I initially applied as a supply teacher but was offered a Head Start teacher position replacing the teacher who was going on maternity leave. During my time as a Head Start teacher I worked with Jenny ${ }^{1}$ who was the other Head Start Teacher and a qualified early childhood educator. At the time I did not know what Head Start was and why it was referred to as such. I assumed that 'Head Start' was a fancy name for a nursery school. My training involved shadowing the ECE teacher, learning the routines and reading manuals. I worked in that position from May to July, as the program was shutting down at the end of July.

1

Jenny is a pseudonym used to safeguard the anonymity of my co-worker. 
A typical day at Head Start began for the teachers at 8:30 in the morning. From 8:30 to 9:00 a.m., our tasks involved getting the classroom ready, setting up different play areas, preparing snacks and attending to administrative requirements. The teachers would go out to meet the children as they arrived in the two minivans. The bus monitor would travel in one of the vans to pick up and drop off the children. With the help of the bus drivers, we got the children off the vans and into the classrooms. The drivers would often walk with us to the classroom door. They were extremely friendly and helpful. Upon arrival, the children changed from their outdoor to indoor shoes. They were then served a morning snack that included milk or juice, a fruit, and some form of carbohydrate often in the form of toast with a spread or cheese. Provision was made for children with various forms of dietary restrictions and allergies. Thereafter we would proceed to some of the planned activities that included a fine motor activity like colouring or painting. Children also had the option of working in the block or drama areas.

A mandatory part of their day was outdoor play. While one group remained inside to partake in small group activities such as arts and craft or a board game, the others would change into their outdoor attire and head to the playground. The groups would then rotate. The outdoor activities were likewise planned and would include anything from water play to bike riding. Towards the end of the session the groups would come together, use the bathroom, wash hands and have another snack, which was different from the morning snack, but which would be similar in nutritional content. We would end the morning with "circle 
timen", which included stories and singing. At this point the bus monitor or floating teacher would come in to help the children change into their outdoor shoes, gather their belongings, line-up and get on the bus. They would leave at approximately 11:30 a.m. Just as they were leaving however, the other full day preschoolers would be settling in for their hot lunches that were prepared by an on-site cook. The Head Start children often looked on yearningly at those meals, but were hurried off to their waiting buses. I sometimes wondered why they could not enjoy hot meals as did the rest of the childcare kids? I justified the answer with the reasoning that they were not at the centre long enough to get this meal. Looking back, it seems peculiar that they were not entitled to receive full meals when they were among the most vulnerable and perhaps most needy children at the centre.

After the children were seen off on the bus, my co-worker and I would return to the classroom, write up individual logs, a class log, tidy up, and sometimes wash and rotate toys. Other times we worked on plans for upcoming weeks. I did not feel comfortable or competent in suggesting or contributing to those plans and often tried to retreat to tidy-up and organize the playrooms. In retrospect my feelings of incompetence were rooted in my limited knowledge in early childhood education. I knew how to interact with the children, sing to them, and play with them, but I did not understand the academic reasoning for doing what I did. I enjoyed spending time with the children most of all, but simply did not have the formal training necessary. 
Despite the many similarities between Head Start and the other childcare program there were some marked differences. There was clearly a greater representation of children of diverse ethnic backgrounds in the Head Start classroom. In some of the cases, the children were still learning to speak in English. The presence of behavioural issues was also more prevalent in the classroom. It was such an issue that while the other groups were able to go off site for walks; we were not able to do so out of concern for the safety of the children. For example, I remember my co-worker trying desperately to organize a walk to the nearby museum. Yet we could not go unless we got the parents of Stella $^{2}$, a child who had been diagnosed with low functioning autism to accompany us. Stella required one-on-one supervision as she had a history of running away when not closely monitored. We feared that she might run out onto the road.

I also found it to be unusual that I did not know the parents of the children I worked with. If the children were going to be absent from the centre on a particular day, the call was made to the bus drivers and they would in turn inform us. I was curious to know where these children were coming from and who they spent time with. Although the program was coming to an end, the centre was working on getting the teachers to occasionally accompany the children on the buses. I got to do the drop off on one occasion. I remember meeting just one parent as the other children were picked up by their babysitter. The bus driver

2

Stella is a pseudonym used for confidentiality purposes. 
introduced me to the.caregivers. I was somewhat disappointed that I did not get to meet more parents on that occasion, but I their absence was due to other demands like work.

In time, I became aware of the other ways in which Head Start was different from the other preschool programs. It was the only room in the childcare centre where there was an external expert visiting on a regular basis. A behavioural therapist came in bi-weekly from CHEO. She mostly interacted with Jenny, the senior teacher who had been working with the children and who knew them much better than I did. The two would meet to review notes after which the therapist would join us on the floor. A most memorable moment for me was getting hands-on assistance from the therapist. Stella, the child with low functioning autism, would stand on the table and wriggle aggressively. This behaviour was unsafe to her and the other children. My efforts to get her down and to remain off the table were futile. She would throw a fit and return to her spot on the table. The therapist who witnessed the scene indicated that Stella was deliberately seeking the attention that I gave each time that I went to get her off the table. The therapist then proposed that we try a different approach to curb the unsafe behaviour. As she demonstrated I stood by and observed. She went over to Stella who was standing on the table, gently picked her up and set her on the floor. The therapist's face however was turned away from Stella's visual range. The therapist then walked away from her. Stella stood there for a moment seemingly assessing what had just happened. Usually, when I had gotten her off the table she would return to the top without hesitation. This time she seemed slightly confused 
about what had just happened, but still returned to the spot on the table top. The therapist then urged me to try the strategy. As I walked away from Stella, I could see that she was starring in my direction. At this point little Stella looked around then directed her energy to a more appropriate activity. The therapist suggested that I join Stella and reward her choice. I remember standing there in awe thinking 'this is like magic'. To consolidate and help me understand what had happened, the therapist told me a personal story of her wedding where she had specifically and repeatedly told her wedding planner about the flowers she did not want for her ceremony. To her horror these were the very flowers that were ordered by the planner. According to the therapist the story emphasized the need to focus on the acceptable behaviour rather than the behaviour we wish to curtail. This vignette demonstrated that the hands on and direct help that the children received from trained professionals through the program was indeed beneficial.

Overall, I admired and appreciated the work that the coordinators and teachers and staff members put into the program. Even though the children were present for just two and a half hours I often felt overwhelmed. I found myself alone with the larger group as Jenny tried to work one-on-one with Stella. It was truly rewarding to see the children make progress no matter how small.

\section{Research Questions}

The future existence of Head Start may be in jeopardy in light of political concerns with government deficits, and the resulting cuts to childcare and education. The following research questions were formulated with the aim of better un- 
derstanding the social dynamics involved, determining whether Head Start should continue to be supported by governments, and whether the funds and efforts directed at Head Start would be better spent on other childcare programs.

1.What is the Head Start Program, what is its purpose, and what differentiates it from other nursery school programs?

Through this question I sought to understand the underlying fundamentals of the Head Start program in the United States and Ottawa, Canada. Specifically I wanted to develop an understanding of the factors contributing to the front line functioning of Head Start, the daily routines of the program, and the varying individuals that contributed to the functioning of the program. Further I wanted to examine how Head Start might be different from other childcare programs, and whether such differences warranted special attention. The discussion within this research can be better formulated around the role and purpose of Head Start by developing a concrete understanding and appreciation for the program's inner workings.

2. What factors have contributed to the sustenance of the Head Start? What are some of the challenges that workers and users of the program have had to deal with and overcome?

This question sought to address and outline factors that were necessary for the ongoing sustainability of social welfare oriented programs such as Head Start. Does the strength of the Head Start program lie within the model itself? Or is the program's survival better understood as the result of external factors such as legal and political endorsements, continuous advocacy, financial commitments, or perhaps a combination of these factors? 
3. How do aspects of the history of Head Start help us understand the current operation of the program and how has the history of Head Start in the United States influenced the formation and functioning of the program in the OttawaCarleton region?

This research question aimed to examine the Head Start program in the larger context of childcare delivery at the municipal, provincial, and federal levels. This analysis required an understanding of how policy makers perceived Head Start and how these perceptions influenced and affected the operation of Head Start. It is very rare that social service programs, particularly those of a selective rather than universal nature, are able to last through the decades with ever shifting political, social and economic conditions. It is even more astonishing that Head Start has been able to continue functioning for over 47 years in the US and 42 years in Ottawa. The reasons for the survival of Head Start may be diverse given the different contexts of local programs, but I believe that there are lessons to be learned from the program's longevity.

4. How is Head Start understood by the providers of the program?

In addition to examining the model on which Head Start is built this thesis will attempt to explore the extent to which Head Start programs are meeting their stated objectives. This information was gathered from directors of the Head Start programs who took part in a focus group. As part of this exercise they provided concrete examples of the program's performance. Efforts were directed at understanding what the mission of the program and its vision means to the directors, as well as current and past factors that may be preventing the fulfillment of the ideas conveyed in the program's stated vision. An understanding 
of Head Start mission statements is relevant to appreciating the expectations of the program for its users and how it seeks to help families.

5. What is the future direction of the Head Start program and what can be leamt from it as program of a Social Welfare program?

It is hoped that an exploration of the Head Start program will reveal some characteristics which can be incorporated into other childcare and welfare programs. Additionally it is anticipated that recommendations can be made for future improvements or streamlining of the Head Start program, to maximize the use of resources but also to maximize the benefits to the users of the program.

\section{Summary of Research Questions}

To gain a more in-depth understanding of the dynamics of the program and the various levels of interaction, it would have been ideal to interview and study all parties i.e., parents, children, teachers, directors, founders and policy makers. This would provide a first-hand view of the operations, challenges and impact of the program. Fortunately, there was an opportunity to review three reports prepared by community developer Shirley-Ann Moy on Head Start programs in Ottawa. One was on the transportation system another on the speech and language program and the third examined gaps in the operation of Head Start in Ottawa. Unlike the limited research on Head Start in Ottawa, there was

extensive research on the impact of Head Start on the individual, community and society in the United States.

Head Start, like most publicly funded social programs, was affected by policymakers who have only a limited understanding of the need for such services, 
or the positive contribution to society of such programs. The political and economic climates governing the region dictate the establishment, expansion and possible closure of social programs. Head Start America operated under the Economic Development Act (1965). As part of a health initiative, the American program appeared to be better able to withstand the changes in political will, while the Ottawa programs, which happen to be the primary Head Start programs in Canada, appeared to be more vulnerable to policy and funding shifts within the municipal government. It appeared that the founders of Head Start in the United States had determined that the risk faced by impoverished children and their families should be treated as a health concern. Children living in poverty are more likely to suffer from ill health due to poor nutrition, reduced access to healthcare and lower education level of parents. Consequently, Head Start advocates recognize that these children are denied the opportunity to reach full potential and to contribute fully to the societies in which they live. More so, if early intervention and support was not available to these families and their children, they are apt to remain dependent on the welfare systems throughout their life span (Mc Cain \& Mustard, 1999).

Where possible, the research questions will be examined in a way that follows the time line of the Head Start program's development to recognize the potentially changing roles of the historic and regional context in both Canada and the United States.

The research relied predominantly on qualitative data to understand the operations, the usefulness, and future direction of the Ottawa Head Start pro- 
grams in Ottawa. While statistics may be extremely useful for understanding the utility of a social program, detailed accounts of everyday operations were essential for policymakers to better appreciate how the Head Start program affects families within its service delivery environment.

Following this introduction, the second chapter of this thesis outlines a description of Head Start which includes the structure of different programs in Ottawa in terms of management. This section also highlights the steps involved when a parent applies for placement for their child in Head Start. In chapter 3, there is discussion of the theories and ideas that have informed the establishment of the program and those which help us better understand the operation of Head Start. Chapter 3 is followed by the literature review where the head start model, the origins, philosophies, vision and mission statements of the overall Head Start program and individual Head Start nursery schools are discussed. Chapter 4 outlines the many approaches which can be employed when assessing the Head Start model within the field of social work. Based on a preliminary review of Head Start in terms of its history, activities, target groups, goals, and objectives the social work approaches that best aligned with the work of the program were the structural framework, the anti-oppressive approach, and the empowerment perspective. However, Bronfenbrenner's ecological systems theory and the studies of Weikart have guided the foundation of Head Start Nursery school model from an Early Childhood education perspective. The methodological process and the findings are contained within chapter 5 and 6 respectively. 
Data was gathered using three primary methods. These were interviews with founders of Head Start nursery schools in Ottawa, focus groups with current directors and review of Ottawa Carleton Head Start Association of Preschools ${ }^{3}$ (OCHAP) directors' meeting minutes and documentation. Interviews and focus groups were audio recorded while relevant data from the minutes was reviewed and typed. The findings chapter is divided into two segments; chapter 6, part a, highlights findings from the interviews and the focus groups while part $b$, focuses on findings from the minute and documentation review. Some of the key themes emerging from the findings were the history of Head Start, defining the program, parental involvement, the work of OCHAP, funding and staffing of the Head Start programs. These themes are further analyzed using ideas from the frameworks and theories on which Head Start has been built and preceding theories which help us understand the work of Head Start. Some of the major points of analysis were the lack of consistent funding directed at Head Start programs and the consequences of this unreliable funding. Another major concern was the disconnection between parents and staff of the program.

The final chapter, the conclusion uses information from the research to provide direct answers to the research questions and make conclusions about the history, the current situation and future direction of the Head Start program in Ottawa.

3

While OCHAP combines the word 'Headstart', most other sites and documentation break the word into 'Head Start'. Hence throughout this paper the most commonly used form Head Start is used. 


\section{Description of Head Start}

The Head Start Nursery school program started in the United States in 1965 as part of President Lyndon Johnson's "war on poverty". The inception of Head Start was spearheaded by Sargent Shriver in collaboration with an eclectic team of experts from psychology, social work, education and social planning. Head Start was designed to meet the early education needs of children from low income, highly marginalized communities. Head Start offered a specialized form of early childhood education to its users. Generally, the program targeted children and their families facing multiple barriers and challenges associated with living in poverty and or marginalized groups in the community. Ideally the Head Start model stressed the importance of care giving, child education, parent education and access to other community resources. The model assumed a holistic view of the child and family unit as it attempted to consider multiple factors influencing the well-being of the child such as schools, daycare programs, social welfare programs and levels of income. Centers using the Head Start model do not just act as childcare providers, but also address health, housing, parenting, child mental health, and language barrier concerns. Historically Head Start has been known and widely accepted as a program which makes a positive impact on the lives of poor children and their families. However, with the passage of time, and with changes in economic and social conditions, it has become a question of whether Head Start is still serving its purpose or whether it 
is missing its target, and if so how do policy makers and providers of the service respond.

Head Start in the United States began as a summer school venture but was eventually extended to a year round program. According to a member of the Ontario Carleton Headstart Association of Pre-Schools, (OCHAP) four women from Ottawa went to the United States shortly after Head Start was established there, and upon returning, adopted the idea and launched Head Start in Ottawa. Like the American Head Start, Head Start in Ottawa begun as a summer project. It was first located at the Algonquin College. The Young Men's Christian Association, Young Women's Christian Association (YMCA-YWCA), on Argyle Street in downtown Ottawa was the first organization to house a full time, year round Head Start nursery School in 1966. Between the period from 1966 to 1990 the program expanded to include twelve other centres at the height of its popularity (Moy, 2001). Within that period however two closed down entirely (the YMCA-YWCA and the West End Head Start Nursery Schools) and another was absorbed into another Head Start program. In 2006 there were ten Head Start Nursery schools operating in the Ottawa Carleton Region, serving 290 children and their families (OCHAP, 2006). Ten schools continue to be in operation today. These ten schools are governed under six managerial boards. The Annavale Nursery School (1) is under the management of the Carlington Health Center while the Children Aid's Head Start (2) is attached to CAS Ottawa. Pinecrest Queensway Head Start (3) is led by the Pinecrest Queensway Community Health Centre. Esther By Daycare (4) and Foster Farm (5) childcare centres are under 
the direct supervision of the City of Ottawa while Cornerstone (6), Heatherington (7) and Hawthorne Meadows (8) Head Start programs fall under the board of the Hawthorne Meadows Nursery School Incorporation. The Queensway (9) preschool once run as an independent school but was forced to merge with Nanny Goat Hill nursery (10) when it faced possible closure due to a lack of funding. This merger meant that although the schools were at different locations both centres were now under that management of the Somerset West Community Health Centre. Some programs operate two half day shifts while others run full day. The half day programs can accommodate twice as many children, as there are morning and afternoon shifts, while the full day programs accommodate fewer children but they are open generally from 7:30am to 5:30pm depending on the centre. The table below shows the current breakdown of the managing agencies of each of the Head Start Schools and identifies those programs which operate on a half day or a full day schedule.

\begin{tabular}{|c|c|c|}
\hline Managing Agency & Head Start Centres & Hours of operation \\
\hline Children's Aid Society & Children's Aid Head Start & Full days \\
\hline $\begin{array}{c}\text { Pinecrest Queensway } \\
\text { Community Health Centre }\end{array}$ & $\begin{array}{c}\text { Pinecrest Queensway Head } \\
\text { Start Nursery School }\end{array}$ & Half days \\
\hline $\begin{array}{c}\text { Carlington Community Health } \\
\text { Centre }\end{array}$ & Annavale Nursery School & Half days \\
\hline $\begin{array}{c}\text { Somerset West Community } \\
\text { Health Centre }\end{array}$ & Nanny Goat Nursery School & Full days \\
\cline { 2 - 4 } & Queensway Preschool & Half days \\
\hline City of Ottawa & Ester By Daycare & Full days \\
\cline { 2 - 4 } & Foster Farm Nursery School & \\
\hline
\end{tabular}




\begin{tabular}{|c|c|c|}
\hline \multirow{4}{*}{\begin{tabular}{c} 
Hawthorne Meadows Nursery $\begin{array}{c}\text { School Inc. } \\
\text { Scherstone Children's Centre }\end{array}$ \\
\cline { 2 - 3 }
\end{tabular}} & $\begin{array}{c}\text { Hawthorne Meadows Nursery } \\
\text { School }\end{array}$ & Full days \\
\cline { 2 - 3 } & Heath days \\
\hline
\end{tabular}

The closure of the YMCA-YWCA and West End Head Start Nursery Schools and the forced merger of the Queensway Head Start raised questions around the viability and sustainability of the program. Likewise, in the United States the Head Start program faces uncertainties due to government funding cuts to childcare services. In the United States more than 150 concerned groups rallied in early 2012 against possible closure of many childcare services following proposed federal funding cuts of $\$ 170$ million (Knako, 2012).

While there are significant differences between a Head Start program in the United States and the programs in Ottawa, the underlying principle of providing high quality nursery school experience to underprivileged children with the goals of bringing them to comparable levels as children from middle class backgrounds is the same. The overall purpose of this thesis was to develop an understanding of Head Start Nursery schools in Ottawa as it related to the history, the factors that have contributed to its sustenance, the patterns of growth and challenges encountered, the perceptions of the providers of the program, the purpose of the program as well as future directions of the Head Start Nursery School in Ottawa. Historically, Head Start has had the reputation of a social welfare program directed at young children of impoverished families. 


\section{The Application Process-Ottawa}

A significant component of any program is eligibility. Boundaries, requirements, testing, and interviews are used to determine who is eligible for a social service as more programs were being delivered on a selective rather than universal level. In this section I examine the process of applying for a spot at Head Start. The Head Start program in Ottawa was fully subsidized by the municipal government (City of Ottawa, 2012).

As with most welfare programs, the application process was, and continues to be a significant hurdle. It must be followed carefully to increase one's chance of obtaining a spot. The application process is two-pronged, as parents are required to secure a spot at the school and secure subsidized funding. An individual who is already receiving social assistance can get help from their Ontario Works case worker with the application process, but others are expected to navigate through the process on their own. The provision of subsidized funding to a family is determined through an intake and assessment process which scrutinizes and carefully evaluates need. The parents are required to contact by telephone the Employment and Financial Assistance Branch of the City of Ottawa. During the phone call they follow a prompt to childcare, which then offers the option of contacting the childcare subsidy office. The phone lines are opened Monday to Friday from 8:30 a.m. to 4:00 p.m. and a call last between 15 to 20 minutes. 
When a caller gets through, they are required to ask for an eligibility assessment for a Head Start program. At this point, a verification specialist asks basic identifying demographic questions. Part of the reason for this telephone interview is to gauge the needs of the families. In cases where parents are working, they are required to produce the most recent pay stub in support of the hours worked during a monthly period, and in cases where pay stubs are not available parents must produce a recent letter of contract which states their work hours. In cases where parents are returning to work after parental leave, a letter must be produced again identifying their start date. For those parents who attended school, proof of school registration and class schedules is required (City of Ottawa, 2012). Parents are then instructed to produce a portfolio of supporting documents, ranging from bank books, insurance check stubs, birth certificates, to OSAP assessments. There are a total of 21 documents that applicants could be required to submit for each member of the family including the child. These documents are to be produced within 10 days of the initial phone call .

Once the supporting documents are presented, the parents are then contacted for the next phase of securing Head Start subsidy for their child. They are usually contacted within $2-3$ weeks. This is followed by an assessment interview conducted by an Ontario Works case coordinator. It may last one and ahalf to two hours, after which the worker would decide whether or not the family

4

The booklet does not specify whether these are to be produced in 10 calendar or business days. Applicants have the flexibility of mailing, faxing or bringing these documents to the office. 
qualifies. At this juncture, the family may be required to provide further supporting documents. In this interview there is a review of family assets, total family income and their normal monthly expenditures. If it is a two parent family both parents must be present. The interview is repeated on an annual basis in the event that the family's financial circumstance changes within the year. The follow-up interviews must be booked before the end of the subsidy period to maintain continuity. If accepted parents were also notified of rules and regulations, such as child were allowed 36 days of holidays or absenteeism per year. If absenteeism exceeded 36 days the family is required to pay the full care of childcare in addition to their regular monthly fees (City of Ottawa, 2001-2012). Parents on the other hand who are deemed ineligible for subsidies have a right to appeal the decision (OCHAP, 2010).

According to the City of Ottawa (2001-2012), the childcare subsidy program is financial assistance made available to families residing in Ottawa. Parents of eligible families are often members of the working poor, job hunting, or enrolled in school during the times that the child would be requiring childcare. $A$ small segment of the eligibility description indicates that families in which the parent(s) or child may have special needs of either a medical, social, or emotional nature may also be considered for a subsidized spot. Subsidized spots for Head Start are part of this exception. One's eligibility for Ontario Works may also be used as a qualifying determinant for a childcare subsidy. Beneficiaries of this program are expected to meet certain financial criteria. Subsidized 
assistance is available for children between the ages of 0 to 9 years and 10-13 under special circumstances.

Although most spaces are fully subsidized, an income test derived from the federal notice of assessment, along with total family income from the Canada Child Tax Benefit are used to not only to confirm eligibility, but also to determine how much subsidy is assigned (City of Ottawa, 2012). It is somewhat confusing that Head Start spots are referred to as fully subsidized, and yet methods of testing are used to determining how much a family pays. During a focus group directors noted that while the service could potentially be fully subsidized, parents are required to pay what they can afford. They referenced one family where a child had severe developmental disabilities and could not find appropriate childcare. A Head Start spot was available to the child but the parents were able to pay the entire cost of childcare. It appeared that full subsidies are made available on a means tested basis. In addition, to apply for childcare, the parents must have filed income tax returns as information from Line $\mathbf{2 3 6}$ of their most recent notice of assessment is used to calculate the amount. Recent immigrants may apply for childcare but need to make this information available after their first income tax return (City of Ottawa, 20012012).

The City of Ottawa website indicated that parents are responsible for finding their subsidized spot and warns that spots may not be immediately available. As a result children may be placed on a centralized waiting list until a spot becomes open. Directors of the Head Start program expressed concern that 
the central list disadvantages parents who are in immediate need of their services. They did not feel that Head Start should be pooled with all other childcare spaces on a subsidized waiting list because their services are highly specialized and may sometimes be needed with urgency. The centralized waitlist likely creates distance between the service providers and the target population.

One of the few comprehensive studies undertaken by OCHAP was conducted by community developer Shirley Ann Moy in 2001. In her research, Moy discussed the issues with the overly complex application process. She noted that the directors of the program identified the intake process as "bureaucratic, intimidating, and disrespectful to parents" (Moy, 2001). The information provided to parents by the subsidy office was sometimes inaccurate and resulted in some parents being turned away unnecessarily. In some instances families may not qualify for subsidies, but their children may benefit or be in significant need of programs of an enriching nature such as Head Start. Similarly, some families were at the cusp of the low-income qualifying levels and may be disadvantaged by the restrictions. Parents likewise expressed dissatisfaction with the process of applying for childcare subsidies and felt interrogated and to a certain extent violated (Moy, 2001).

\section{Applying to an American Head Start}

While there are considerable differences between the Head Start program in Ottawa and the United States especially in methods of funding, the size of the program and perceptions of the program, it is nevertheless useful to compare the 
two application systems. The application process appears to be less complex in the United States. While there may be slight deviations from one program to another, the Bloomingdale Family Program of Manhattan New York, under the heading of how to apply states, "Come in, bring your child to any of our three centres". This is followed by notification of the days and time frame within which they may do so. This section is then followed by a listing of what is required for the enrolment of the child and identifies seven items of which two are directly concerned with the identification and care of the child. This included their birth certificate and health card. Other required documentation includes welfare identification, health insurance for all members of the family, proof of income, social insurance card if applicable, and school schedule if the parents were attending school. It then states that children would be placed in full or half day childcare based on family's needs (Bloomingdale Family Program, 2012).

This comparatively small emphasis on eligibility in the U.S. is reflective of the fact that the program is federally funded and is more universal in nature. The program is less concerned with streamlining the population to determine eligibility. The Head Start program in Ottawa lacks sufficient supply of resources to meet the demands of families requiring childcare programs of an enriching nature and must hence ration and be highly selective in the use of those limited spaces. 


\section{Theoretical Framework}

In planning the project a variety of approaches and theoretical lenses were considered. As can be expected with a program that has been in existence for such a lengthy period, the frameworks through which the Head Start program can be best understood have changed over time. Likewise, the framework through which we can examine Head Start in Canada tends to be different from that of its American counterpart. While some of the frameworks like Bronfenbrenner's ecological system theory and the Perry Preschool project informed the formulation of Head Start others like the structural and antioppressive approach emerged after Head Start but are instrumental in helping us understand the operation of the program. While directors of Head Starts endeavoured to follow an established model, the application of the framework varied from one centre to another. There have also been sustained and developed commonalities across Head Start programs and at individual centres, despite the vast differences between the time the programs were established and their local context. Social Work perspectives help shed a different light on the operation and function of Head Start than Early Childhood theories. Examining Head Start programs using theories from both fields however, offers a more enriched understanding of the program in terms of its goals, why it exists and the population it serves.

Many approaches can be employed when assessing the Head Start model within the field of social work. Based on a preliminary review of Head Start in terms of its history, activities, target groups, goals, and objectives the social work 
approaches that best aligned with the work of the program were the structural framework, the anti-oppressive approach, and the empowerment perspective. Prior to discussing the Head Start Model, it is imperative to recognize that Head Start is part of a broader childcare system. Advocacy efforts directed at creating a more sustainable and comprehensive childcare system are often guided by a feminist approach. Figure 1 illustrates the relationship between the overall childcare system and the Head Start nursery school program, and the varying frameworks that would be best suited to understanding the functions of the program.

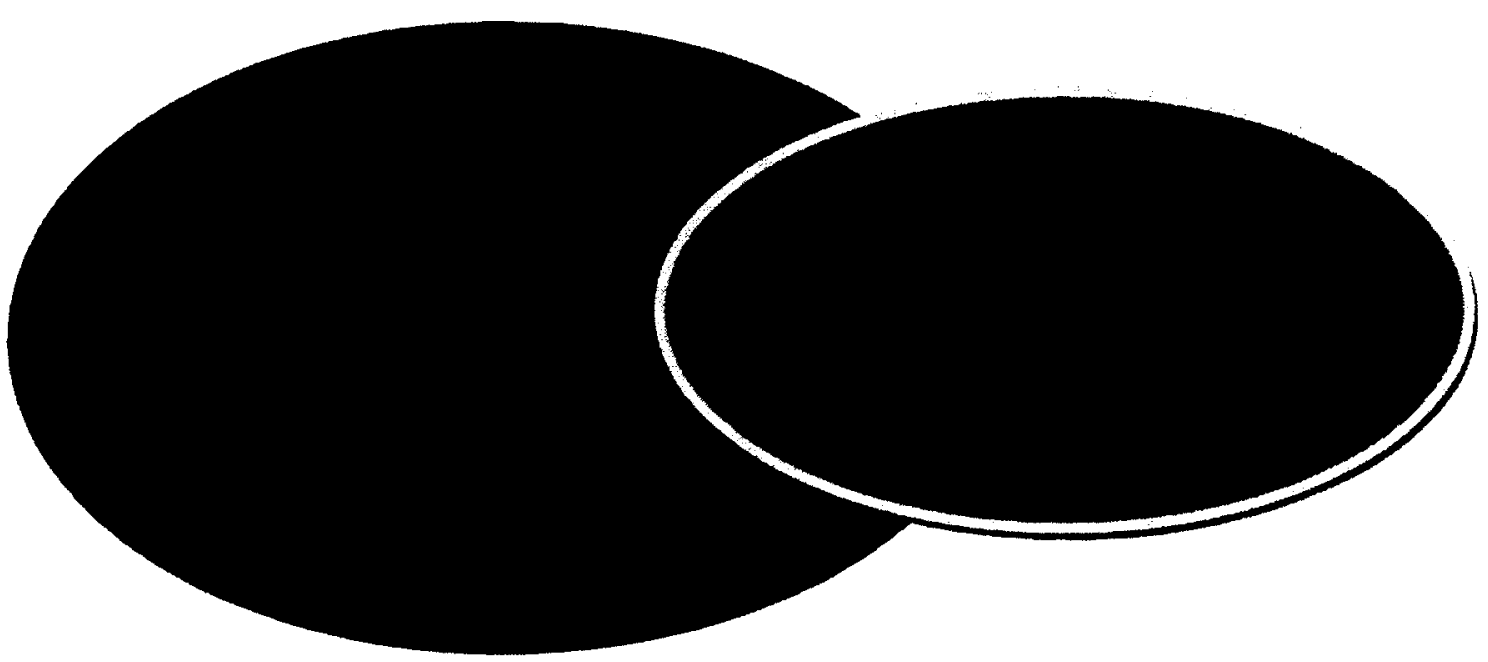

Figure1. Social Work Frames used in looking at Childcare and Head Start Nursery Schools.

Feminist Approach and Childcare

Second wave feminist theorists have drawn attention to the oppressed position of women across societies since the 1960s. Feminist social workers 
developed an understanding of the socially constructed marginalized roles and positions of women (Payne, 2005). Roles are described as a pattern of behaviours that have certain attached values and are associated with race, culture, sex, age and gender. Individuals or groups of people are expected to fulfill different roles in society (Turner, 2011). Women for example are largely responsible for providing care to children, elderly, the sick and those with disabilities (Wood, 1993). The feminist economist Marilyn Waring (1988) spoke extensively about the values attached to these different roles. According to Waring, economists thought of labour as those activities that produced surplus value and were profitable. Therefore, those roles that do not produce a surplus, such as caring for children, are not considered part of the production process. The time that women spend maintaining households, educating and nurturing children are regarded with minimal value. As a result, the plight of women with respect to the role of primary childcare givers is treated with little regard. Waring believed the failure to recognize the work of women as a primary form of production was indicative of a major shortcoming in a male dominated economic system (Waring, 1988). A similar analysis was supported by a 2010 report from the Social Council of Ottawa which stated that women with children continued to be among the group at risk for becoming impoverished. When compared to their male counterparts in caregiving years women had higher rates of unemployment, lower median incomes and were more likely to have part time jobs. This report also claimed that the unavailability of affordable, quality, licenced childcare with flexible hours was a major oversight on the part of policy makers, and that the 
needs of families, women and children were being neglected (Jimeno, Chung, Bouchard, Martinovic, \& Urquhart, 2010).

The aim of feminist practitioners is to work in groups to raise consciousness around issues that affect women and influence their social relations within their environment (Dominelli \& McLeod, 1989). Feminist approaches range from advocacy for radical changes, to creation of societal structures to reflect greater equality, to approaches that foster more individualistic personal and social growth (Payne, 2005; Dominelli \& McLeod, 1989). A crucial debate has centered on how women have been able to reconcile their double roles as caregiver and participants in the paid workforce. Women are disadvantaged from pursuing professional careers and attaining promotions like their male counterparts as they feel obligated to fulfill the mother-caregiver role. Then there are some mothers who would prefer not to work outside the home but the increasing demands and pressures to support their family financially have forced them into the paid workforce (Leira, 1992; Gilbert, 2008; Sugar, 1994).

One of the strategies used to devalue childcare has been by categorizing it as a matter of the private sphere rather than as an issue in the public sphere. Waring proposed that the issues in the private sphere were perceived to be the sole responsibility of families, and as such warranted minimal interference from state. Within the private sphere however, men were often revered as the head of the household, whereas women were subordinate. Likewise, in public spheres, men were at the helm of government, exercising control and making funding decisions (Waring, 1988). Childcare, which has primarily been regarded as an 
issue for women and children, and as a result it does not receive adequate funding and support from government bodies. The following table extracted from a Social Council report (2010) highlighted the breakdown of the distribution of government transfers to residences within Ottawa. More significantly, it also showed contribution of government in the form of transfers which makes up $7.3 \%$ of total sources of income.

\begin{tabular}{|l|l|}
\hline \multicolumn{2}{|c|}{ Distribution of Government Transfer Payments } \\
\hline $\begin{array}{l}\text { Old Age Security Pension \& guarantee } \\
\text { income supplement }\end{array}$ & $1.9 \%$ \\
\hline Canada Quebec Pension Plan & $2.6 \%$ \\
\hline Child Benefits & $0.7 \%$ \\
\hline Employment Insurance Benefit & $0.8 \%$ \\
\hline $\begin{array}{l}\text { Other income from government } \\
\text { sources }\end{array}$ & $1.4 \%$ \\
\hline $\begin{array}{l}\text { Total Government Transfer } \\
\text { Payments }\end{array}$ & $7.3 \%$ \\
\hline
\end{tabular}

Source: Social Planning Council of Ottawa, 2010

The smallest percentage of government transfer went to child benefits.

This indicated that the concerns of women and children were marginally supported by government funding and as long as the level of support remained small, individuals from this group will become more vulnerable.

The issues of government debt and deficits have resulted in both cutbacks and detrimental financial decisions impacting social programs. This instigated a vicious cycle where the welfare state continues to be eroded, forces increasing numbers of women into the workforce to help sustain their families and fails to support working women in their double roles (Roach-Pierson \& Griffin-Cohen, 1995). Women are expected to undertake dual roles within the paid labour force 
and the unpaid labour force. Part of the feminist approach was to promote the issue of childcare as an issue of the public sphere that should be discussed and addressed at all political levels. The continued effort to bring private life issues into the public arena reflected a belief by feminist thinkers that personal matters are political (Sudbury, 1998). There continues to be a push for universal childcare, which allows women to have the option of using daycare services if they so choose. Moreover, the quality of childcare should be of a standard where children are exposed to enriching and nurturing experiences. The provision of good quality childcare has been linked to reduced rates of criminal involvement, lower dependence on welfare, increased educational acquisition and ultimately gainful employment (Glover, Hammel, Knapp, Jackson-Brown, \& Burley, 2012). The provision of adequate, efficient childcare services and support for women choosing to remain in the home to care for their children gives women the opportunity for advancement within society.

The work of women as primary caregivers in the household has been undervalued and their work continues to not be paid. This has contributed to the impoverished of most women who chose to remain at home with their children (Roach-Pierson \& Griffin-Cohen, 1995). Feminist theorists are demanding that women be afforded greater choice in how they are expected to function as primary caregivers and breadwinners. They continue to demand compensation for the work that women do as primary caregivers. Likewise, there has been continued advocacy for the provision of affordable, good quality childcare 
services as a choice to women who choose to join the workforce outside of the home.

Does a Feminist Approach Suffice?

While feminist theorists made bold arguments for a more comprehensive childcare system, there was concern that changes did not benefit all women equally. Based on findings from this study, providers of Head Start, which included administrators, directors and founders, pointed out that the provision of childcare was not entirely about inequalities between men and women. Cuts to childcare often had the most negative effects on those families that were poor and unable to purchase good quality childcare services. Like many other services, for example education, healthcare and social assistance that have a history of being provided through public entities, childcare was becoming increasingly privatized. In a privatized market for childcare, only those women with financial resources were able to afford 'quality' childcare and have sufficient income to benefit from tax deductions attached to the private cost of childcare (Baines, Evans, \& Neysmith, 1998). In 2008, Klien and Wekerle determined that there was only space for $19.6 \%$ of Ontario children between ages $0-5$ in regulated daycares. Moreover, it was suggested that while the Ontario Government provided a $\$ 100$ subsidy per child per month the average cost for childcare was $\$ 800$ per month (Klein \& Wekerle, 2011). The monthly subsidy only covered one eighth of the average cost of childcare. For families with more than 
one child, the gap was further widened, as the family needed to supplement multiple childcare costs. The following excerpt summarized the plight of families, particularly those with children as they attempted to sustain themselves.

The presence of children results in a higher risk of family poverty. The size of the family, particularly the number of children present, is a factor in the risk of poverty. $60 \%$ of families living in poverty in Ottawa in 2006 had children. With just 3 or more children in a family, the incidence of low income rises to $12.8 \%$ for couple families or $48 \%$ for lone parent families, compared to $11.1 \%$ for all families. Furthermore, families with younger children have a higher rate of poverty on average than families with older children (Jimeno, Chung, Bouchard, Martinovic, \& Urquhart, 2010, pp.6).

It has become clear that a feminist approach alone is insufficient when looking at the target population of the Head Start program. For example, for Black women in Canada, the issue of private versus public spheres has not been the focal point of their struggles. Roach et al. (1995) argued that African American women face a history of being confined to menial wages and lives of impoverishment. They further indicated that the divisions of spheres further compounds their struggles, but the roots of their social struggles are founded in racist and discriminatory social and economic relations. "Once privileged white women begin to acquire economic power and privilege the revolutionary and allencompassing visions of feminism become lost" (Hooks, 2000). The Head Start programs were not simply about the delivery of childcare, but rather focused on an array of issues that come with being a member of a marginalized group. Baines et al. (1998) stipulated that there needed to be systemic alterations to the childcare system aimed at benefiting all groups of women. 


\section{A Structural Approach to understanding Head Start}

Structural Social Work emerged at Carleton University during the 1970s under the leadership of Professor Maurice Moreau. This theory combined perspectives from Marxist, radical, and in the later years feminist theories. Moreau posited that personal difficulties were the consequence of inequalities embedded in overarching societal structures. Economies based on capitalist ideologies tend to perpetuate social welfare states which further excluded groups on the basis of class, gender, age, race, mental and physical abilities as well as sexual orientation (Moreau, Frosst, Frayne, Hlywa, Leonard, \& Rowell, 1993). Structural social workers argue that structures are set up in such a way that members of certain groups are exploited to benefit members of supposedly superior groups (Hick, Peters, Corner, \& London, 2010). While structural social workers tend to focus on the overarching institutions which 'oppress' people, they do not ignore the struggles of individuals (Hick, Peters, Corner, \& London, 2010).

Considering Head Starts emergence from President Lyndon Johnson's "national war on poverty" the structural lens provides a context for in depth analysis of the program. Clearly, there was the recognition that massive groups with the population were experiencing poverty and so, a national approach was needed to address the issues of poverty and marginalization. Even as the Head Start program provided care at the individual level, it aimed to place groups of disadvantaged children and their families onto more equal footing with average American families. Indeed, an individual's success or failure was greatly 
influenced by the tacit regulations, rules, and principles guiding the structures within a society. In terms of addressing those inequalities, Moreau et al. stated that "ultimately solutions to private troubles, then, lie in the transformation of our society to a humane [one] based on human need, not profit" (Moreau, Frosst, Frayne, Hlywa, Leonard, \& Rowell, 1993, pp.2). Weissbourd (1996) argued that structural issues play a significant role in impeding the progress of marginalized children. These structures perpetuated inequalities that reinforced gaps between 'haves' and 'have nots'. He went on to say that responding effectively to the challenges of children required better teachers with a sound knowledge of teaching methods and more culturally relevant curricula. Achieving this required change to the fundamental structures of the education systems (Weissbourd, 1996).

According to structural approach thinkers the marginalization of certain groups by powerful overarching structures functions as a response to the increasing emphasis on neo-liberal and capitalist policies in our society. In the post war era between 1945 and 1973, free market ideologies were increasingly replaced by a Keynesian approach to welfare. Changes in technology, increased automation, downsizing, amalgamation, and outsourcing were common strategies implemented by wealthy, and highly influential multi-national corporations (Mullaly, 2007). Neo-liberals worked to weaken labour laws and dismantle the protection of workers. This shift reinforced the vulnerabilities of marginalized groups like women, children, visible minorities, and those living in poverty. When these systems fail to endorse and support programs that seek to 
alleviate and change the conditions of vulnerable populations in society, the welfare system breaks down. Welfare systems if provided adequately add significant value to the overall functioning of society by helping marginalized people to rise out of their impoverished conditions. As they are elevated and were equipped to participate fully in the labour market only then can they make contributions to society. As a result the entire community stands to benefit. As advocates for the oppressed, most social workers believe that a program which sought to change the life trajectory of those who fall in historically marginalized groups should ideally be supported at all levels of government.

\section{Anti-Oppressive Practice (AOP) and Head Start}

Anti-Oppressive social work practitioners argue against the inequalities resulting from dominant groups' power over others. These are perpetuated through unequal structures and include racism, colonialism, patriarchy and capitalism (Carniol, 2005; Ames \& Ellsworth, 1997). The anti-oppressive approach (AOP) looks at the various ways in which oppressive behaviours are fostered. In understanding oppression and how it works, it is imperative to recognise that oppression does not specifically imply evil intent on the part of the dominant group and a passive reaction of the oppressed groups (Mullaly, 2002). In theory, the Head Start Nursery School program reflects characteristics of the AOP approach particularly in its emphasis on strong parental and family involvement. The AOP approach encourages us to examine how structural 
arrangements favour the dominant groups. When we consider the population that Head Start targets, there is an awareness that some families and communities are not in a position to provide enriching and stimulating environments to their children. These barriers include inaccessibility to basic necessities such as food, clothing and shelter, and limited knowledge about how to be effective parents (Zigler \& Valentine, 1979). Such barriers are the reality for many marginalized and impoverished families in both Canada and the United States. This does not suggest that poverty equals poor parenting. In contrast, dire circumstances adversely influenced how much parents can do for their children. For example, parents of middle to upper class can afford to pay for the non-subsidized childcare even when these were limited. In addition, those of more affluent backgrounds have the option of staying home with their children or may use hired help in fulfilling childcare roles.

Marginalized families, particularly those living in poverty, are excluded from the opportunity to access quality preschool and more positive early years experiences for their children. Early Head Start programs require knowledgeable and dedicated staff, well equipped centres, innovative ideas, satisfactory working conditions, good compensation for staff, and the involvement of the families. With the privatization of childcare services, the cost of providing nursery school of a reputable standard was often offloaded unto the families of children. Carniol (2005) explained this phenomenon as governments being primarily interested in the cheapest way of delivering a service rather than paying attention to the wellbeing of the service users. Families living in poverty simply cannot afford the 
prices that were demanded to ensure that their children were exposed to stimulating early year experiences (Pierson, 1995).

Anti-Oppressive advocates posit that while experiences of hurt, frustration and restriction were commonalities shared by all of us at some point or another, experiences of oppression become a cause for concern when groups are blocked from opportunities for self-development. These barriers are widespread, impenetrable, and exclude groups from full participation in society. This results in second-class citizenship, and limited or compromised rights (Mullaly, 2002). Head Start advocates in both Ottawa and the United States recognize that the program's target population are those who are challenged by a multitude of intersecting oppressive environments. Some families may be contending with one barrier while others were facing many barriers. Head Start supporters are concerned that even a single unattended barrier could fester and cause other social problems for vulnerable or impoverished families. Furthermore, the Head Start model assumes that oppression is compounded and becomes more debilitating as the barriers intersect (Mullaly, 2002).

The Intersectional model helps to explain how the intersectionality of various oppressions occurred. A person may be affected by various oppressions which become mutually reinforcing (Mullaly, 2002). According to this model, a person may experience multiple identities as their varying characteristics intersect, placing them into many different stigmatized and 'inferior' groups. A single mother, from a racially marginalized group, who is working for minimum wage earnings, is likely to experience oppression in magnified ways, in contrast 
to a single mother from a 'superior' racial group earning a middle-class standard salary. No oppressed group stands alone and nor is one oppression greater in its harm than another. Efforts directed at fighting oppressive behaviours, attitudes, and structures need to make the latter point clear, as it becomes the foundation for raising consciousness and bringing awareness to the issue. An understanding that one oppression does not outweigh another is also necessary in creating alliances and coalition among oppressed groups (Mullaly, 2002).

As Head Start strove to give children from oppressed families a fair and equal educational experience as more privileged children, the program required the support and resources of agencies and the communities within which they existed. While the intersectional model is presented as a sub-category of the AOP approach, it has not been studied in depth. The intersectional approach explores the effects of multiple risk factors and possible solutions to multiple risk factors, particularly in the early years. Accordingly, intervention should be implemented at multiple levels on a continuum to make a more notable and longer-lasting impact (Mullaly, 2001). For example, when working with lowincome families, support can be provided to an expectant mother, which can then be continued through the earlier years of the child's life. After the child moves on from Head Start there should be a more formal transition process where Head Start teachers can pass on information to the child's new teachers. Providing assistance to children from low-income backgrounds should be continued throughout their primary school years. This continuity ensures that the small efforts put in were not lost but continued. Figure 2 depicts how intersectionality 
occurs specifically as it relates to some of the most frequently identified oppressions faced by Head Start users.

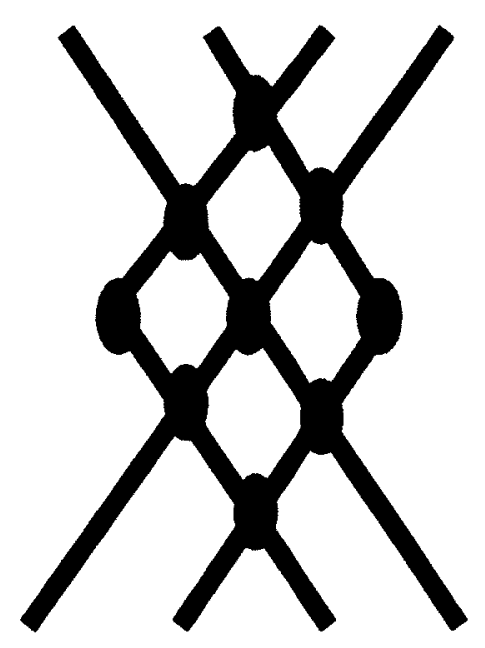

Class Gender Race Age (Mullaly, 2002)

The idea of the intersectionality of oppressions can be expressed in an algebraic formula and suggest that the impacts of oppressive behaviours and attitudes towards members of oppressed groups grow exponentially.

Oppression $=a+b+c(a b)+(a c)(a+b+c)($ Mullaly, 2002)

Where $a, b$ and c represented different oppressions, this is what oppression would look like with a racialized women living in poverty.

Oppression $=$ poverty + woman + black $+($ poverty $\times$ woman $)+($ poverty $\times$ black $)+$ (woman $x$ black $)+($ poverty $x$ woman $\times$ black $)$

The idea of intersectionality can be further understood by assessing the statistic on the rates of poverty of certain groups living in Ottawa. This table below highlights groups with the highest percentage of members living in poverty. 
There was an increased risk of living in impoverished conditions if a person was a member of one or more of these groups.

\begin{tabular}{|l|l|}
\hline Individuals by Groups & Rates of Poverty 2005 \\
\hline Children and youth age 0-24 & $21.2 \%$ \\
\hline Children under 6 & $19.8 \%$ \\
\hline Seniors living alone & $20.8 \%$ \\
\hline Women & $15.9 \%$ \\
\hline Immigrants & $22.7 \%$ \\
\hline Recent immigrants & $43.4 \%$ \\
\hline Visible Minority Residents & $30.5 \%$ \\
\hline Aboriginal Identity Residents & $25.3 \%$ \\
\hline
\end{tabular}

(Jimeno, Chung, Bouchard, Martinovic, \& Urquhart, 2010)

The demographic of people that the Head Start program historically sought to serve in Canada includes similarly oppressed groups; for example, people of colour, people living in poverty and immigrants. The statistic presented in the table above supports the argument that ethnic groups are among the poorest in Ottawa with $30.5 \%$ of them living in poverty. The Head Start model represented a way to combat intersecting oppressions as they affect children and families by offering a program with intersecting services. This point will be discussed in more detail in a subsequent section of this paper. 


\section{Empowerment through Head Start}

The third social work framework that can be applied in understanding Head Start is the empowerment approach. Empowerment social work began in the United States during the 1980s and quickly gained popularity in Western nations (Connolly \& McKenzie, 1999). Empowerment can become a contentious concept as it may be interpreted and manipulated to support both right and left thinking ideas. In studying families for example, liberal thinkers would regard less paternalistic attitudes as empowering, while conservative writers would regard cuts and claw backs of social services as empowering as this reduces government control. To overcome the ambiguities, Connolly and McKenzie, 1999 suggested that we need to acknowledge that some people and groups have more power than others. In order to overcome these power imbalances societal rules and policies need to encourage the redistribution of this power.

Moreover, practitioners using this lens tried to find ways of empowering people across life spans at the individual, familial, group, and communal level with the ultimate goal of amassing the potentials necessary for making just changes (Turner, 2011). The concept of 'life span' is fundamental to the Head Start program as providers recognize that the small investments made in children today serve as a boost to academic and social performance in elementary, secondary, and post-secondary education and ultimately throughout their lives. This is particularly necessary for children of families where quality childcare cannot be afforded or where parents may be forced to work night shifts leaving 
children unattended while asleep (Harris, Rome \& Slaght, 1999). With the inflexibility in childcare hours parents may resort to informal care from friends and neighbours. This leads to increased risks to children in these external forms of care as the providers may be unreliable, abusive, and unskilled. Moreover, the supervision of such childcare operations is jeopardized, further compromising the safety of children (Harris, Rome \& Slaght, 1999). Marginalized families are at most risk and in the most disempowering position in providing quality care to their children as a result of inaccessibility and lack of affordable facilities. Greater efforts needs to be directed at providing needed resources to assist parents to provide for their children.

Social Work practitioners who use the empowerment approach recognize that poverty was experienced mostly by those living at the margins of society and among many of those who care enough to work with them (Turner, 2011).

Poverty has been defined as inadequate income to meet the needs of the family (Cool, 2009). In Canada, there are a variety of measures used to determine the rate of poverty, such as the market basket measure (MBM), the low Income measure (LIM) and the Low Income Cut-Off Measure (LICO). In the most commonly used measure, LICO it is stipulated that families living in poverty spend more than $\mathbf{2 0} \%$ of their income on the basic necessities namely food, clothing and adequate shelter. LICO may be measured before or after income tax deductions (Cool, 2009). The rate of child poverty in Canada in 2006, when assessed after taxation was $15.8 \%$ (Cool, 2009). The reasons for the high rates of poverty in a country were varied and were influenced by a push and pull 
between economic trends, government decisions, and demographics (Cool, 2009).

Likewise, the effects of poverty on children are extensive. Poverty has been identified as the single most important factor causing avoidable mental and physical health problems (Kitchen, Mitchell, Clutterback, \& Novick, 1991).

Children from families living below the low income cut off are more likely to be living in inadequate housing, are more likely to go hungry, experience more severe health problems, are more likely to miss school and are more likely to be denied participation in extra-curricular activities such as hockey which requires specialized equipment which must be paid for the child's family (Zigler \& Valentine, 1979). When behavioural, mental, or learning disabilities were present, parents were unable to afford private, early intervention programs. This constant state of not having enough is draining on parents which in turn perpetuates a cycle of stress in the home (Kitchen, Mitchell, Clutterback, \& Novick, 1991). The sense of powerlessness that constantly pervades those experiencing this state of impoverishment may extend beyond individuals to permeate neighbourhoods and a larger community. Hence, by empowering individuals within a community, the entire community stands to benefit.

Poverty is not only measured by material possessions. Power is also associated with cultural wealth in the form of parental education and knowledge in arts, science, literature, and basic life skills within a given society or environment (Kitchen, Mitchell, Clutterback, \& Novick, 1991). A wealth of 
knowledge puts parents in a better position to mentor their children and to foster their development.

The principles of the empowerment approach indicate that for the empowering process to flourish, the commitments, narratives and efforts should come from the users of the service.

The authenticity of empowerment should derive from and be rooted in the circumstances of those who use the services, not those who commission, manage, or deliver them and those who research, write and teach about them" (Turner, 2011, p. 158)

Empowerment thinkers like Turner also posited that empowering must simultaneously occur at multiple levels to be most effective. Head Start, and other progressive programs developed in the 1960s, gave rise to different ways of working. They gave rise to raising people up so that they could challenge power. Later such approaches came to be theorized as an empowerment model. Empowerment of members of marginalized communities should occur at both the personal and political levels. To address issues such as poverty, racialization, and discrimination experienced by the users of Head Start, practitioners became co-investigators of the realities of their clients' everyday life. For example parents and teachers can work together to understand how racist thoughts and behaviours are manifested, and the impacts on the child and family, and how as a team they can work towards over overcoming the oppressions. In addition, there is a need to validate the collective experiences of marginalized groups even as efforts were made at developing individual potential and effecting structural and political changes (Turner, 2011). Support for marginalized and vulnerable groups from this framework requires identification and fostering of 
strengths, challenging unjust and external obstacles, problem solving and raising consciousness.

\section{Ecological System Theory and Head Start}

Individuals involved in the creation, management and delivery of Head Start programs were aware of the structural issues and barriers encountered by users of their services, but tended to use more narrow and family-centred approaches in their delivery of the Head Start model. In preliminary discussions with a director of Head Start in Ottawa, she indicated that the program was

guided by Bronfenbrenner's ecological systems theory. The minutes of March 11 1994 also discussed ways in which the team of directors can revisit the work of Bronfenbrenner to better understand the child within the social context. Bronfenbrenner argued that a child was located in a system of complex interaction with the environment, people and structures (Kail \& Barnfield, 2009). This theorist suggested that there were four spheres interacting with and influencing the child's life. The first sphere is the microsystem, which includes people and structures in the immediate surroundings. For a child, this includes their family, daycare, peers, church etc. Surrounding this sphere is the second layer referred to as the mesosphere, which signifies that spheres influence each other. To put this into a Head Start context for example, a family that is unable to afford breakfast for their child would send a hungry child to school. This child would be subdued and unable concentrate on learning in school. The next 
sphere is called the exosytem, which referred to structures that do not directly affect the child, but still plays a part in their development. Some of these include community services and the media. Lastly, there was the macrosystem that demarcates the societal cultures and subcultures that encircled the other layers. Attitudes, beliefs and cultures all make up the macrosystem (Kail \& Barnfield, 2009). Based on my initial reviews of the operation of Head Start in Ottawa, emphasis was placed mostly on the first two layers; the microsphere and the mesosphere.

Bronfenbrenner's systems are not static, and while there were commonalities within communities the system will vary from one individual to another. Bronfenbrenner's approach has been modified by American writers and researchers of Head Start to represent the systems that are reflective of the realities of their users (Alkens, Hulsey, Molduddin, Kopack, Takyl-Laryea, \& West, 2011). The following diagram was extracted from the research of Head Start Family and Child Experience Services (FACES), which conducts annual longitudinal studies of Head Start in the United States. 


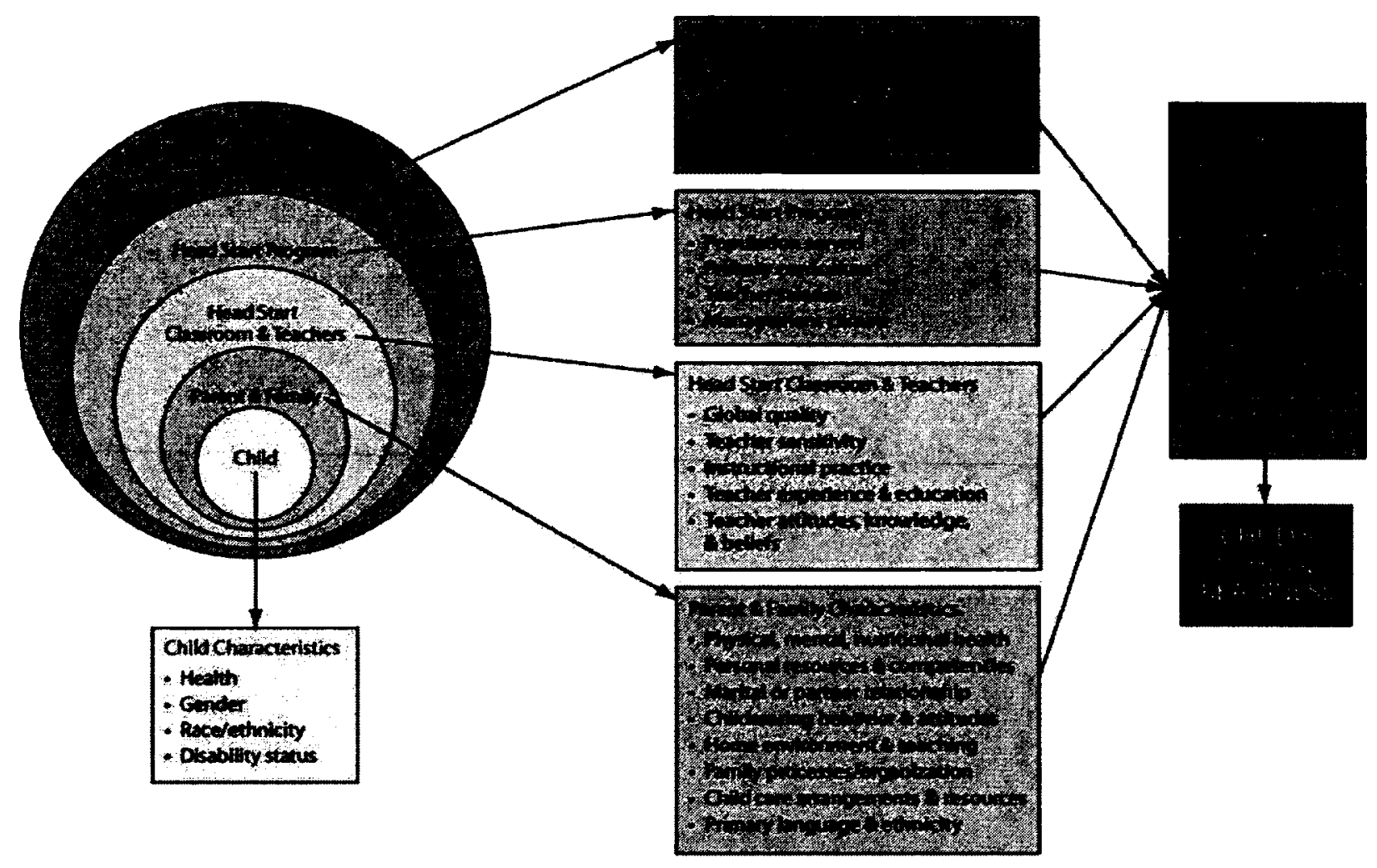

(Alkens, Hulsey, Molduddin, Kopack, Takyl-Laryea, \& West, 2011)

The Ypsilanti Perry Preschool Project

The work of Weikart et al. in the Perry preschool project has been fundamental in shaping the work of Head Start. It was referenced throughout the research for this thesis. The Ypsilanti Preschool project, like Head Start, was designed to assist economically disadvantaged children. The Ypsilanti Perry Preschool Project began in the early sixties in the town of Ypsilanti, Michigan. Economically high-risk children participated in a research project where the randomly selected experimental groups of three and four year old children attended preschool while a control group got no intervention except for testing. Both groups entered public school with no further intervention, and a series of 
intelligence and psychometric testing was conducted on both the experimental and control groups. Five cohorts of participants were entered with each group being a year apart. Weikart and his research team spent many years following those children and studied their progress into their post-secondary education (Weikart, Bond, \& Mc Neil, 1978).

Some of the key findings emerging from this project were that children from the experimental groups consistently scored higher on aptitude and achievement test than those from the control groups. In general, those who had attended preschool were less likely to repeat grades and required less special education than their counterparts who did not have the preschool experience (Weikart, Bond, \& Mc Neil, 1978). Weikart has been a strong advocate of early childhood education programs designed to maximize the potential of economically disadvantaged children. According to Weikart et al....

Fortunately Head Start and publicly supported preschools in general were saved from closure by parents and educators who recognized the potential of early childhood education. Now our task is to design educational systems which can realize that potential for all children, recognizing, however that educational programs, no matter how effective, do not eliminate the need for broader social change (Weikart, Bond, \& Mc Neil, 1978, p. 96).

\section{Summary of Theories}

Based on my assessment the feminist perspective was the primary underlying theory when looking at the challenges associated with the provision of childcare. Bronfenbrenner's theory along with the extensive research of Dr. David Weikhart on the Perry Pre-school project has been instrumental in informing the practices of the Head Start Nursery School. When examining the Head Start 
program through social work lens; structural, anti-oppressive and empowerment frameworks were most applicable in understanding why programs like Head Start are needed and how they operate. 


\section{Literature Review}

\section{Philosophy and Objective}

Directors at the different schools had different ideologies, affecting their understandings of the political environment, social relations, racial difference and the economy. The original objectives and motives of the program were debated from the inception and continue to be challenged today. The Early Years Report by Mustard and Fraser (1999) has since its publication, provided important support for programs employing the Head Start model. The Early Years Report was based on an extensive Canadian study that focused on the benefits of early childhood education with supporting evidence from neuroscience, developmental psychology, social science, anthropology and epidemiology (Mustard \& Fraser, 1999).

As a Head Start nursery school teacher my sense was that front line workers were not overly concerned with the political ideologies attached to the program. My colleagues and I were more concerned with getting the job done and making do with the limited resources available. As one text outlined, "the Head Start teacher is probably another child's stressed out mother who may simply see her job as child monitoring rather than facilitating" (Levitt \& Dubner, 2005). This observation does not align with the Head Start ideal as the program prides itself on being much more than a childcare service. In the United States fewer than $30 \%$ of Head Start teachers have a Bachelor's degree and they were paid an average of $\$ 21000$. This compares poorly to kindergarten teachers who 
earn an average of $\$ 40,000$ (Levitt \& Dubner, 2005). During my time as a Head Start teacher, I earned $\$ 14 /$ hour. A consequence of poor wages was that the program fails to attract more qualified teachers (Levitt \& Dubner, 2005). Yet Head Start workers are mandated to make the program work with minimal wages and often times distressing work environments. These working environments will be explored in depth in the finding and analysis sections of this research.

In OCHAP documentation it is stated that Head Start teachers are required to have an early Childhood Education (ECE) Diploma, and it is expected that they would bring a variety of child developmental approaches to their practice (Ottawa Carleton Headstart Association for Preschools, 2010). As will be discussed further in this thesis, an efficient and long-lasting Head Start teacher requires much more than an ECE diploma.

While debate on the principles of Head Start and its effectiveness has emerged predominantly out of the United States, it has also surfaced in Ottawa where funding concerns have been pressing. As discussed below, the program has been criticized as unethical and ineffective by some, while others have hailed it as a valiant effort to raise oppressed children and adults out of their impoverished living conditions. Dobson et al. (2007) for example suggested that the program has positively affected family relationships, personal development and health education. Some longitudinal studies indicated that Head Start has had little impact on the long run wellbeing of attendees, while others suggested otherwise. Zigler \& Seitz (1982) and Berenbeim (1992) have argued that inefficiencies of Head Start programs were the result of the substandard quality 
5

and residual approaches to funding for the program. It was also posited that emphasis should not be on the critical window of the early years as the point for intervention, but rather on a continuum of quality and stimulating childcare to support children and families living at the margins (Zigler \& Seitz, 1982).

In addition to examining the philosophies and objectives of the program the mission statements of the Head Start programs helped shed light on the approaches taken and the understanding of each program of what was required for children to excel, particularly those who face many barriers.

\section{Mission Statements}

The Ottawa Carleton Head Start Association for Preschools (OCHAP) was established in the early 1980 s. Its mandate was to advocate for Head Start programs focusing attention on alleviating barriers such as poverty and the multitude of stressors affecting the developmental wellbeing of impoverished children.

A review of the ten mission statements and philosophies of these programs contained on the OCHAP website (see appendix 6 for a copy), suggests that the leaders of these programs were well informed and attuned to the developmental, social, and environmental needs of children. Most seem to identify with models which affirmed that a child's development is dependent on a

5

Residual model is based on the idea that government should play only a limited role in the distribution of social welfare and that state intervention should be targeted at those in high needs or at highest risk (Hick, 2006). 
supportive and stimulating environment. Some Head Start nursery schools emphasize the importance of creating a growth-stimulating environment at their centres, while others emphasize working with a child's family. Other schools are more comprehensive and focused on the holistic environment of the child, which is defined as comprising the home, daycare, wider community, and the diverse, multi-cultural backgrounds of the families using Head Start (OCHAP, 2006). While there are differing missions and philosophies across the ten schools, there is a fundamental consensus that an array of positive experiences in the early years is critical to overall development. For example, the Annavale Head Start (located in Ottawa West) has a progressive mission statement which integrates principles from the Ontario Ministry of Education on Multiculturalism in Education. It states that "Every child, of whatever colour race, religion, age, or sex has the right to be treated with respect and understanding (OCHAP, 2010)". The program's mission statement asserts that the provision of appropriate daycare is a matter of social justice. It also inter-weaves aspects of the Ontario Multicultural Policy of Equality and indicates that individuals should enjoy the freedom of access to community services and the right to maintain one's cultural heritage (OCHAP, 2010). This approach is strategic in seeking accountability from political institutions such as the Ontario Provincial Government ministries in the provision and support of comprehensive childcare programs.

A commonality across the mission statements of the programs is the encouragement of parental involvement in the program. The Queensway Preschool for example, seeks to incorporate parental participation through parent 
groups, home visits, and open invitations to be a parent volunteer. The involvement of parents is thought to be critical to the operation of the program as both parents and teachers are an integral component in the development of children. Additionally parental involvement presents the opportunity for mutual learning between parents and teachers. Most of the programs provide some form of transportation to and from the centres. Transportation is however often limited to the catchment area of the centre.

\section{History of Head Start in the United States}

In an increasingly neoliberal environment, where the provision of social welfare is informed by a residual approach, it is surprising that Head Start programs, both in the United States and Canada, continue to survive (Hick S., 2006). When a social welfare program has survived through four decades of different political shifts, one cannot help but wonder about the features that have allowed it to be sustained, and how these features might be applied to other welfare programs. Although it has been modified, often criticized as being ineffective, and although some schools have been shut, the underlying principles of Head Start programs have persisted.

Initially, my focus was on looking at the history of Head Start in isolation, but as I continued to study the program I realized the need to look to the broader context. Head Start is a microcosm of a much larger movement and its history is a meshing of political, social and economic agendas (Brauer, 1982). Head Start began as an initiative of the United States Department of Health and Human 
Resources in 1965. It was designed as a six week summer supplementary program to help children get ready for kindergarten. According to Cohen (1996) the early 1960 s saw a shift in the attention given to early childhood education which resulted from research that suggested that early childcare influenced academic performance in later years. By focusing on early childhood education the program served as a channel through which child welfare could be improved. Head Start received state funding under the Economic Opportunity Act, and was a program in President Lyndon Johnson's 'war on poverty' (Caputo, 2003). Some authors asserted that it was introduced with the belief that a competent early childhood education program would have an impact on the existing high rates of poverty. Yet, others have pointed to more strategic political motives, as they argued that it was introduced to win the votes of the Black community. Ames and Ellsworth (1997) argue that its continued existence is based on the fact that if functions as a political entity. Through the Economic Opportunity Act policy makers (1964) developed a series of programs geared towards improving job training, community action, health care, housing and education (Quadagno, 1994).

Kail and Barnfield on the other hand suggested that the American Head Start program originated in the early 1960 s when researchers' were producing data that indicated that the environment had a greater weight on a child's development than had previously been thought. They stated that the work of psychologist Joseph Hunt supported the position that children can reach levels of outstanding performance under an optimal environment. Kail and Barnfield also 
suggested that the introduction of the program was the result of a political twist of fate. When President Lyndon Johnson launched the 1964 'war on poverty', there was a huge revenue surplus at his disposal, but the head of the Office for Economic Opportunity, Sargent Shriver, was reluctant to spend money on the adult population for fear of public backlash. As a result funding was directed to helping children in poverty. Children unlike adults could not be chastised as being lazy and responsible for their impoverished circumstances (Kail \& Barnfield, 2009).

Shortly after, Shriver was able to create a multi-disciplinary advisory committee comprised of medical professionals, educators, social workers and a psychologist. Within a year, in 1965, the first Head Start programs were opened during the summer, serving half a million American children who were living in poverty. Today the American government spends $\$ 7$ billion on Head Start annually (Kail \& Barnfield, 2009).

To place Head Start in a larger context, it was part of a movement to raise a struggling Black minority underclass out of their slums and onto equal economic footing with White Americans. Ryan argued that with carefully thoughtout, well-organized pre-school programs children from the lower class could be elevated to a state of readiness comparable to that of middle-class children (Ryan, 1976). Brauer (1982) has identified three primary motives behind the initiation of the war on poverty: the rising influence of the social sciences, political 
6

calculation, and the cyclical theory of reform . The Head Start program has also been a target of much criticism. Some writers for example have referred to it as a national laboratory, and have argued that researchers who had suggested that there were long term benefits of Head Start were wrong (Zigler \& Seitz, 1982). They also felt that efforts of the program could not possibly be successful as the age at which a child was allowed to start Head Start was occurring too late in a child's life (Zigler \& Seitz, 1982). Ryan (1976) believed that the real issue lies in the overall education systems where the schools were prepared to meet the needs of middle class children, but not those of lower socio-economic status. Ryan located Head Start within the larger structures, and problems of the education system.

The original Head Start program has undergone many revisions and modifications through the development of Home Start and Health Start programs. The Home Start program involved home visits from workers whose goals were to enhance parenting and family functioning (Harden, Denmark, \& Saul, 2010). Health Start, which as the name implies provided the tools and support for improving the health standards for at risk children. These off-shoot programs were developed only in the United States where the program has been federally funded, unlike Head Start in Ottawa which is supported at the municipal levels.

6 change

Cyclical theory of reform: the cycle of a period of dormancy followed by sweeping impulses for 
History of Head Start in Ottawa

While the origin of Head Start in the United States has been carefully examined by American researchers, there has been little documentation on the first fifteen years of Head Start's existence in Ottawa, Canada. Recordings improved after the establishment of OCHAP. The association was established in 1980 , fifteen years after Head Start came to Ottawa. The lack of documentation and historical analysis of Head Start became evident when I attempted to identify the pioneers of Ottawa Head Start.

In my preliminary discussion with members of OCHAP I was informed that shortly after the establishment of Head Start in the United States, four women from Ottawa travelled south, examined the program, adopted the idea, and transplanted Head Start to Ottawa. I was also provided with the names of some women who might have been around during those times. By meeting and interviewing women who were involved in the program during the early years, 1 was able to recover and develop a better understanding of the beginnings of Head Start in Ottawa. Some archival notes also provided insight into the earlier existence of Head Start in Ottawa. 


\section{Methodology}

To understand issues related to children and the viability of the program a multidimensional approach was used in this research. Allison James has suggested that it is necessary to use different methodological and conceptual insights when trying to understand and study children and their development (James, 2004). The current research uses interviews, focus groups, review of current literature, archival evaluations and reviews of meeting minutes. As indicated, Head Start nursery schools operate in an effort to give children and families who are typically stuck in a cycle of poverty the opportunity to rise out of otherwise unpromising life trajectories. Head Start advocates believe that what is occurring at the individual level is largely influenced by larger and more powerful overarching structures of society (Ames \& Ellsworth, 1997). Their attempts at effecting change are not only directed at children and their families, but have also targeted social and economic inequalities that produce extreme vulnerabilities of some groups.

Interviews were conducted with two individuals who were actively involved with the establishment of Head Start programs in their communities. They were also teachers and directors of their respective schools and other childcare programs in Ottawa. It was a challenge to identify and to connect with these individuals. I had been told that they would likely be elderly and might have lost mobility. I was prepared to meet at locations that were most convenient to them. Eventually I conducted interviews with Diane Blenkiron at her workplace, The Military Family Resource Centre, where she functions as the manager of the 
child, youth and parenting services. This meeting took place on Thursday May 3 2012. The second interview took place at the home of Kathy Yach on Wednesday May $16^{\text {th }} 2012$. Yach had recently retired from many years of service in childcare, although she had not specifically worked at Head Start. Yach had taken the liberty of inviting Charlyn Monahan to join the meeting. Monahan has been credited with establishing two Head Start centres in Ottawa. Presently, Monahan works as the child care coordinator for the Language Instructions for Newcomers to Canada (LINC) program in Ottawa.

While a semi-structured interview guide (appendix 1) was developed with the aim of answering the specific research questions, interviews were less structured and took on a more conversational form. This was to accommodate unanticipated directions and new perspectives. Interviews are thought to be like conversations, where both verbal and non-verbal cues are involved in the exchange of feelings, ideas and information (Marlow, 2011). Using the semistructured interview allowed for more detailed discussion and greater opportunity to fill in the gap of the earliest years of Head Start in Ottawa. The insights of the interviewees provided a critical understanding of the historical context and evolution of the Head Start program in Ottawa.

The first interview with Blenkiron was recorded by hand while the interview with Monahan was audio recorded. The audio record was then transcribed. The recorded information was then transcribed. The transcribed material was read repeatedly to deduce the important and recurring ideas which are referred to as 'meaning units' (Marlow, 2011). Units with similar meaning were categorized. In 
some cases one meaning unit fit into multiple categories. The major themes emerging from the founders interview were historical view, definition of Head Start, funding and parental involvement.

Both women seemed offended by the claim that four women from Ottawa had adopted the idea of Head Start from the United States. They believed that this interpretation undermined the effort and work of the pioneers of Head Start within the Ottawa community. Before beginning the interviews I was unclear about the relations of the interviewees to Head Start. When initiating this project I had little information about the history of Head Start, and had to rely largely on anecdotes. For example, I was told that the potential interviewees might know something about the inception of Head Start in Ottawa. Yet, when interviewing Blenkiron, I learned that she was in fact a founding member of a Head Start nursery school, which suggested that there was a lack of clarity regarding the earliest years of Head Start in Ottawa. This segment of the research was of a more exploratory nature. When little is known about a topic exploratory research may be used to determine a study's feasibility and lays the groundwork for further questioning and research (Marlow, 2011).

In addition to the interviews, I conducted a focus group with the directors of the Head Start program who were also the representatives of OCHAP from their various centres. The initial plan was to conduct individual interviews with each director, but this changed after an introductory meeting with the group, where there was a richness and depth emerging from the group discussions which would not have been available through individual interviews. The focus 
group was also practical as participants shared a common interest and were from comparable positions of authority within OCHAP (Padgett, 1998). Members were also able to provide supporting examples on points of discussion presented by their colleagues and offered clarifications where necessary. The group discussion also served to identify the differences between the different schools. The group conversation also allowed for an unfolding, real time development of reflective analysis. Following the introductory meeting the decision was made to abandon individual interviews in favour of focus groups, as the latter provided richer and better information from the directors. It has been pointed out that focus groups bring out aspects of the topic that had not been thought of previously (van de Sande \& Schwartz, 2011).

The decision to use a focus group was also related to the fact that in Moy's research back in 2001, individual interviews were used with the directors. Most of them still continue to function in the role of director. I was interested in the communal ideas and how they operated as a unit or group. While the primary concern of the focus group was around anonymity, due to the small and specific sample, neither anonymity nor confidentiality could be guaranteed as the group members knew each other. Following an informal introduction at the monthly directors' meeting, a date was set for the focus group. The directors of the Head Start program were targeted as participants of the focus groups as they were in a position to provide in-depth accounts of the day-to-day operations within a Head Start centre. Directors, unlike the teachers, had insights on the administrative challenges facing Head Start, and also had a holistic view of the operations of 
their programs. As discussed in the findings, directors have been in that position for many years and would have a thorough understanding of the overall dynamics of the program. Between the 7 directors present, there was a total of 100 years of experience working with the program.

The focus group took place on Wednesday June $6^{\text {th }} 2012$ at the Annavale Nursery School. The session lasted approximately an hour and 10 minutes and a semi-structured question framework was used based on the research questions. See Appendix 2. The focus group discussion was recorded using a voice recorder which was then transcribed. Like the raw data from the founders' interview the raw data was coded and categorized. As mentioned above, some units fit into multiple categories. For example, the ongoing battle for lower children to teacher ratio was categorized as both a staffing issue and lack of funding. The major themes emerging from the focus group were; definition of Head Start, how Head Start works, funding, staff concerns, parental involvement and the role of OCHAP.

I also reviewed the minutes and documents of OCHAP meetings to gather data on Head Start in Ottawa. Files were stored at two locations: the Children's Aid Society (CAS) Head Start and the City of Ottawa. The CAS Head Start files date from 1980 to the present. Files were randomly reviewed. These archived minutes addressed general issues of Head Start throughout the last 30 years. The minutes also revealed the strategies the directors of Head Start had used to sustain a presence in Ottawa child care systems over the years, as well as providing insights into the place of Head Start in the childcare system. Collection 
of this form of data allows for secondary analysis, as information that has been previously gathered by others for one set of purposes, is used subsequently for other research purposes, to thereby provide review and insight into the operation of a program (Neuman \& Kreuger, 2003). My initial analysis of the minutes was designed to allow me to become familiar with common themes and topics after which I begun to categorize new information into those central themes.

The data at the CAS Head Start was slightly different from that found at the city, as the CAS minutes focused specifically on the directors' minutes, while the data gathered from the city records was mostly on special assignments undertaken by subcommittees of OCHAP in which the city was directly involved. Further details will be provided below when I address findings.

After all data was appropriately coded, I began the process of recording the findings and analysis. In some cases the contents of main categories were compared. For example, I compared the views of Head Start held by the founders to those held by current directors. The findings were also discussed in the context of the literature review and theoretical perspectives. This helped to determine whether the Head Start program in Ottawa functioned in reality as was presented on paper.

Considering the age and history of the Head Start program in Ottawa, multiple research methods were used to answer the research questions and ultimately understand the operation of the program. For example, the director's focus group alone would have failed to provide an in-depth understanding of the earlier years of the Head Start programs, as most of the current participants 
became involved with Head Start only in later years. In contrast the review of minutes and documentation provided an outline of events that occurred during Head Start's early years in Ottawa, but failed to provide in-depth attention to the daily workings of Head Start as was revealed in the focus group.

\section{Ethics}

Consent to conduct this study was obtained from the Carleton University Research Ethics Board. This consent expires on May $31^{\text {st }} 2013$ (See appendix 3). Participants were required to sign consent forms prior to participation in interviews and focus groups (See appendix 4 and 5). All transcribed and audio taped data was kept in a secure location in my home. This material will be destroyed and erased upon completion of the project. Prior to the completion of the thesis, all written components were stored in a password protected USB stick. 


\section{6a. Findings-Interviews \& Focus Group}

Founders' Interviews \& Focus Group Findings

The findings will be presented in two chapters 'Founders interview and focus group findings' and 'Review of Minutes and Documents'. Founders' interviews were conducted with Diane Blenkiron, Kathy Yach and Charlyn Monahan. The focus group was attended by 7 directors of the Head Start nursery school in Ottawa. The chapter is organized based on major themes emerging from the research.

\section{Founders Interview Findings}

The first interview I conducted for this thesis was with Diane Blenkiron a founding member of the Pinecrest Queensway Head Start. The second interview/discussion was with Kathy Yach and Charlyn Monahan. While Kathy Yach was not directly involved with the Head Start program, she hosted the interview and extended an invitation to Charlyn Monahan who was directly involved in the formation of two Head Start programs in Ottawa. They were able to share their experiences of Head Start in the earlier, formative years.

\section{History before OCHAP}

Diane Blenkiron was directly involved in the creation of the Pinecrest Queensway Head Start program. Blenkiron estimated that the program was 
established around 1971. She outlined, that the idea for the Pinecrest

Queensway Head Start program started at a community playground while having a conversation with another parent. They observed that there were inadequate childcare facilities to meet the needs of the community, but also noted that there were many low income housing blocks within the neighbourhood where many families were struggling with poverty and marginalization. She had become familiar with the circumstances of these families through her work as a public health nurse.

The initial meetings were held in Blenkiron's home. She gathered support from Algonquin College (which ran a Head Start summer program much like the start of Head Start in the US), the social planning council of Ottawa, and members from the community, to set up this nursery school. Blenkiron noted that the initiative required input from many different bodies within the community. Kate Danier from the social planning council for example, supported the project by identifying and presenting statistics on rates of child poverty in the region. The pro bono work of a lawyer was used to handle the legal issues which included the registration of Head Start as a charitable organization.

Chartyn Monahan, who participated in the establishment of a Head Start program, affirmed that the YMCA-YWCA and the Children's Aid Society (CAS) Head Starts were the earliest established in Ottawa. Prior to setting up the Hawthorn Meadows Head Start in 1978, she visited and gained insight from these programs. According to Monahan, Anne Clifford was the CAS supervisor while Joan Burrant was the operating supervisor from the YMCA-YWCA Head 
Start. She recalled that Joan McCulla, Anne Clifford, and Janet Whyte might have gone to a conference in the United States and returned with further ideas to build on Ottawa Head Start. Monahan identified that the outstanding work of Joan McCulla and Joan Burrant from within Algonquin College was the catalyst in the creation of Head Start in the Ottawa Carleton Region. While the YMCAYWCA Head Start has been credited as being the first in Ottawa, Blenkiron affirmed that the first Head Start started as a summer program at the Algonquin College after which the model was further used in the community.

Monahan's idea of starting a Head Start in the Heron Gate community followed the culmination of a Canada works grants which allocated $\$ 6,000$. a year to the functioning of a nursery school program. The end of that program meant that there would no longer be a nursery school in that community. In her efforts to secure funding for a child care program, Monahan met with then mayor Marion Dewar, as well as the head of the regional childcare services to plead her cause. Dewar brought the proposal before council, and following council's approval, funding was granted but with attached conditions. Monahan was hired by the Confederation Court (a cooperation of public housing) to run a Canada Works Child Care Program geared towards welfare recipients who were taking a skills program. Monahan acknowledged that Confederation Court was spearheaded by a well-known Ottawa social worker, Joan Gullen. This skills program was intended to help mothers on welfare find a job.

The different Head Start programs in Ottawa had different and unique stories but the demographic characteristics of the target populations were 
consistent. There was also a reliance on a combined community effort to get Head Start programs moving and sustained in the earliest years.

\section{Founders view of Head Start}

According to Blenkiron, the children attending Head Start often lacked language skills, basic conceptual understandings, stable relationships and socialization. She also indicated that many of the children were often hungry. When I asked how she knew that they were hungry, she replied, 'they told me'. Part of their obligations as Head Start directors, was to feed the children enrolled in the school.

Blenkiron frequently described the work and efforts of Head Start as an enrichment program. The programs and the activities according to Blenkiron were geared towards providing the children and families with enriching experiences. For example, the staff incorporated regular field trips to venues that would allow the children to develop their knowledge and skills. She felt that it was important that the Head Start centers owned their transportation, as this made it easy to get around the city. She reflected that the teachers and children particularly loved going to the beaches in the Mooney's Bay and Pinecrest areas. She believed that the children benefited therapeutically from sand play. Blenkiron observed that playing in the sand was so absorbing and relaxing for the children and that this activity provided the adults with an optimal time to play along with the children and to engage them in conversation. The children enjoyed the discovery of the distinct properties of sand; and for some sand was used to 
express strong emotions as they built and demolished sand structures. Further, sand play allowed children to work both individually and communally. When playing with others they worked to build castles, roads, bury and find treasures; which in turn contributed to social growth.

The children of the Queensway Head Start also often visited museums and other places of interest within the community. Blenkiron fondly recalled "One of the most memorable trips was on a train ride; we even went for a plane ride out in Rockcliff with a pilot who was seeking to make up his flying time". She believed that it is was crucial to connect children to their environment "simple activities like walking through the Jack Pine Forest whilst feeding chickadees, smelling the leaves, and feeling the crunch of leaves beneath their feet are all very enriching for children".

Blenkiron believed that the facilitators of these programs needed to be caring, empathetic, kind, and most significantly, to be able to put themselves in the shoes of the children and their families. Blenkiron noted that her drive to be a part of this program stemmed from her love for Head Start. She found great pleasure in going along the Morrison bus route picking up children and the parents, getting to know the people, and going into their homes. Blenkiron expressed those thoughts when she stated "l enjoyed being a kid with the kids". She also noted that Head Start was not merely about the provision of childcare to the child, but that the program also attempted to address the various needs of the families they served. For example, she would make herself available as a friend and interpreter for parents applying for various forms of support and 
subsidy. Such intimate interactions differentiated Head Start from other nursery school programs.

Monahan believed that the primary differences between the users of Head Start Nursery School program as it was envisioned then and other nursery school programs were the family backgrounds as well as the differing families' needs. Families using regular nursery schools were most likely from a middle class background. Monahan illustrated her point by outlining that in a middle class nursery school, two and a half year old children typically spoke in full sentences while those from lower classes often had reduced language skills. Teachers communicated differently with children from middle class backgrounds compared to children from disadvantaged homes. She recalled one child who came to the Head Start program with about three words of English in her vocabulary, "no, fuck-off and pooh". The language used initially with this child had to be simple and comprised mostly of one word phrases. The program developed for this child was designed to meet her developmental needs and to work on a gradual expansion of her vocabulary. Speaking at the child's level in the initial phases also allowed for relationship building between the teacher and child.

Monahan added that she believed that the underlying philosophy of all nursery schools remained the same. In all programs there is a deliberate attempt to meet the child at their developmental level. Kathy Yach, who was not directly involved with the Head Start program, but spent many years working in childcare, shared similar sentiments by explaining that the child's brain developed as their range of experiences get stored in memory. According to Yach "all it takes is a 
trigger to bring memory and recollection back to consciousness and learning and it is essential that childhood educators understand the importance of creating as many positive and varied experiences for a child as possible". On that note Monahan pointed out that most Head Start programs operate on a half day basis as this allowed them to serve more children. Yach, referenced Dr. Weikart who argued that this was not the best decision, as half-day care does not offer enough exposure to foster developing experiences as full-day care.

The food served to the children of Head Start was also a point of much discussion. Blenkiron described the food served by Head Start as enriching. She illustrated this when she stated "Not just a biscuit, but food from all the food groups, that are vitamin and protein enriched". Her view of the types of foods served to the children of Head Start was shared by Monahan who pointed out that the meals were balanced, as children likely arrived with empty stomachs. The aim of the providers was to give children as many nutrients as possible. Monahan hoped that in a full day Head Start the child can be provided with at least $1 / 3$ of their daily nutritional requirement.

The providers of the Head Start program recognized that the users of the program were in need on multiple levels. The founders of Head Start identified language and dietary deficiencies as two of the primary struggles of these

7

Dr. David Weikart the primary researcher in the Perry Preschool Project from Ypsilanti, Michigan. 
families and their children. Efforts were then made at providing a nursery school program where as many of those needs as possible were being met.

How Head Start got a Start

As with many smaller programs and organizations that do not generate immediate benefits, Head Start has struggled financially. The following section highlights feedback from Blenkiron and Monahan who were involved in the establishment of Head Start in Ottawa. They shed light on the process of acquiring funding for both the establishment and maintenance of the program.

Blenkiron expressed mixed emotions regarding funding. She indicated that there was no start-up capital, which meant that the community, which included parents and some experts, had to engage in fund raising to get things moving. Once the program was initiated, she noted that it became easier to secure funds as the program received the support of various institutions such as Algonquin College and the City of Ottawa. The city agreed to provide subsidies for half of the attendees to the Head Start nursery school.

Monahan likewise characterized the ability to secure funds for programs like Head Start as highly political. In order to secure funds for Hawthorne Head Start Nursery School for example, she had to reach out to well-connected individuals across the city. Yach reported that she was told by the regional chair that there was 'no money for any program in the city'. At the time she was trying to implement Dr. Weikart's 'High Scope' program in her daycare. This program was derived from the extensive research of the Ypsilanti project in Michigan, and 
proposed that children learnt most when engaged in hands-on play and direct interaction with others. Yach had visited the United States and become acquainted with Dr. Weikart and his work. She said that she called up the regional chair, who she happened to know well, and asked if he would like to meet Dr. Weikart to discuss the High Scope project and its implementation into the nursery school. After a two hour meeting between Haydon and Weikart, Yach was informed that she would be granted full funding for the implementation of the program. While Yach was not certain about what Dr. Weikart said or did, she concluded that things got done when you had the support of an expert with strong, persuasive evidence. She also found it puzzling that Weikart, an American was able to easily influence decisions occurring in Canada.

Four years following the opening of the Hawthorne Meadows center, Monahan led the opening of Heatherington Head Start nursery school program, which she later got designated as a Head Start program by the Ministry of Children and Youth Services. While she was able to secure funding to support programs like language stimulation, funding was not provided to reduce the teacher-child ratio. The former directors also believed that programs, such as Head Start, were obligated to meet the needs of both the children and their families. Furthermore, eligibility for such heavily subsidized programs was often dependant on some form of self-enhancing activity by the parents, such as enrolment in school, taking job or skill training, or drug and alcohol counselling, etc. 


\section{Parental Involvement}

The founding members insisted that there were significant benefits for children of parental involvement in the program. Blenkiron insisted that a crucial aspect that differentiated Head Start from other child care programs was the involvement of Head Start workers with the children's families. She observed that by being present on the bus during pick-up, she was able to meet and interact with the children's parents. She recalled an occasion where another teacher was able to go into the home and assist in getting the child ready for school. This sort of closeness and trust between the users and providers of the services made Head Start standout from other nursery school programs.

During the fall and winter sessions of the earlier days of Head Start, weekly parenting groups were held. Topics for discussion were mostly open, and of the parents' choosing, but often centred on life skills and parenting strategies. It was a time for sharing, deriving communal answers to emerging concerns, and a time to nurture interpersonal connections. In addition, Blenkiron indicated that it was an opportune time to gather feedback from the families and to discuss ways for meeting their needs. During the summer months however, there was a weekly field trip and barbeque where the parents came along, and food was provided free of charge. Blenkiron described these events as 'very, very special times'. Blenkiron also added that the success of the program was based on the combined efforts of all parents as they made the decision as parents to choose a better life for their children. She expressed these sentiments when she stated 
"with love and caring comes positive feelings and self-esteem which creates movers and shakers". She went on to say that working with a single family in isolation simply does not work.

Monahan had a slightly different take on the involvement of parents. She identified the program as being a bit of a 'respite' for parents. Through parent discussion groups, Monahan learned that some parents took the time to stay at home and to attend to personal, work and school related matters. Some of the topics covered during the parent discussion groups during Monahan's time, included child development, behavioural guidance, nutrition, life issues, and provision of support. Monahan noted that Hawthorne Meadows was established in a city ward with a significant Somali immigrant community, where many families faced differing and multiple challenges. She pointed out that many families were victims and witnesses of war in Somalia. Part of the problem stemming from the displacement and violence brought on by war was the fragmentation of families where children were left parentless. As these children went on to become parents themselves they had very limited experiences about parenting. Monahan also suggested that the families may have been 'broken' through patterns of violence, abuse, and substance misuse.

Monahan indicated that Head Start families valued the support that they found in the program. She attested that they would not go to an Early Years program even if it was across the street, but that they would travel the distance to Head Start where they felt comfortable. She also thought that there was considerable value in having parents on site, and working along with the children, 
as it allowed greater opportunities for fostering parenting skills. She observed that Head Start workers had to be strategic when trying to get parents involved and willing to show up. She summed up her thoughts in the following excerpt:

Saying to Kathy, you live in Ottawa Public Housing, you're a high stressed parent, come to my nursery school and I'm gonna teach you how to be a mother...that's not gonna work. But if I say Kathy, I have some great treats and I can give you a break from the baby and show you a fun time...

She believed that Head Starts increased parental involvement by making the interaction entertaining. She also indicated that childcare workers are in an opportune position to acquire trust and connections with the families as they are not identified by parents as a part of the cohort of experts involved in their lives, such as CAS workers, school social workers, elementary school teachers, multicultural liaison officers, welfare workers, and doctors. She thought that many marginalized parents are inundated by contacts with helping professionals, and do not want contact with anyone else who judges them. Rather they just want consistency and people who genuinely care. According to Monahan, they do not want the attitude of "I am better than you". To illustrate her point, she relayed a story of her earlier years as the Head Start director.

There was a mom of two boys who were around seven and four. They were very busy! The oldest one loved taking things apart. He loved it and he was ingenious. He was fast. This was before I had the bus, the parents would walk them. This mom came through the doors and the kids run in laughing. I was at the door trying to develop a relationship with her and I said "how is it going?" She asked if she could speak to me so I said 'sure' and took her outside as I didn't have an office in those days. She then asked 'did CAS call you? I beat the shit out of Sam last night and I could not stop, one of the neighbours had to call CAS. So I asked "Are you ok?" The mother burst into tears and fell in my arm as she said 'You're the first person who ever gave a fuck about me. 
Monahan was unsure why she asked the question, "Are you ok", because she admits that as parents and teachers our first concern and empathy is more often directed to the child. Monahan added that in her years as a child care provided, she has worked with thousands of parents and that they all want to be the best parents that they can be. Through her many years of working in childcare she has only met one parent who she believed did not have the capacity to parent due to severe mental health concerns. She reiterated that a parent's life experiences determined how they reacted and related to their children.

Monahan also recalled an incident where she had to be innovative in order to get parents actively involved. She had six open spots, but the neediest families in the community were not part of the provincial work program, involvement in which was mandatory to receive care from the Head Start nursery school. She convinced her manager to agree to have the parents volunteer one day a week in exchange for childcare. Two of the parents went on to become teachers at the Head Start. Monahan praised such an approach as she reflected on her current position as the director of Language Instructions for Newcomers to Canada (LINC): a federally funded program targeting immigrant families with minimal English speaking skills. She recalled a recent incident where a new mother from a war ravaged region presented herself to the centre. Her child was born at a refugee camp. The mother had never been to school and did not speak English. Monahan described the mother as subdued until she was introduced to a staff 
member who was from the same country and spoke the same dialects. Monahan described the point of contact as 'opening up a flower'. After that first contact the mother became encouraged and very receptive once she realized that there was someone present spake her language and understood her.

The information gathered from the founding members of the Head Start program reflected an energized and progressive Head Start. Even when struggles presented there were methods and ways of overcoming. Head Start was mobilized on the will and determination of the community and flourished in the earliest years.

\section{Finding of Director Focus Group}

As pointed out earlier the focus group was conducted with existing members of the Head Start program in Ottawa. Between the eight participants, there was over one hundred years of experience both as teachers and supervisors. In addition some of the participants had experiences working within the wider childcare community.

The Directors define Head Start

The directors of Head Start viewed the program as the opportunity to prepare children for the formal school system. One member spoke of cases where children new to the program may have never held a pair of scissors or a crayon. One director said that she believed that having a child in Head Start for as short a time as a year can make a significant difference for the development of the child, while another director expressed uncertainty about just how much 
time was needed to make a long lasting impact. Another director referred to the program as a "life line where parents and children can blossom". The program offered routine and structure where children can strive. Head Start has occasionally been defined as an "early intervention" program which gently transitions the child and family into a more rigid school system. The directors observed that while parents often feared authority figures in the school system, Head Start served as a supporting bridge for families and their children.

The Head Start program has a higher concentration of children with special needs than any other nursery school program in Ottawa. Many have behavioural issues such as poor coping skills, poor self-regulation and reduced impulse control. The proportion of children with special needs registered in Head Start nursery schools was described by a director as "unbelievable," i.e. it is extremely high. It can be understood then that for children with a history of behavioural issues and struggles change and transition can be unsettling.

\section{Daily Operations of Head Start}

The focus group and my experience as a Head Start teacher allowed me to see Head Start through the perspective of the directors of the program who spoke in detail about the day-to-day operations of Head Start including foods served, what brings families to the program, and the general demographics of the users.

As noted above, the type of food served to the children is well thought-out. While it may not vary significantly from other nurseries, tremendous effort is directed at providing substantial meals to the children. In the half day programs for 
example where they do not have to provide meals, every child in the Head Start Program gets at least two meals. The Day Nurseries Act of Ontario 2012 which governs the operations of Ontario's nurseries including Head Start requires that meals include food from each of the food groups. The individual programs are attentive to varying dietary restrictions based on culture, religion, family diet and a child's allergies. This may mean that staff members have to prepare vegetarian, halal, pork free, and allergen free foods. Recently, efforts were made to move away from canned, bottled, and preserved items to preparing all meals from fresh ingredients. For example, tomato sauce was made from fresh tomatoes, herbs and flavourings. Along with this shift, most programs have reduced juice (a concentrated form of sugar) intake to a minimum based on recommendations from public health officials. Instead of fruit juice, fruits, milk and water are served. This is a direct response to increasing rates of childhood obesity as well as efforts at reducing dental decay. One of the programs attached to a community health centre gets approval of their menu from an on-site dietician.

Referrals to Head Start come from many different locations across the city including partners in the community such as The Children's Aid Society (CAS), Better Beginnings - Better Future, Ottawa Treatment Children Center, and First Words. There are also a significant number of referrals from healthcare professionals. Parents likewise may self-refer. This has resulted in an extensive waiting list as there are more needy children than spots.

The bulk of Head Start children came from high-risk families with poor coping skills. It was estimated by members of the group that approximately $75 \%$ 
of the users of Head Start have four or more risk factors which included inadequate housing, poverty, lack of food, abusive conditions, speech and language deficits. Many of the families using the services were from diverse backgrounds and in some cases were new Canadians. Many of them were also receiving Ottawa housing assistance. However, as can be expected, there have been fluctuations in the specific demographics of individual families over the years. Two of the directors indicated that there continued to be an over representation of Somali-Canadians using Head Start services. The more senior directors, have also seen a few cases where two generations of the family have presented themselves to Head Start. They interpreted this as a sign of intergenerational cycle of poverty, but could also be a sign that Head Start is not functioning optimally.

Although the program was designed for children of low income, high-risk backgrounds, there were specific guidelines around eligibility. The city of Ottawa website outlined the eligibility requirements. Beneath the directions for applying for subsidized spaces, instructions suggest that exceptions should be made for families enrolled in provincial work or study programs or for families with special needs. Unlike other nurseries with subsidized spaces in Ottawa, it is not mandatory that the parents of a child attending Head Start attend full time school or that they have employment (City of Ottawa, 2012). This is the only program that supports children whose parents may not be able to function at work or in full time school. Being out of a job or out of school does not automatically eliminate a family from accessing subsidized childcare. 
Head Start's Funding Pot

The current directors reported that Head Start nursery schools were currently subsidized $100 \%$ by the City of Ottawa. Today's programs work through a "purchase of service" agreement, whereby the city purchases the childcare from the centres. One member described it as a commitment made in 1989 by the city to the children and people of Ottawa. It was part of an effort to provide care for high-risk children. In addition to the full subsidy arrangement, most programs engage in fund raising, and some are currently recipients of charitable donations from an affiliated church and other private 'unnamed' organizations. This additional funding is necessary as the $100 \%$ subsidy is insufficient in meeting the needs of the children registered.

In its annual budget the City of Ottawa has a specific amount of funding allotted to all childcare in Ottawa. Out of these funds, a portion is assigned to Head Start. Each centre is paid a per diem rate based on the number of children in attendance. The city is the primary decision-maker determining the amount that each program is paid. This per diem rate varies from one school to another depending on location, whether employees were unionized, costs of transportation, provision of full-day or half-day care, and whether it is city administered or privately administered. The highest per diem rate is $\$ 63$ while the lowest is $\mathbf{\$ 2 8}$. If centres happen to be operating under capacity, payment is withheld for unused spaces. This means that the centres are obligated to keep spaces full at all times. In the event that parents suddenly decide to take their child out of the program, the city allows for a ten-day grace period within which 
the centres need to fill that spot. Although a specific amount of money is set aside for the purchase of Head Start services, if some of it is unused by the end of the financial period, the extra does not stay with the program but has to be returned to the city.

Although Head Start programs are advertised as fully subsidized by the City of Ottawa, there is a sliding fee system in place, where some parents may be required to pay partial fees based on their family income. Fees may vary from $\$ 0$ to $\$ 600$ per month. In one case, parents were paying full fees as there was no other nursery school available to meet the needs of their special needs child. For this family, the problem was not a lack of money, but rather finding a nursery school program that could accommodate the needs of their child.

Members of the focus group were requested to imagine an ideal model of Head Start, and to identify that which created the greatest barrier for achieving the ideals of Head Start. Participants unanimously agreed that their main barrier to achieving their goals was inadequate funding. There was the specific concern that funding for Head Start was part of the funding pot for all childcares. Hence changes to the childcare system at large inadvertently affected Head Start. In justifying the need for a separate funding pot, the group of directors argued that there are clear demarcations between the Head Start and other nursery schools. They were convinced that only by demonstrating how Head Start was different from other programs would they be able to justify their overall worth and distinct contribution to impoverished and marginalized families. 
Working on the Head Start Floor

As a result of the over representation of children with special needs enrolled at the Head Start programs and the need to provide quality care and attention to each child, members of OCHAP have continuously advocated for lower ratios of children to teachers. The pleas appeared to have gone unheeded as the programs are now operating at an 8:1 teacher-student ratio for preschool and 5:1 for toddlers. These are the ratio for regular nursery school programs. While one director observed that a high proportion of children with special needs did not necessarily mean that the classroom becomes unmanageable, others identified cases where the behaviours were so extreme that a child should be regarded for the purposes of calculating participants as more than one child. It is frustrating, according to the directors, that the program is expected to integrate children with special needs, but fails to provide enhanced such as reduced ratios or prorated funding. One director expressed her concerns by observing, that "some days when I walk out of work I am just thankful that everybody is alive". The limited financial support has meant that directors have had to turn away many incoming referrals. In addition, a lack of resources has also resulted in high burn out and staff turnovers at the centres. The directors agreed that for children of Head Start, a major contributing factor to their overall progress is consistency. If the turnover rate of teachers is high, this created added disruptions for the children.

It has been noted that the intensity in a Head Start classroom combined with the high child/teacher ratios is a deterrent to potential teachers. Most come 
in as part of their ECE training from Algonquin College, and although they are encouraged to leave their resumes if interested in working as supply teachers, many choose not to. While the minimum academic requirement for a Head Start teacher is an ECE diploma the directors were in agreement that it takes much more than a certificate to become and remain a Head Start teacher. According to one director "those who get hired tend not to last long once they recognize the challenges existing in the classroom". Survival and success required teachers who were patient, caring, non-judgemental, tenacious and accepting. Teachers also need to have an innate understanding of the families and the risk factors affecting the children. The directors speculated that part of the reason that parents come to the program is that they see Head Start as a great opportunity for their children. Staff needed to be fully invested in the model and its mandate to carry out their daily tasks.

There is no formal training for becoming a Head Start teacher. Becoming a well-rounded Head Start teacher involves a process of informal education. For example, successful teachers try to learn to speak to the parents of children in their first language, or work to be aware of, and empathetic to their circumstances. One director supported this point when she stated "sometimes a new teacher might sneer out the word subsidy, as if it was a dirty word, but in short order they would leam how to speak about families in less negative and more respectful tones".

A particularly telling moment was the group's reaction and response to the question on the overall demographic profile of teachers at Head Start. There was 
a rare moment of silence followed by the response of "female for the most part, occasionally there is a male teacher but for the most part female". This was the extent of the conversation on the demographic profile of teachers. This was significant for two primary reasons; first, it supported the social construct that the caregiver role rests almost entirely on women in both the private and public sphere. Secondly, beyond gender identity, many social services have not yet managed to establish a corresponding identity based on race and culture that matches the client populations.

Directors expressed concern about the abrupt end in contact between Head Start teachers and children after the child leaves Head Start. They felt that they often times had valid information on children which would be beneficial to their kindergarten teachers but that there was no avenue to allow for this connection. It was believed that such a transition would contribute to a continuum of care to the child and families.

\section{Parental Involvement: The Directors' View}

On the topic of parents and their involvement in the program, the directors suggested that there was variability between programs. As a general rule, opportunities were provided to parents to attend workshops, to ask questions and to find information as needed. One centre facilitated a "parent chat" while another recognized that parents were more likely to engage in conversations with each other in the hallways. There was, however, the concern that direct, hands-on 
parental involvement fell below expectations. A number of reasons were identified for this gap in parental involvement and connection with the program.

One reason given was that there were many other parenting programs operating within close proximity of the Head Start programs; hence parents were occupied with these other programs. This meant that other parenting resources available to the parents of children attending Head Start had lessened the load of providing parenting mentorship at the centres. At this point in the discussion, directors of programs attached to community health centres confirmed that this arrangement of being tied to a community centre placed them at a significant advantage. They had the in-house capacity to offer extended services, which the stand alone programs were unable to provide. Richard Weissboard (1996) made a similar argument pointing out that different professionals involved in a child's life offered inconsistent information. This is understandable as the teacher's judgements were based on direct observations, academic grades and attendance while the healthcare provider sees both the parent and the child, but usually only at brief and irregular periods. On the other hand, police and social workers were likely to engage with children and parents in their homes, but during periods of upheaval. Moreover these different experts use different methods of analyzing and understanding family situations. Their approaches to problem-solving were likewise different (Weissbourd, 1996). This can contribute to confusing and even contradictory messages from different professionals. This is not to criticize the contributions of different helpers but rather to recognize the 
challenges of working coherently with families and the potential benefits of more integrated and coordinated efforts of professionals involved in assisting families.

The members of the focus group also pointed out that there was not enough staffing available to make and maintain connections between families and the program. This connection was necessary at it was believed that a strong parent-teacher team was ideal for intervening with children. The high ratio of children to teacher left little time for activities outside of the classroom. Their efforts were limited to posting flyers about sessions and greeting parents who presented at the centres. An interesting discussion ensued about the role of the

\section{8} floating teacher who also served as the bus monitor. This individual was in the most opportune position to meet and engage with the parents during pick-up and drop-off. This again raises the concerns expressed above, that different professionals have different perspectives about children. The perspective of the floating teacher who interacts marginally with the child in the classroom and on the bus may be entirely different from that of the in-class teachers who works with the child more directly for an extended period. It is hence important the ratio of staff to teacher is at a level that allows time for establishing relationships between families and staff members, particularly with the staff that work most closely with children.

8

A floating teacher is one who provides support in all areas of the center particularly during busy periods. This includes meal time, nap time or getting dressed. 
One director felt that most of the parents did not really have a strong interest in participating in the enrichment aspects of the program but were mostly using it for childcare. Parents typically did not respond to questionnaires and did not provide information concerning the care of their children. Parents were often times contending with other personal struggles such as addictions, mental health, housing, and poverty, and thus the issue of childcare and parenting, tended to be a lower priority than other survival needs. This observation was contrary to the founders' observations that parents were trying to be the best that they could be. An alternative perspective was also discussed. An incident was mentioned where parents reported to teachers that an absent parent was very happy with the work and effort of staff members. The parent who was so full of praises for the teachers was unable to express those feelings to the staff members. She was very shy and would hardly smile at the teachers. According to the directors, it often took months before parents were able to engage and respond to overtures from teachers and staff. Another problem area with respect to parent participation was that while there was the opportunity for parents to be board members there were not any in this position at the time of the focus group.

\section{OCHAP and its Work}

The Ottawa Carleton Association for Preschools (OCHAP) was established in the 1980s in an effort to bring together the individual Head Start Programs of Ottawa. The directors were the primary representatives of each centre in the association and attend monthly meetings. The directors of Head Start were confident that the existence of the association gave an advantage to 
Head Start programs, as they could meet monthly and regularly via phone and email to discuss, share, and advocate on behalf of the users of the Head Start program. OCHAP functions as a support system for the directors and workers of the program. In addition to providing this support, OCHAP also serves as the primary advocating agent for funding within Head Start, such as challenging the proposed cuts to childcare in 1995.

Some ongoing issues for directors included high teacher to child ratio ( 8 children to 1 teacher), limited number of spaces, and insufficient speech and language services. These challenges were associated with insufficient funding allocations. At the time of the focus group, there was a degree of uncertainty surrounding the childcare system, as governance was being moved from the Ontario Ministry of Children and Youth to the Ontario Ministry of Education. Head Start programs were also attempting to cope with the implementation of a new policy that provided parents with floating spaces. This means that parents can move their subsidized space to any child-care centre in the region, in order to allow them to search for better jobs or housing. While this offers flexibility and freedom to the families, it means instability for Head Start programs, as it made it very difficult for them to plan and budget programming when families left.

An interesting feature of the advocacy work undertaken by OCHAP is the approach taken in publicizing the conditions in which Head Start families live. They do their best to be discrete and tasteful in their request for resources, funding and support for these families. OCHAP directors believe that it is important that the integrity of the users of the program be protected. OCHAP 
members have been deliberate and tactful in exposing just enough about the realities of families living in impoverished conditions to secure funding. This is comparable to the American Head Start programs where significant emphasis is placed on understanding the nature of the difficulties that families face.

\section{Summarizing Founders Interviews and Directors' Focus}

The primary emerging themes from the interview held with the founding and former directors of Head Start nursery schools in Ottawa were the formative years of Head Start, the definition of Head Start, staffing of the program, funding issues and parental involvement.

In the earlier years, there is a sense that while the Head Start programs encountered challenges, there was the will and public support to overcome. Methods of obtaining funding were also less bureaucratic. As the years passed the directors have had to devise methods and strategies to sustain and compete with other emerging nursery school programs. Head Start directors have had to prove why they deserved to be supported. In both the earlier and current operations of Head Start they have used two fundamental points in proving their worth. Firstly, that the population served by Head Start was different i.e. children and families from lower income backgrounds who typically struggled with language, behavioural and poverty issues. The second point was that the program provided by Head Start was different from typical nursery school programs as it was more enriching and holistic in nature. 


\section{6b. Findings/Reviews of Records}

This chapter highlights the findings from the review of the minutes and documentation at two primary locations; the CAS Head Start at 1602 Telesat Court and the City of Ottawa at 100 Constellation Drive. The minutes at the CAS location represented regular meetings of OCHAP directors' from 1982-1994 while those at the City of Ottawa office documented work done by smaller subcommittees of OCHAP. Five major themes were identified, and these are reviewed in the next section below.

\section{An Archival view of Head Start's History}

In one of the earliest reviews of Head Start in 1983, the directors claimed that the program in Canada was first established to meet the special needs of disadvantaged children and youth. An undated record specified that there were eight centres in Ottawa, and that the earliest full-time Head Start school was created in 1967. This file, which was kept at the City of Ottawa, also stated that in 1966 many communities around Ottawa were beginning to recognize a need for services in support of low income families. This same record also discussed the establishment of what was believed to be the first Head Start nursery school in

Ottawa. The Queensway Head Start program started in response to a survey conducted by the Parkdale United church to determine the needs of the community. This survey sought to understand the circumstances and needs of children from low income families. The report indicated that with the support of four local churches, the Head Start program at the Queensway centre was 
started. The report also outlined that the regional municipality has been a primary supporter since that time.

\section{The Work of OCHAP}

The minute review provided excellent data for assessing some of the work and interests of OCHAP. It was anticipated that the minutes would reflect some of the details of the association's history, daily operations, challenges and accomplishments.

According to the minutes, OCHAP was incorporated in 1980, and existed to represent children, their families, workers of the program, and members of the Head Start Board. OCHAP operated under a licence from the Ministry of Community, Family and Children's Services, as well as the 1990 Day Nursery's Act (DNA) (OCHAP, 2006). OCHAP amalgamated the voices of all the parties involved in Head Start in Ottawa in the delivery of high quality, comprehensive early childhood care. As outlined on the website, the purpose of OCHAP included: providing a central body to coordinate services, providing ongoing education to staff, supporting parent education initiatives, advocating and promoting Head Start programs in the community, and doing advocacy work on behalf of parents. To work to achieve these objectives the directors, at monthly meetings discussed practical ways to foster education, network with other

agencies on issues of housing, poverty, and family stress. Minutes from Oct $2^{\text {nd }}$ 1991 , suggested that yearly in-service training, professional development days for staff, periodic forums and focus groups were organized through OCHAP. 
OCHAP has also been active in raising awareness about child and family poverty. In minutes from 1983 the following risk factors were identified among users of the program and children who were living in poverty in general:

- Lack of consistent treatment by adults and parents

- Lack of positive attention by adults to aid in the mental and physical development of children

-Frequent changes in adult care-givers

-Developmental delays, especially in language

-Poor nutrition

-Poor dental care

- Lack of outdoor play space

- Lack of warmth and nurturing

- Lack of stimulating material

-Poor housing conditions (crowded, drafty, and cold)

-Frequent moves in search of housing

-No respite for parents

-Poor self-images for all family members

-Suffering from 'poor kids equal bad kids syndrome'

When I reviewed the minutes of June 1990 , it was noted that one of the directors and long standing members of the programs had given an inspiring speech entitled 'National Issue to eliminate child poverty" to the Child Action

9

There is the common assumption that children from lower socio-economic backgrounds are bad by virtue of their status. There is the tendency on the part of adult care-givers to show discontent towards children of this group. 
th

Poverty Group. Minutes of March 261994 highlighted discussions on the dismal progress of Campaign 2000, which was endorsed in November 1989 with the aim of eliminating child poverty in Canada by the year 2000 . The impact of poverty on family members and the community at large was also a popular topic for discussion.

Reactions to proposed cuts to childcare and various other social services by the federal government were well documented in the minutes of 1994 . The minutes recorded for March $26^{\text {th }} 1994$ highlighted a proposed 26 million dollar budget cut to childcare which was using only $1 \%$ of the national budget. This posed a direct threat to subsidized spaces and wages for the workers. OCHAP along with the broader childcare community quickly mobilized to counter those proposed cuts and to protect the childcare system. Children were being asked to participate in activism by drawing pictures representing what their nursery schools meant to them while parents were provided with letters to sign or asked to write letters to the government. The Childcare Council which continues to be an influential organization on childcare issues today was born out of the efforts to combat those cuts in 1994. Even with its limited budget, OCHAP made direct financial contributions to the establishment of the Council. Today, Head Start maintains a vote on the council board.

The issue of 'gender and childcare' was closely linked to the discussion on poverty. The minutes of May $11^{\text {th }}, 1994$ reported that in those years $64 \%$ of women with their youngest child less than six years were in the paid labour force. 
In the discussion, it was proposed that a strong childcare system was vital component to women attaining equal status in the public sphere. It was argued by the directors, that Canadian tax laws did not support parents and that further considerations needed to be given to assisting working poor parents, in particular women.

\section{Head Start as defined by the Minutes}

My review of OCHAP minutes revealed different ways in which Head Start directors had to shift and at times manipulate their models, objectives and definitions to meet the demands of their communities and to attract potential funders. Notes from a document dated November, 1983 outlined that one of the purposes of the Head Start program was to prepare disadvantaged children to be ready to enter school with a similar chance of success as other children. As supported by most of the other findings, the reviews (June 1984, March 1986, Sep 1990) revealed that the core tenets of the program were consistently maintained across the years:

1.Parent Education and Counselling

2.The provision of Health Services

3.Psychological Assessment with treatment

4.Nutritional Support

5.Professional Understanding of the program

Principles were applied to the everyday operations of a program. Some of the ways in which Head Start workers have tried to implement those core principles are listed below. 
- Enriched pre-school programs, which includes exposure to range of activities and experiences for children

- Individual Program Plans (IPP) designed to meet the needs of individual children and their families

-Hands-on learning whereby the centres can make use of the resources existing in the community

- Language programs

- Liaison with schools and other agencies

-Self-esteem classes

Based on the reviews, the programs attempted to incorporate these into the daily operations but met difficulties, and at times were threatened due lack of funding, political support and resources.

Many of the goals and objectives which defined Head Start were influenced by American literature and research. While some supporting data was Canadian, most have emerged from American studies. Some Canadian studies mentioned were the 'Poor Kids Report' by Harriet Kang (1983), as well as the 'Early Years Report' by Mustard and Fraser (1999). Some of the American authors referenced included David Weikart with 'The Ypsilanti Perry Preschool of Michigan', which included a series of reports written from 1967, Shaffer (1985), Edward Zigler, and Alan Moffitt (specific dates were not referenced for these writers).

As indicated in the minutes, Head Start administrators often discussed how best to define the program to attain necessary support, such as additional funding, legislative changes, and political backing. In discussions in the minutes from May $6^{\text {th }}$ and $26^{\text {th }}$ of 1987 there were efforts to label Head Start as a 
preventative and remedial program. It was believed that prevention of developmental and behavioural problems were achieved through the provision of enriching and stimulating programs. There were efforts to shift from a predominantly remedial approach to strategies like correction, repetition, relearning, re-educating, stimulating, individual programming, identifying problems and needs, as well as providing language catch up programming. The underlying goals of these approaches however remain the same, which was to permit children with 'special requirements' to achieve their full potential. These proposed changes were designed specifically to attract the support of the Ministry of Health. The ongoing changes and alterations across the different schools also worked against Head Start as reflected in the minutes of February $16^{\text {th }} 1989$. In a review of programs for children with special needs, conducted by representatives of different municipalities, Head Start was criticized as having inconsistent philosophies, intake procedures, assessment of child and families' needs, program goals, components and activities. It was argued that ideally programs should be transformed to meet the changing needs of the populations they serve. However Head Start has been changing mostly to fit the criteria of various funders. There was rarely any examination of how the needs of families had changed throughout the years.

Despite such criticism, many aspects of Head Start were changed or modified over this time period. Nowhere was this more evident than in the question of eligibility. Most definitions of eligible users of Head Start have tried to be inclusive of physical, emotional, communication, intellectual, and 
behavioural needs of both the child and the family. On November $12^{\text {th }} 1986$ a brief was submitted to a task force mandated with reviewing social assistance and social service programs outlining the purpose of Head Start. The brief addressed its' unique features and how they met the needs of the population they served. In a report prepared by a subcommittee in March 1988, OCHAP members considered using the term 'special needs child' to describe the populations served by the program. The directors however, decided against using the term 'special needs' as they became wary of an expansion of children's needs beyond that which they could meet. With limited spaces and often minimal resources, centres had to exercise selectivity in determining who gets in. How the programs demarcated their eligibility determined how they were funded. A review ordered by the RMOC, and conducted by Helen Charron in 1987 , suggested that a variety of factors were considered in determining eligibility, such as whether a family was in low income housing, if they were self-referred, agency referred, or were court ordered, results of needs tests, their qualification for subsidized childcare, if they were working poor, or if there was CAS involvement. A vision planning committee of $\mathbf{2 0 0 2}$ was set up to determine whether Head Start was meeting it goals or needed to change the direction of the delivery of services.

Funding Woes since the Inception

The minutes reviewed provided more evidence that the Ottawa Head Start program suffered as a result of under-funding. As the City of Ottawa has been 
the primary funder of the Head Start program, budgetary details were not discussed in the minutes. Many minutes included calls to the community to provide funding, staffing, and support for the program. Efforts at retrieving annual budgets were futile but it was later revealed by a former director that such documents were confidential. This confidentiality was rooted in the disparity between the per diem rates of the different Head Start programs, which had created contention among the various directors.

Not surprising, a program which was designed to alleviate the barriers faced by children of families who live in poverty itself operated under impoverished conditions. Some recommendations called for the Ministry of Children and Youth to supplement the program where the OCHAP was unable to provide. The reliance on charitable donations was reflected in the inception of the hot meals program. Minutes dated October $2^{\text {nd }} 1991$ claim that in April of 1991, the Kiwanis club of Ottawa provided funding for a two year pilot project in three of the programs; CAS, Queensway, and Heatherington. Minutes recorded on December $4^{\text {th }} 1991$ indicated that even sponsors of the hot meal programs the Kiwanis club of Ottawa requested a definition of Head Start along with an account of how the money was being spent. The challenge of relying on charitable contributions became evident when the Kiwanis club in 1994 was unable to continue as sponsors of the hot meal program. Recognizing the overwhelming need for such a service, the program directors considered using a hospital food supplier as they were cheaper than other catering companies or 
professional cooks. As noted the hot meal program remains an integral and defining component of the Head Start program.

Another barrier faced by the directors of Head Start was the limited physical space in which the programs operated. Most of the programs existed in spaces borrowed from schools and community centres. The minute review of January $18^{\text {th }} 1989$ demonstrated the problem as the Hawthorne Meadows Head Start location could not get its lease renewed from the elementary school in which it was being housed. Other Head Start nursery schools were asked to make available any space they may have had to help alleviate the situation. This centre continues to in operation today.

There were many examples in the minutes where requests for research funding, improvement of ratios, additional support staff, and a behaviour management specialist were turned down. Minutes of June $2^{\text {nd }} 1989$ for example, reported that a request to the Child Care Initiatives Fund (CCIF) for Head Start research purposes was turned down due to federal cutbacks. Minutes of Oct 2 1991 indicated that the ministry was cutting funding to toddler and infant programs in Ottawa. In cases where programs gained approval for specific services like speech pathologist or additional spots, additional requests and demands were placed on the directors as part of the approval. An example was revealed in a copy of a letter dated January $29^{\text {th }} 1982$, in which then social service commissioner, Arthur J. Pope, to Harriet Lang of the Ottawa Committee 
for Head Start, indicated that funding for a speech therapist could be provided. He wrote:

The one condition we would place on this agreement is a review of the assessment criteria, before, after and during of children by the teachers. In addition, a more detailed statement of how you intend to assess the progress of parents would also be of interest to us. Finally, we wish to be assured that we will receive a complete assessment of the project upon completion for our consideration.

\section{Staffing in the Minutes}

Over the years reviewed in the minutes, staffing was a persistent concern for the directors. Information contained within the minutes indicates that it was difficult finding, retaining and supporting eligible staff for the program. Programs also had to deal with sharing specialized staff. Some of the staff shared between the centres included speech and language pathologists, speech and language 10 consultants , family life educators, social workers, and behaviour specialists. The contributions of these practitioners were necessary components to the functionality of Head Start. The centres were forced to make do with what was available to them.

Minutes from the planning committee on January $15^{\text {th }}, 1988$ outlined some of the suggestions made by members of the Day Nurseries Act (DNA) Revision Committee of Head Start ahead of the DNA (1990). The DNA governs the

10

Language consultants would conduct assessments and make recommendations for intervention while speech pathologists were able to both assess children and execute interventions. 
operations in all nursery schools across Ontario. One of the central recommendations concerned the ratio of number of children to a Head Start teacher. The ratio in the DNA prior to the 1990 revision was 8 children to 1 teacher but the planning committee was proposing 5 children to 1 Head Start teacher. The 8 to 1 ratio was too high to accommodate special needs children such as those served by the program. It was also argued that a reduced ratio would allow the teacher to allot more time to individual children. Although OCHAP had advocated special accommodations for special needs children, to this day, it continues to struggle under the same ratios as all other centres.

Despite the shortage of Head Start support staff, the program continued to function with those available. Over the period of time covered by the minute review each of the Head Start centres was led by a director who represented their individual centres on OCHAP. A review of minutes from April $5^{\text {th }} 1989$ claimed that apart from their duties with OCHAP, directors oversaw the overall operations of the programs. They were responsible for hiring, firing, communicating with external agencies, accepting referrals, preparing and monitoring budgets, obtaining needed equipment, arranging admissions, dealing with parents, making recommendations, and developing policy with boards and property management. Supervisors were also reliant on teachers to provide supervisory support when necessary. While the supervisors were the only voting members at OCHAP, the contributions and inputs of collaborating experts such as the speech pathologist and social workers were welcomed. 
An Early Childhood Educator (ECE) is anyone who has met the requirements of an early childhood diploma at a recognized college or university. Throughout the early years, various workshops and training were made available to Head Start teachers. Minutes from April $5^{\text {th }} 1989$ for example stated that training was provided to teachers as they were required to conduct language and speech assessments to provide support in light of the limited availability of the speech pathologist. This approach was necessary to provide support to the lone speech pathologist so that more children could be aided. Other workshop training directed at teachers included language stimulation, child abuse and multicultural awareness. In the OCHAP minutes of February $21^{\text {st }} 1991$, the cultural awareness component was described as "one more responsibility and stress to the staff". In these same minutes it was emphasized that the staff have a keen awareness of the needs of families and children.

In a review of minutes from 1982 it was noted that efforts were made to incorporate the Head Start philosophy into the training of early childhood educators. This resulted in a certification program from Algonquin College. Some of the older teachers at one point were required to take refresher courses as ongoing training for the program. Under the co-ordination of Lucette Potvin a five part certification program was offered through the family services department.

The courses were:

-Introduction to Head Start

-Programingllssues of work with low income families

-Behaviour management 
-Income Assistance and resources

-Family Intervention

The minutes reviewed thus far suggested that the strides made by the Head Start program came with ongoing awareness, a determination to overcome presenting challenges and advocacy work. OCHAP has been a front runner in keeping the Head Start program together and promoting its mandate. There were however some marked shortcoming occurring both within and outside the program.

\section{Speech Pathologist}

The work of the speech pathologists featured prominently throughout the minutes. As with most other programs requiring the services of speech pathologists, acquiring those services was a constant struggle for the centres. Minutes of April 1989 outlined that the programs shared a speech pathologist who was only funded for three days a week. In another instant, they relied on a speech pathologist consultant who would identify the children most in need of care prior to the speech pathologist providing service, as the services of the consultants were cheaper than that of the speech pathologist. In the minutes of February $20^{\text {th }} 1989$ the Head Start Review Committee on Staffing listed some of the roles of the speech pathologist within the Head Start programs.

-Providing staff with training and education on how to identify language problems and implementing 
-Assessment (only possible if ratio was low)

-Referral to other speech and language services

-Consultation with parents

-Work closely with other support service such as social workers

-One-on-one therapy for speech

-Modelling on the floor

-Conducting workshops for staff on language development

-Providing language and speech pathology services

The speech pathologist provides an integral component to the operation of the Head Start program. To function optimally however, this services needs to be available on a more consistent and regular basis.

\section{Were parents present then?}

The marginal rate of parental involvement at Head Start was evident in the minutes. One of the primary methods in which the program attempted to reach out and connect with parents was through the involvement of a family life educator (FLE). Some of the roles of this staff member were to provide better communication between the parents and the schools as well as to facilitate weekly parental support groups. Unlike the speech pathologist there was reduced emphasis placed on the role of this worker within Head Start. The speech pathologist and their roles in the Head Start program were mentioned more frequently than that of the FLE. Minutes from April 1991 suggested that 
mini-parenting workshops were intended for OCHAP executives but not for parents. It appeared that parenting skills were being passed from the expert, to the providers with the expectation that it would then be trickled down to the parents. The minutes reflected a push to get parents involved as volunteers, as this was seen as an opportunity for staff to model good parenting skills to caregivers. Before actually modelling to parents however, parents needed to be present at the centres. As transportation was available to get children to and from the various locations parents were not obligated to present to the centres. Minutes from a Head Start planning committee of February $16^{\text {th }} 1989$ added that results from questionnaires sent out to 350 parents in May 1987 raised concern that, even when parents were present, they did not feel comfortable expressing their viewpoints. In the discussion, the specific reasons for this discomfort were not identified. Efforts to overcome the lack of parental involvement included a mandatory bi-annual parent/teacher meeting.

I came to a deeper appreciation of the need for parental involvement when I came across a 1995 minute which cited the work of Shaffer in 1985. Shaffer argued parents who were actively involved at their nursery schools, were apt to become more satisfied with their child's school performance, and in turn begin to have higher occupational aspirations for their child, unlike those who were not involved. Getting the parents involved alongside the children was crucial in breaking cycles of poverty and raising families out of impoverished conditions. 
The success of Head Start as reflected in the minutes and documentations reviewed was similar to the data derived from the interviews and focus groups. Head Start does not merely operate as a childcare provider but takes on the role of a social service program directed at meeting the needs of not only children but that of their families and their communities at larger. By virtue of its nature a residual model has been used by the municipal governments of Ottawa in funding this program. As the program attempted to meet the needs of the users at multiple levels the program required more than the bare minimum. To sustain and be effective therefore, the programs have had to rally together and continually advocate for their cause. 


\section{Analysis and Discussion}

The analysis developed in this chapter will be organized in the same se-

quence as the major themes emerging from the findings of the research. I begin with the definition of Head Start and the distinguishing components of the program, then explore the funding allotted to the program. I will then address the role of parents/caregivers, the degree to which they are involved and the implications of involvement. The final segment of the analysis will touch on the staffing and training of those who are in the forefront of Head Start operations. The analysis will be focused on answering the research questions, amalgamating the findings, theories and literature review, and drawing conclusions.

\section{What does the program do? How it works?}

The goals and objectives of the Head Start program were outlined previously. Briefly and based on a collective review of the objectives of the program at different points in their history it was determined that the primary objective of the Head Start in Ottawa, is providing an enriching educational start to children from historically impoverished groups. The underlying aim is to elevate their chances of success in life. While program directors believed that Head Start makes a positive impact, the absence of longitudinal studies on the former children of the program limits the extent to which effectiveness can be determined. Based on the feedback from both the former and current directors of the program, the short term goals (e.g., language development, dental health improvement and devel- 
oping coping skills) were being met to a certain extent. The story of the child, who was only able to actively participate in class activities after his teeth were cared for, is a direct realization of short term goals. What is not known at this time is the long term impact, i.e. how were the children who had participated in Head Start functioning as elementary school students, adolescents and adults.

In a preliminary discussion, directors expressed concern about the abrupt end in contact between Head Start teachers and children after the child leaves Head Start. Their concerns expressed recognition of the political environment where the provision of social assistance is short lived and generally lacks attention to a long term vision. As a result of this political environment, Head Start itself was unable to set out goals and objectives with a long term vision. This likely stemmed from unstable and marginal commitments from those making the decisions about funding. This explained why Head Start workers have had to engage continuously in advocacy for funding. One has to wonder why a program of this nature has to prove its worth year after year when the rates of child poverty have yet to improve in Ottawa or Canada generally. Waring's (1988) analysis continues to be useful. She addresses the fact that the decision makers of social policy most often operate in the interest of a male upper class, and as a result devalue roles typically assigned to women. This devaluing was clearly reflected in the fluctuating and unstable support for Head Start (Waring, 1988). 


\section{Defining Head Start}

The definition of the objectives and target population of Head Start underwent many changes that reflect variations in political administration, economic conditions and the demographic of the users. Through the years, some of these include being called "early intervention" and being regarded as a program for children with 'special needs'. The continual redefining of the program in response to political and economic changes has been spearheaded by members of OCHAP. Throughout the years, the motivation for the existence of such programs like Head Start in Ottawa remained visible. Poverty, trauma, illiteracy, hunger and learning difficulties for example, continued to be prominent issues afflicting impoverished families of society. The rate of child and family poverty in Ottawa has remained consistently high. As reported in 2006, the rate of poverty in children under six years in the Ottawa region was $19.8 \%$ (Jimeno, Chung, Bouchard, Martinovic, \& Urquhart, 2010).

Definitions of Head Start have remained focused on what was lacking and the deficiencies of the families rather than on the potential of the families and children. The existence and operation of Head Start expressed the belief that with adequate support and guidance for children and families, that they have the potential to raise themselves out of their impoverished conditions. This belief could have been more strongly reflected in the operation of Head Start through deeper involvement of parents. While it was necessary to understand the needs of families, it was just as important to acknowledge the strengths and abilities of those families to contribute and ultimately control their lives. An empowerment 
approach would allow workers to focus on the strengths and abilities of parents. Strengthening families and encouraging their participation could help to influence long standing change. As Shaffer (1985) observed, by changing the expectation of parents for their children, the performance of children increased. Shaffer's work counters the too common assumption that people living in poverty lack the ability to be good parents, or that they should lose the right to be parents. In the 1999 Early Years Report, Mustard and Fraser argued that poverty does not equate to poor parenting skills, although, this does not mean that low income levels do not put a strain on a person's ability to parent their child.

Although the families of Head Start may continue to face multiple oppressions and multiple risk factors it cannot be assumed that each family was in need of each of the services available in the program. This is part of the reason why it was essential that teachers and staff of Head Start establish a close connection with the families involved with the program. This connection allows for dialogue, and provides the opportunity to determine where each family was at, to get firsthand information of what each family needs and how best to meet those needs. Bronfenbrenner's Ecological System theory (1979) helps to explain the intricacies of the different families who have been involved in the program and how the different layers of a child's life, i.e., family members, nursery schools, elementary schools and neighbours affects the child. Teachers who are culturally sensitive and aware of the lived experiences of these families would be in a better position to understand the needs of both the child and family. While this may have added responsibilities on teachers, the presence and support of resource staff can facili- 
tate this process of greater parental involvement in the program. Likewise, lower teacher to child ratios would allow more individualized time for each child.

Compared to the American Head Start program the directors of Head Start in Ottawa used markedly different strategies to advocate for funding. First, unlike the United States, where family stories and situations were used to raise funds and support, the Ottawa Directors, insisted that they treated families with greater respect and out of this respect they refrained from using the intimate stories of families as part of their fundraising campaigns. OCHAP programs were more focussed than the American programs on protecting clients against the dense layers of social stigma that came with living in poverty, in low income housing, being immigrants and members of marginalized communities. While the efforts to protect the families can be appreciated, the issues of poverty and oppression were and continue to be largely ignored in the community. Perhaps, this is due to the fact that Ottawa is a city of relative affluence. The median income of families in Ottawa in $\mathbf{2 0 1 0}$ was $\$ 94,700$, which was the highest for metropolitan cities in Canada while the national median income was $\$ 69,860$ (Statistics Canada, 2010).

For affluent families the daily commute is relatively easy. However for some families the everyday travels involves multiple transfers and becomes an added cost to already strained budgets. Moreover, the demand to get children ready and into daycare on time can be quite difficult for some. With the availability of only half day services and inflexibility in hours of care, it may be a daily struggle getting children organized and in school punctually. Further, a parent 
may be suffering a mental health issue and getting out of bed may be a challenging task. Head Start program directors have recognized this and have done outreach to all families by providing transportation. As stated by the current directors, children require consistency to function optimally and the provision of transport facilitated consistency. This was substantiated by the report completed by Moy (2003) on Head Start's transportation system, in which she indicated that the directors agreed that transportation to and from the centres improved overall attendance. Knowing and understanding the fine details of these struggles has allowed advocates and policy makers to make more informed decisions such as the provision of transportation for Head Start children.

The provision of nutritious meals was also a defining feature of Head Start programs in Ottawa. As reiterated by the founders and current directors of the program, efforts were made to ensure that each child had at least a third of their daily nutritional requirement. While the Day Nurseries Act, following the recommendations of the Canada Food Guide considered it necessary to provide all children with healthy age appropriate meals, meeting that requirement was more difficult for families living below the Low Income Cut Off (LICO). Unfortunately, some parents may not be aware of what constituted a balanced diet. For this reason, meal plans and schedules were routinely sent home to the parents of Head Start. A recent study (2012) from the University of Alberta has reaffirmed the fact that children from poorer families often have unhealthy eating patterns. Of 1800 parents surveyed in the Edmonton area, it was determined that $54.5 \%$ of all children drank at least one soda per week compared to $\mathbf{4 0 . 8} \%$ of those from 
higher socio-economic backgrounds (Nauert, 2012). Children from low-income families drank more sugary juices and sodas, and less water and milk. The results of this research were described as alarming (Nauert, 2012). For the most part parents from low-income backgrounds were unable to afford healthier but more costly alternatives such as fresh fruits, and vegetables. A recent study however suggests that it is not the cost of healthy food that's the problem but rather a perception that healthier is more expensive and the preparation time involved in preparing healthier foods. Parents from low income families are occupied with other responsibilities, are not privy to hired help in the home and resort to quick and fast ways of providing meals to their children. Those pre-packaged meals are not only more expensive but are less nutritious. This pointed to a broader structural problem when families of low income cannot afford healthy foods for their children and have to resort to cheaper versions or junk foods. The increasing numbers of children and families presenting themselves to local food banks in Canadian cities further substantiates the need for more comprehensive social services targeting the poor. The Hunger Count Report of 2011 included the finding that in Ontario, there was an increase of $25.7 \%$ of families using the food bank between 2008 and 2011. This report was a snapshot taken of the entire month of March 2011 in food banks across Canada. Of the 851,014 people who visited a food bank that month, $38 \%$ were children and youth under 18 years (Ottawa Food Bank, 2011).

The directors and founders believed that the nutritious meals they provided were of prime importance. However, my experience as a Head Start 
teacher suggests otherwise. I observed that the cold snacks provided were not seen by the children as inviting as the hot meals served in the adjacent (nonHead Start) full day program. It is understandable that children who are in nursery school all day, should be served hot meals and children who are in nursery school for $2 \frac{1}{2}$ hours, be served a light snack. However, balance becomes different when one takes into consideration the many risk factors presented in children of Head Start nursery schools. As pointed out through this research, the children using Head Start are highly vulnerable and from impoverished backgrounds. In my opinion greater efforts needs to be directed at improving the qualities of their meals regardless of how long children spent at the programs. It is true that children can get up to two-thirds of their daily nutritional requirements from a cold snack of toast, cheese slices, fruit, and a cup of milk, why not aim at providing a wholesome and appetizing hot alternative that might be their only hot meal of the day. Meals like rice, baked chicken and steamed vegetables, are typical for children in the regular nursery school program of the YMCA-YWCA. This shortcoming was mentioned during the interview with Yach and Monahan who pointed out that the exposure to positive experiences and valuable resources like nutritious meals were limited in the half-day programs. Recognising this, OCHAP members continue to advocate for the expansion of Head Start nursery Schools into more full-day programs.

Directors aimed to ensure that at least one third of a child's daily requirement was provided through the school meals. Both the founders and current directors of Head Start programs recognized that children who are not well fed are 
often anxious, unable to function, and moody. They recognized these behaviours as signs of malnourishment. Analysis of the mesosphere, Bronfenbrenner (1995) explains how the interactions between different spheres impact on individual children. For example, the inability of parents to provide adequately for their children can be recognized as rooted in a broken social security structure that failed to support impoverished families. The vulnerability of the parents in turn trickled down to the children, who as a result of poor diet and nutrition are often unable to concentrate and learn from their school experiences. Head Start has sought to alleviate the effects of these social fractures by serving nutritious meals, but also by sending meal plans home to parents. I was also concerned with the low levels of parental involvement in the hands on preparation and serving of meals. This was a missed opportunity for parents to learn vital nutritional skills. Nutrition and the value of nutritious meals should be taught to all children in nursery school but it becomes more vital to make nutritious foods available when children are malnourished. Head Start was ideally positioned to fill in those gaps where structures failed to meet the needs of families in the area of diet. Head Start was, therefore, more than just a nursery school as it functioned as a critical social support service (although with more funding it could have been doing a better job).

The third component of Head Start in Ottawa was the provision of language and behaviour management programs. Children who are not speaking at the same level as their counterparts often experience reduced self confidence and self-esteem, and may consequently be even less inclined to talk. Such "silencing" is detrimental to their emotional and psychological development (Beck, 
1999). The directors of the programs believed that correcting language in the early years and introducing children to enriching vocabulary would facilitate more efficient learning in later years. Advocates of the empowerment approach discuss the significance of intervening with the intention of generating change across a life span. Targeting language and speech in children of the Head Start program was a strategic way of making changes that could potentially have a positive influence into adulthood. The latest update from the program as revealed during the focus group suggested that OCHAP had recently secured significant funding for Head Start language program. While directors were excited about the new funds, they required the assurance that a consistent source of funding for these interventions was never made available to them. As a result the constant need to advocate for basic necessities made this component continuously vulnerable.

In the almost fifty years of its existence the objectives of Head Start have changed many times. One can guess that the modifications are designed to meet the demands of existing funders, and to attract new funders. Despite changing objectives, the fundamentals and core mission has remained the same, as indicated by founders, the minute reviews and focus group discussion the issues affecting parents and children involved with the program have remained constant.

\section{Staffing and Resources}

Integral to Head Start were the people working 'on the floor', that is directly with the children, in the day to day operations, as well as specialized staff such as the speech pathologist, and the social workers who brought their exper- 
tise to Head Start. The findings from the focus group and minutes/document review highlighted a constant struggle to secure adequate staffing ratios and qualified staff.

The discussions in the focus group about the demographics of teachers of Head Start were illuminating. Although the discussions about the users of Head Start touched on issues of their gender, race and class, when it came to discussions addressing the demographic of teachers was limited to gender. Focus group discussions reaffirmed that the roles of caregiving and child rearing most often rest on women in both the private and public spheres. However, the focus group participants were either uncomfortable about or unaware of the mismatch between the racial origins of the users and teachers/directors of Head Start. Of the seven directors in attendance only one appeared to be 'non-white', and yet a picture used on the front page of the OCHAP website, a group of eight children is shown, with only one appearing to be from a white background. Boykin and Allen (2004) spoke of the values of psychological integrity. They argued that the experiences of children in school should be coherent with their lived experiences. In Head Start programs, children typically bring differing habits, values, and beliefs from those of the 'main stream'. Their unique differences need to be nurtured. Hence the teachings of the classroom would be most beneficial if aligned with cultural teachings and beliefs in the home. To best foster congruence between the realities and learning of children, it would be beneficial to recruit and to hire teachers from diverse racial and cultural backgrounds and also to promote educational experiences that are pertinent to the realities of children. This also 
speaks to the earlier argument that a feminist approach alone is insufficient to meeting the childcare needs in impoverished communities. The website of the American Head Start Bloomberg Family Center ${ }^{11}$, currently reports one third of the teachers of Head Start were initial users of the service. Other kinds of programs within Ottawa support this movement, including the Language Instructions for Newcomers to Canada (LINC) which offers childcare programs for the child and English classes for parents. The parents however move on to their program when a connection has been made between staff member and the child. This helps foster relations between the parents, the children and the staff members.

The fact that each of the seven directors in the focus group had worked with Head Start for up to twenty-five years and a minimum of twelve years ${ }^{12}$ was indicative of individuals who were dedicated to Head Start and enjoyed what they did. They spoke about their work with passion and had a genuine interest in the wellbeing of children. Even amidst constant funding instability they have continued to be supportive of the Head Start program. This stands in striking contrast to the high turnover rate for teachers in the Head Start program, my own experience and the difficulties encountered by directors in recruiting new teachers. This suggests that the needs of teachers were not being met. For one thing their salaries were not consistent with the work that they were expected to do with high needs, vulnerable children. I earned $\$ 14$ an hour as a head Start supply teacher

The Bloomberg Family Centre is one of the many Head Start programs in the United States. It is located in Manhattan, New York. 
in 2003. Unfortunately, the history of Head Start is marred by the fact that many teachers found themselves moving in search of more lucrative jobs that are less demanding and offer more opportunity for advancement. Weissbourd (1996) wrote that it is government's responsibility to ensure that those working with disadvantaged families are rewarded appropriately for their work. This is particularly true for children who have especially high need for routine and continuity of care. Provincial and municipal governments tended to shun their responsibilities through an over-reliance on volunteerism and charitable offerings while the federal governments resorted to methods of devolution, where responsibilities were handed down to the provincial and municipal governments. This is evident in the operation of Head Start in Ottawa as it has never been able to attain federal support. This may help explain why the growth of Head Start has remained stagnant.

Staffing at Head Start, like many other components of the program has suffered from a lack of predictable financial support. Although, teachers are positioned optimally to connect with both the child and family, teachers were not adequately supported in this venture. Burnout was also inevitable given the unmanageable teacher to child ratio, inconsistent language and behavioural support and inadequate salaries. This results in the resignation of staff from the program, which in turn ultimately negatively affects the children. 


\section{The Roots of Head Start Ottawa}

While the exact dates in which some the Head Start centers in Ottawa were established remains unclear, it is clear that they all emerged from similar identification of need. This was the recognition in the community by individuals or groups, that children and parents from impoverished families needed support, and who then mobilized to establish Head Start programs. Most of the Head Start programs were an expression of a grassroots movement.

The beginnings of Head Start were reflective of the empowerment approach. Members of the community were able to identify a need, recognize and tap into resources and set the program in motion. Blenkiron was able to share her expertise as a public health nurse with members of the community to build a grassroots project. Based on her description of the early years of the Pinecrest Queensway Head Start she clearly enjoyed working in the community and was well regarded and trusted. Algonquin College provided training for staff, which contributed to the credibility for the program. In sum, influential and knowledgeable individuals supported and helped maintain a grassroots social welfare program. However, by their nature these kinds of program lack the ability to generate their own funding and must ultimately look to outsiders and government for support.

While some Head Start nursery schools were being formed and funded in response to clear social needs in the community, other centres had unique stories. The Heatherington location, for example, was built on a "workfare" model. 
Under a Canada Works grant, parents in this centre were provided childcare in exchange for their attendance at a skills program. Today this Head Start program has moved away from this philosophy to one where eligible parents are not obliged to be seeking or in full time work. However, the complexity of the application process and other strict eligibility requirements continue to make it difficult to attain a subsidized spot in Head Start programs in Ottawa. The process of applying for Head Start space and subsidies is highly bureaucratic, intimidating, and disrespectful and violates parents' privacy and likely dissuades many parents from applying. From a pragmatic perspective this approach may be strategic as it reduces the size of the applicant pool. Even so there are not enough Head Start spaces to meet the increasing need. Ottawa has grown in population and continues to absorb a large number of recent immigrants which means that social safety networks need to be in place to best support the populations in need.

A third model was the "charity" model exemplified by the Queensway Preschool which was established in 1969. This centre emerged from a needs assessment survey done by the Parkdale United Church. This center has continued to be housed and supported by the church. Although it is now fully subsidized by the local municipal government this does not mean that the program is free of financial woes. In fact when faced with possible closure, they were rescued through an amalgamation with the nearby Nanny Goat Hill program.

Downsizing and amalgamations of social welfare programs are characteristics of free market economies in which necessary social services are funded and treated as residual and marginalized. Such approaches reinforce the vulner- 
abilities of marginalized groups. The delivery of social welfare type programs within the community too often becomes the responsibility of charitable groups within the community. It was largely through their continued efforts and advocacy that these programs were initiated and kept going. Although the work and efforts of the community are necessary throughout the process, the support of policy makers is integral at every step of the way. To work most effectively, there needs to be a balance between the involvement of the community and policy makers in the provision of services. Incidentally, the Head Start programs which were attached to the health centre for example Annavale and Pinecrest Queensway or managed directly by the city have been better able to withstand financial stressors. They have been able to benefit from the resources of these agencies.

To summarize, the formation of independent Head Start in Ottawa in the late 1960's stemmed from a combination of needs in the community, the will of the community, and American influences which generated support from the municipal government. The growth of Head Start in the Ottawa region has, however been, stagnant unlike the country-wide growth in the United States. This may be explained by the fact that support for the Head Start program in Ottawa, did not garner more than municipal government. While the program has not experienced significant growth in terms of the number of centres, it has remained constant through the years. The location of the Head Start program in the more politically charged capital city of Ottawa has likely contributed to its forty-six year survival. Despite the fact that some centres have closed down the endurance of the program as a whole is commendable. 
Bridging the Gap: Getting Parents More Involved

A major concern that emerged from this research was the problem of how to get parents more involved in the program. This fundamental theme will be discussed in three segments. Firstly, I will discuss the extent to which parents were involved. Second, the case for greater parental involvement will be presented. Finally, some strategies which could be used to get parents more engaged in the Ottawa Head Start Nursery School program will be highlighted.

How involved are Parents?

In the formative years of Head Start in Ottawa there was greater parental involvement than is the case today. The directors expressed discontent with the current parental participation, and pointed out that the connection between teachers and parents also seemed strained. The directors also observed that some teachers spoke of families with disregard or demonstrated limited understanding of the challenges faced by families living in poverty. Generally, even the directors did not seem to understand why parents chose to not get involved in issues related to their children.

It was likely that sociocultural factors played a role in this. Monahan pointed out that there was an influx of Somali immigrants into Ottawa in the 1980s. Many settled in the Heron Gate community, and this is in fact why she established a Head Start centre in that neighbourhood. 
Moy (2001), who studied the demographics of Head Start users during the 1990 s, reported that $50 \%$ were from non-white backgrounds. The fact that a vast majority of the teachers were White indicates that there is a miss-match between the Head Start program staff and the community they served. The question arises as to whether this mismatch works to alienate families and to discourage their involvement in the program. A third factor is the increasing workload of Head Start teachers overtime. They have little time or energy to bond with families. The high teacher to child ratio (eight children to 1 teacher) in Ottawa programs significantly limits the amount of time available for activities beyond the classroom.

Somewhat counter intuitively, another possible explanation for the lack of parental involvement in the program focuses on the availability of transportation to and from the centres. While transportation is an invaluable asset and component of the programs, the provision of transportation means that parents are not obliged to come to the centres for drop-off and pick-up. As well, teachers do not routinely accompany children on the buses and parents were not necessarily the ones doing the drop off. Although in one case a bus monitor also served as a floating teacher accompanied children on the buses, there still remains little opportunity for parents and teachers to meet. It would perhaps be more beneficial if the regular classroom teacher could make the trip or perhaps alternative means could be developed for them to come in contact with the parents on a more regular basis. 
While the lack of parental involvement within their Head Start programs was clearly disappointing for the directors, parental involvement or family involvement was often used synonymously with mother's involvement. As discussed previously this is the trend with childcare related discussions. Although this has historically been the case for Canadian childcare more generally the objectives of Head Start were geared towards supporting and raising families out of poverty. There was a sustained priority to nurture and expand the mother/child dyad. James 2004 supported a feminist stance in understanding how we viewed parenting as almost always mother/infant and tended to neglect or undermine a child's social relationship with other family members and friends. This is not to suggest that too much focus is being placed on the mother/child relation but to acknowledge that the caregiving role of children should be shared among parents (where there are two parents) and mothers should not feel that the wellbeing of children is entirely their responsibility.

\section{Why should parents be involved?}

The provision of Head Start nursery school was often characterized as a form of respite for the parents, where they can have some time away from caregiving roles. Although the benefits of respite were appreciated, considering the ongoing challenges of parenting, it was not the central aim of the Head Start program. The child cannot be assessed and assisted separate from their family or primary caregivers. Bronfenbrenner's ecological system theory, on which the Head Start Model was built, notes that children are affected by layers of interac- 
tion, especially the interaction with parents. Emphasis was placed on working with the parents and the child's extended family. Today, Head Start Ottawa falls short of achieving this goal as the focus remains primarily on the child, rather than the child and his/her extended social networks.

It has been repeated throughout, that one of the most important reasons for having parents actively involved with the program is that it offers an opportunity for teachers and staff to demonstrate more parenting skills. Monahan discussed how simple strategies like placing a toy a little further from an infant and encouraging them to reach for it can be very stimulating but that such techniques were not known to many of their parents. She also noted that naming objects when interacting with the child to encourage acquisition of new language may also be a new idea to some parents.

If parents are present within the classroom they can observe some of the strategies used by teachers and practice them. Directors expected that parents would learn and use them with their children out of the classroom. Another argument for parental involvement is that being present and working alongside the teachers and staff members fosters continuation of the learning process for children. For example, vocabulary learned in class can be used and supported in the home.

It has been argued that justice for the marginal members of society can only be truly realized only when they are actively involved and not merely passive recipients of aid (Coleman, 1999). As discussed in the literature review, the mis- 
sion statements of the Annavale Head Start nursery school identified that the start-up and provision Head Start programs was for the founders a matter of social justice. They believed that children of marginalized communities deserved appropriate forms of care. An anti-oppressive framework, which helps us understand the function of the Head Start program, also leads us to recognize that members of oppressed groups should not be regarded as passive and unable to contribute to the betterment of their lives (Mullaly, 2002). Turner (2011) argued that for empowerment to be truly authentic, it must be derived from the efforts of the users of programs rather than the deliverers of the programs. Empowerment thinking also suggested that empowering strategies must be applied simultaneously to be most effective. Getting parents directly and actively involved with the Head Start programs that their children were attending, would facilitate social justice for the children and families, as opposed to having the teachers, directors and policy makers make the major decisions concerning the program.

It was necessary that Head Start workers exercised sensitivity in making suggestions, providing commentary on parenting styles, particularly as the population of Head Start users was diverse. As pointed out by Monahan, if parents felt attacked, criticised and judged they would be less likely to attend the center. It was possible that parental absence accounted for the reduced awareness and sensitivity in the attitudes of teachers towards parents and their parenting skills. For the most part, the directors had been involved in childcare for a long time had developed considerable empathy for the families they worked with. They demonstrated keen awareness of the conditions of impoverished families as they spoke 
of the cycles of poverty and the many barriers oppressing these families. However some teachers and more so newer ones were less knowledgeable, less empathetic and more disconnected.

One participant spoke of teacher burnout, as one of the many challenges of working in the program. According to data gathered in the interviews, focus groups and minute reviews, most of the families served by Head Start live below the poverty line, and were multiple generations living in poverty. Immigrant families using Head Start could also be refugees suffering from severe trauma and a history of homelessness. The issues emerging from these situations are broad and complex. As explained by Monahan, parents will interact with their children in similar ways that their caregivers interacted with them. Monahan further explained that parents who did not themselves receive nurturing care and support from their caregivers are less likely to provide this to their children. Teachers within the Head Start programs had little understanding of dynamics and were poorly equipped to work more effectively with these very needy families.

\section{Getting Parents Involved}

Encouraging and fostering the involvement of parents in Ottawa's Head Start programs is a challenging task for several reasons. The dynamics in which the teachers act as parenting instructors for parents who are learners tacitly reinforces the presumption that the teacher who was modeling the appropriate parenting behaviours was a better parent than are the child's parents. An anti- 
oppressive model helps to explain why it is so important that oppressed groups not feel further oppressed by those who are in the position of the expert. Monahan argued that Head Start teachers were in an optimal position to connect with the parents because they were not part of the group of experts making judgements on their lives (for instance they were not involved in the application process). However, many other factors might work to emphasize the divide between parents and teachers. In addition to their professional role, the differences between teachers and families were great in terms class, race and cultural background, which may all contribute to the perceptions of teachers. Specialized training may be needed to sensitize these teachers to factors contributing to divisive perceptions and to help them be mindful of how their behaviours and attitudes may be further oppressive to the families they work with.

The centres reach out to families in a variety of ways influencing the response rates. Fun-filled activities like beach parties, fiestas and providing snacks proved to be effective ways of getting parents involved. My impression was that the use of phrases like "parent/ teacher meetings, discussion groups" were intimidating to parents, especially in cases where English was not the first language and where their cultures held teachers in very high esteem. The thought of having 'discussions' or being put on the spot and having to speak to the teacher may be very frightening or not the norm for some parents.

A strategy used in the Language Instructions for Newcomers to Canada program (LINC), may offer insights into alternative approaches. Monahan is now director of the LINC program. She explained the significance of fostering connec- 
tions between teachers and children before parents can move on to their program of learning English. The LINC program also strives to hire staff representing the diverse backgrounds of particular communities served by the program. Having members of marginalized groups as teachers and directors, is a necessary first step for dismantling structural barriers. By opening an organization to employing staff from diverse groups, the structures that have kept some groups in the position of 'leaders' and others in the position of 'users' is eroded. This empowers not only the individual but also members of their extended community. Monahan pointed out that parents feel safer and more comfortable when dealing with persons with whom they can identify. The Child-Parent Centre which was designed to catch the over-flow of Head Start nursery school users in the United States was also more direct in requiring that parents provide at least half a day per week to the program in order for their children to participate. Parents helped out with planned activities like reading stories to small groups, changing bulletin board notices, completing activities started by the teacher, listening to children describe their experiences and assisting with field trip co-ordination. These opportunities are not only beneficial to the children, but promote self-confidence in the parents as well (Reynolds, 2000).

\section{The role of Ottawa Carleton Head Start Association for Pre-Schools} (OCHAP)

The Ottawa Carleton Head Start Association for Preschools (OCHAP) was formed more than thirty years ago, in order to create a communal voice for the assortment of Head Start programs that existed at that time. This forum was the 
venue where different perspectives and issues were heard, and shared. It allowed for identification of common problems and for setting out strategies for their resolution. It has also helped members of the association recognize similarities in needs across different pockets of the city. There was focus on both the structural and individual issues as well as the interplay between structural and individual matters and how this contributed to the continued oppression of parents and children. This was exemplified in the case where a child was suffering from severe dental decay but the parents were unable to cover the cost of treatment. The leaders of OCHAP recognized that although the Canadian society valorizes the idea of free healthcare, dental health which is critical to overall health is excluded. Through their work they have identified ways that the short-comings of the healthcare model negatively affect impoverished families who are unable to afford dental health insurance. They observed that the child who was suffering from dental decay was unable to participate in the program and was at risk of missing out on learning opportunities. Through their efforts, routine dental checks and corrective dental work was provided for the child through the subsidized Head Start program.

Over time, commendable work by OCHAP members included the uniting with other childcare bodies to fight the 1995 proposed cuts to childcare funds by the province, which would reduce subsidized spots. Members of OCHAP were also front runners in the establishment of the Childcare Council, an organization which continued to advocate for the welfare of children in childcare centres across Ottawa. There is a strong indication that individual Head Start schools 
would have been unable to withstand those many challenges. The Head Start movement would have likely died out without the uniting forum provided by OCHAP.

\section{Funding}

An understanding of funding patterns sheds light on how well Head Start has and is performing, and whether it fulfills its goals and objectives and ultimately meets the needs of the users. The patterns of funding will be outlined and will be followed by an analysis of the effects of how funding has been distributed to Head Start.

Head Start in Ottawa has historically relied on the efforts of the community and at the theoretical and conceptual level been influenced by the American Head Start Programs and associated research. Although most Head Start programs in Ottawa managed to acquire funding over the years some did not as in the case of the Queensway Nursery which had to merge with the Nanny Goat Nursery school for sustenance. In most cases, the start-up of the program was not externally supported and emerged from the direct work and financial contributions of members of the community. Indications from both the historic and the current data, suggest that in spite of ongoing programs being fully subsidized by the municipal government, there has been continued reliance on private and charitable organizations within the community. In this way the model of Head Start in Ottawa differs dramatically from the American model. The continued reliance on charitable donations has meant that a regular and reliable source of 
funding was never guaranteed. The effect of this was illustrated in the case of Queensway Preschool. This nursery school was under the management of the Parkdale United Church, was on the brink of closure due to lack of funding. The minutes of OCHAP directors meetings also revealed that the Head Start hot meal program was under threat when the Kiwanis club could no longer support that venture. Even when money was provided by the municipal government there were a series of directives which specified the use of funds for specific services, e.g., a speech therapist, and required detailed reporting on services. Also, the per diem system used in allotting money to the individual centres, for example, stipulated that the center was only paid per child per days that each child attended school. In practice, absenteeism was unforeseeable and unexpected absences disrupt the planning and budget of the programs. Floating spaces ${ }^{13}$ also presented a similar problem for the budgetary planning of Head Start programs and affect- most the programs that were heavily dependent on subsidized funding. While floating spaces gave parents flexibility to move their funding to a center of their choice, Head Start loses the funding and may have difficulty filling the position with another subsidized child. Ensuing gaps or lag times between children may be costly to the centers as they must function on a reduced budget. The fact that parents may move at any time without advance warning further adds to the financial uncertainty of Ottawa Head Start nursery schools.

13

Floating spaces is a recently introduced system where parents who are receiving subsidized funding for childcare have the liberty of moving to a different school within the Ottawa-Carleton region and taking their subsidized spot along. 
Although, giving parents and families this freedom was conceived by the government as a means of empowerment, the idea of floating spaces was merely a band aid solution when viewed through a structural lens. The more important issue was to understand what caused these populations to be so transient. Frequent relocation in search of housing and better jobs was detrimental to the children, as it hindered the provision of continuous care. Municipal, provincial and federal governments should be working towards reducing residential moves through affordable housing, comprehensive social services, and worker protection policies (Weissbourd, 1996). There was and continues to be a lack of quality affordable housing in the city of Ottawa, where it was calculated in 2006 that $42 \%$ of renters and $15 \%$ of house owners spent $30 \%$ or more of their earnings on housing. The shortage of housing pushed the costs of shelter to prices that are in the main, not affordable for poor families (Jimeno, Chung, Bouchard, Martinovic, \& Urquhart, 2010). The floating space strategy used by the government, was based on a laissez-faire approach to housing, although it was marketed under the disguise of granting freedom to families. If anything, floating spaces compound the situation of already vulnerable families as constant movement was being encouraged.

Head Start directors are also concerned that, funding for Head Start was put into the same pot as funding for all other types of nursery schools. The directors believed that this jeopardizes the credibility of Head Start as a specialized form of childcare. In the focus group they argued that decision makers have failed to recognize Head Start as different from the regular childcare programs. 
Although Head Start may have similar underlying principles as other nursery school programs, the proportion of children and families with special needs in Head Start was much higher and the needs are more numerous and varied. Hence the programs and services offered by Head Start are different. They required staff with specialized training, and overall are more costly to operate.

To attain the full benefits of a Head Start program, it is important that the needs of families are met in a systemic way. Unfortunately my research revealed repeated instances where elements of the program were revamped at the expense of another activity. For example funding was made available for more spaces but not for additional teachers. Another instance was where provision was made for the services of a speech pathologist, however the hours provided were insufficient to meet the needs of all children in the program. In some cases the teachers or a speech consultant were expected to do the initial assessment. This offloading of responsibility onto the teachers' further compromised their already strained teaching resources. This pattern however seems to be the norm in the provision of services to marginalized communities (Jimeno, Chung, Bouchard, Martinovic, \& Urquhart, 2010). Funders were reluctant to provide adequate resources for the program to function, in ways that would meet the needs of children and their families. Government funders have justified the provision of inadequate resources by claiming, that limiting support, would in turn encourage program recipients to use their own initiative, and to seek out other services and resources to supplement inadequate support. 
The problem with a residual model of welfare is that the provision of inadequate resources does not allow people to raise themselves out of poverty. While the program may have provided speech therapy, two healthy meals per day, if children were going home to empty cupboards, rodent infested houses with no running water or electricity, then the efforts of Head Start were largely negated. The benefits of the program are lessened and lose credibility in the eyes of users because the situation at home does not change.

The lack of adequate funding for the Head Start programs has also affected the structure of the program as most programs have only been operating on a half day schedule. Yach, who participated in an interview, argued that half days were beneficial as they were able to see more children, by having morning and afternoon shifts. However, the half day did not allow enough time to expose children to an extensive range of activities and to consolidate their positive experiences. For example, two and a half hours does not allow enough time for frequent field trips. As Blenkiron noted, field trips offered invaluable and extensive learning opportunities. She argued that if field trips, and other time consuming activities were not offered to children through the Head Start program significant learning opportunities would be missed to see the larger world. Directors of the Head Start programs in Ottawa would like to see more half day programs shifted to full days. Without additional funding, the likelihood of this happening is significantly reduced.

Another point of discussion, related to funding, is the identification of a need for substantial local research. An example of the beneficial use of research 
occurred when Dr. Weikart, who was from the United States, convinced the municipal council to fund the implementation of the "High Scope Project" which was directed at children from poor families. Since the session occurred behind closed doors it was not known just how Weikart convinced the regional chair to fund the project. However, Dr. Weikart was a pioneer in the study of early childhood education and led the famous Perry Preschool projects (Weikart, Bond, \& Mc Neil, 1978). He therefore had a wealth of research to refer to. To date there were no longitudinal studies from the Ottawa Carleton Region. Throughout much of its existence there has been an over reliance on research being done in the United States. It was concerning that while the programs in both Canada and the United States emerged around the same time, several research papers have been published on Head Start in the United States, while just a few have been written on the program in Ottawa.

Head Start in Ottawa and Head Start in the United States differs greatly in terms of size and governmental support. The difference in strategies used in attaining resources is particularly revealing and may reflect cultural difference between the two countries. In the American centers there is considerable openness about the circumstances of individual families using Head Start. Pictures of the children and their stories are used extensively on their websites. The success stories of current and former users of Head Start are also shared on the site. In contrast, the directors of Ottawa advocate caution and sensitivity around how they portray the families of Head Start. They strongly believed that their strength as a program lies in their ability to provide welfare services discretely. Consider- 
ing the stigma attached to living in poverty, the use of subsidized daycare may represent a source of embarrassment and shame to impoverished families. There was a desire to protect children and their families from stigma. On the other hand, there may be value in bringing awareness of their realities to the rest of the population. Part of destigmatizing poverty may require breaking down the walls of secrecy that separate the rest of society from those living in the most dismal circumstances. Anti-oppressive thinkers within the of social work field are mindful of how a lack of awareness of gaps in social class can reinforce oppressive behaviours. Those who are at the helm of society are typically the ones who make decisions about funding. They do not walk a day in the lives of the suffering families. Likewise, the structural approach is also useful as it stipulates that the structures of society control and dictate the lives of those in the lower and 'inferior' groups of society. In the case of Head Start for example, three groups make most operational decisions: directors, executive directors for centres that are attached to community centres and municipal policy makers. Further, parents were not actively involved on the Head Start Board of Directors. The fact that users do not have a voice in the operations of Head Start programs in Ottawa is a serious issue that needs to be addressed in order to build their future success.

Due to the gaps between oppressive structures and the users of Head Start, it has become necessary to convince the policy makers of the worth of the program. In a technologically and scientifically driven nation this requires the use of qualitative and quantitative data. Most important is the need for evidence of long-term impacts. In the absence of data, it might be helpful if families were 
given the opportunity to go public with their stories. This might facilitate fundraising, but also serve as an important educational tool which can draw the public's attention to problem's within their community.

The constant struggle for funding may be attached to the reduced values attached to the role of women as primary caregivers (Wood, 1993). The provision of childcare both in the household and the nursery school setting have traditionally been led by women. As argued by Waring (1988), matters concerning the wellbeing of women, children and those living in societal margins are often not considered relevant by the decision makers of society who are most often male, white, and from middle to upper class backgrounds.

My analysis has revealed a lack of consistent, reliable funding for Head Start Programs. That unfortunately mirrors the state of most social welfare programs in Ontario. The efforts of the founders and both past and present (through OCCHAP) have been heroic. These community leaders highlight the importance of community integration and safeguarded a program they believe in. While their attempts at raising children and their families out of poverty can be applauded, we cannot truly appreciate and understand the impacts of Ottawa's diverse Head Start programs without an investment in longitudinal research. Current strengths of these programs include the provision of transportation and language programs. However, there is room for improvement in the areas of parental involvement, teacher to child ratio and the provision of nutritious meals. 


\section{Research Limitations}

This research benefited greatly from the use of the ethnographic approach which allowed me to aggregate my findings across multiple methods. A major limitation however was the absence of children's voices and their parents. What I heard or learned of the children's experiences was filtered through the ideals and beliefs of the directors of Head Start and of largely American resources. James (2004) forewarned that, too often are the voices of children taken as synonymous with those of caretakers or in the case of this thesis, childcare providers. The addition of home observations and an opportunity to get the children's perspectives would add greatly to our understanding of the effects of the Ottawa Head Start programs. Similarly, interviews with parents/ legal guardians would add greatly to our understanding of the lack of parental involvement. Suggestions for future research therefore include the following recommendations:

(i) Research where the progression on children in Head Start is monitored, where their personal accounts of their Head Start experience is heard and understood.

(ii) As indicated and supported throughout this research the involvement of parents, though a critical component in the development of their children, is lacking. It is not clear why such is the case hence studies directed at giving light to the perspective of parents and generating strategies aimed at improving parental involvement are necessary. 
(iii) After almost 50 years in operation it is imperative to understand the long term effects of the Head Start program in Ottawa. To make truly valuable arguments for the continued support and funding of Head Start, policy makers need to be convinced that today's investments in Head Start bring exponential returns to the users, their families and the community as a whole. 


\section{Conclusion}

The roots of Head Start in Ottawa

The concept of Head Start emerged directly from President Lyndon Johnson's 'war on poverty', and was shortly after inception in the United States, was transplanted and took root in the city of Ottawa. The program has been developed and sustained through the dedication of individuals and organizations in the Ottawa area. When founding members of Ottawa were consulted, they asserted that Head Start in Ottawa was established following the recognition of local needs. The founders were adamant that the idea for the programs was not merely a replication of Head Start in the United States but a response to the lack of quality childcare, increasing poverty, and low income housing in their communities. As other institutions such as Algonquin College and government officials got more involved, the name Head Start was gradually accepted and used in funding application. Regardless of the origins of the program the problems that it sought to address continues to be pervasive in the Ottawa community today. This has resulted in increasing and not decreasing need for programs of this nature.

Pulling the Defining Pieces Together 
Head Start program in Ottawa, and the United States share important features. They represent a specialized form of nursery schools where stakeholders recognised that some families were in need of additional support beyond childcare, such as basic care, nurturing, nutritious meals, parenting, and accessibility to the centres. Beyond the specifics of childcare the Head Start model employs a holistic approach in the provision of care. This approach works better in theory than in practice as the program struggled to match up with its ideals. My findings suggested that the lack of adequate and consistent funding was largely responsible for programs not reaching their stated objectives.

My research revealed several differences between the Head Start program and other nursery schools in Ottawa. Some of these included the provision of transportation for the children to and from the program, strong emphasis on language programs in a remedial and preventative capacity, and the deliberate effort to provide at least two nutritious foods that meets at least one third of a child's daily requirements.

\section{Head Start's place in the current childcare system}

As long as there continues to be widening gaps between rich and poor in Ottawa communities, there will be a need for programs like Head Start (Jimeno, Chung, Bouchard, Martinovic, \& Urquhart, 2012). Without programs that provide for sensitivity and awareness of the issues of poverty among children, those who lived in marginalized communities are likely to continue to fall between the cracks of society. Head Start represents an attempt to break the cycle of impoverish- 
ment. Imagine for a moment, the two year old who has had a piece of toast for breakfast, was wearing the same clothes as she wore yesterday, only knows three words, and remains quiet for most of the day in a regular daycare, while her classmates have had balanced meals at home, speak in full sentences, and have parents with cars and stable jobs. Such a child will feel isolated and left behind, may be teased, and is likely to fall behind academically and socially. This child may learn at a much slower rate than other children. These effects of poverty are well documented in the literature review. A child growing up in poverty can be expected to develop at a much slower rate than a child from a middle class family (Weissbourd, The Vulnerable Child, 1996). Head Start proponents believed it necessary to build and sustain specialized childcare settings where staff members fully understand the oppressive impacts of poverty on children, and well equipped with the knowledge, sensitivity, and passion to not only assist the individual child, but also their families. As one author expressed this concern, "the quality of childcare will determine whether the children reap the benefits of their early childhood experience or suffer the ill-effects of inadequate care" (Ryerse, 1990).

There was also the corresponding need to ensure that there were opportunities for this sector to influence change at the policy level at both municipal, provincial levels and federal levels. The founders of Head Start in Ottawa were cognisant of this fact and created the first Head Start programs in response to the real and pressing needs of the community. They must be commended for laying the ground work for a program that has endured through several decades. 
I was surprised that as the income gap continues to widen, Head Start programs have shut down (the YMCA-YWCA Head Start and West End Head Starts) or have had their services cut and limited rather than growing to meet the demand. In the most recent report from Campaign 2000, it is argued that today child poverty in Canada is worse than it was during the launch of the campaign in 1989. The report also recommended that a federal action plan was needed in the eradication of child and family poverty (Campaign-2000, 2012). The worsening of child poverty rates was evident in the increasing waitlist for Head Start spaces. In one case spaces were lost to ordinary childcare spaces, thereby creating a dysfunctional competition between Head Start and the other less specialized nursery school programs. Spaces that were formerly Head Start spaces were being lost to those who can afford to pay the market price for childcare. This is both discouraging and tragic, as not only will some families be unable to afford the service, but the specialized programming will stop at the centers as well. Head Start, derivatives of Head Start like the LINC, and other programs like Head Start such as Better Beginnings have a place within the childcare system, and that role is to meet the needs of marginalized children and improve their chances of success later on in life.

Fifty years of Service

The longevity of Head Start in Ottawa in surprising and admirable as it has not expanded to other parts of Canada except in the form of the Aboriginal Head Start programs in Edmonton and Ottawa. In addition the program was relatively 
small (ten centers) and yet was able to make a difference in the lives of poor children and their families, and has as a consequence, been able to continue to justify its existence. The persistent advocacy work of OCHAP, the noble objectives of the program's origins, and the closeness to the U.S., especially through access to research and influential American experts, like David Weikart, have all played a part in sustaining the program in Ottawa.

OCHAP has been instrumental in advocating for the needs of the program and its users since its inauguration in the 1980s. Although OCHAP has not been able to raise sufficient funds for optimal programming, the organization has likely contributed to the continued existence and ongoing viability of Head Start programs in Ottawa. The work achieved through OCHAP reflects the effectiveness of communal over individual efforts, particularly when organizing on behalf of marginalized people. As the demand for childcare exceeds the available spaces, it tends to be very costly (due to supply and demand), and as a consequence is generally affordable only for middle to upper-class families. For Head Start programs to survive requires subsidies and funding from sources other than parents.

The thesis needs to end by acknowledging the dedication, sacrifice and principles of the founders, directors and Head Start workers. In addition, over the years, the directors in OCHAP have worked tirelessly to secure funding for speech therapy, family life educators, transportation, the hot meals program, organizing conferences, and professional development. OCHAP has also served as a support network for Head Start directors, as it provided a venue to share and explore ideas, and for generating action plans and decision making to the 
benefit of all Head Start programs. The directors have been at the forefront in protesting cuts to childcare and raising awareness on the impact of poverty on children. Through their efforts they have worked to maintain a public profile for child care in Ottawa, which benefits not only the Head Start programs, but child care generally.

The historical roots of Head Start have seemed to play a role in the longevity of the program. The social problems which resulted in the initial establishment of Head Start have persisted. Poverty continues to be pervasive, just as the fight against poverty is an ongoing battle. The most recent statistics on child poverty in Ottawa indicate that $31 \%$ of the people living in poverty in Ottawa in 2005 were children (Jimeno, Chung, Bouchard, Martinovic, \& Urquhart, 2010). In the face of this reality Head Start reminds us that despite a political turn to the right, some members of the community remain committed to fighting to alleviate poverty. Head Start programs remind us that there could be a responsive and competent social welfare system supporting people living in poverty. The rate of poverty in children between 2000 and 2005 in Ottawa has been virtually unchanged despite the claims that governments were being proactive. Having explored the implications of governmental residual funding strategies, it was apparent that the efforts directed at Head Start have been, and continue to be too limited to make a great impact. There continues to be pressing needs for greater funding not just in terms of subsidized spaces but for hiring more staff. A lower ratio of teacherto-children in the classroom is badly needed but this has never been supported by funding, and the effects of this chronic underfunding have been felt throughout 
the system in the form of teacher burnout and consequently high turnover rates. The latter has been particularly troubling as this high turnover of Head Start teachers was inconsistent with the continuity necessary for a child's development (Weissbourd, 1996).

Another contributing factor to the longevity of program has been the proximity of the City of Ottawa to the United States, where Head Start programs began. Although the programs were too different in terms of size and funding to be compared easily and despite the protest of the founding directors, there was a sense that the Ottawa Head Start program has been piggybacking on the American Head Start program, particularly in the reliance on American research. In my own research, I had to rely on American literature (see literature review) to support and clarify certain points. The fact that Head Start Ottawa has not been provided with sufficient resources to allow for the production of a single longitudinal study, and little in terms of short-term research on the impact of Head Start suggests that they have had to look for data elsewhere to authenticate the effectiveness of the program, i.e., United States. It was unusual that the municipal funding has continued without relevant data on the benefits of the program.

The research clearly indicates that living in poverty has continued effects on child development (Jimeno, Chung, Bouchard, Martinovic, \& Urquhart, 2010). Yet child poverty persists. In the face of child poverty, it becomes critically important that programs such as Head Start be fostered, and expanded. What is needed is a clearer understanding of the impact of Head Start in Ottawa in terms of child and family outcomes and how the program may be best modified to serve 
the needs of its current users. Head Start continues to be funded based on its ability to redefine itself to suit funding models (rather than vice versa). What is needed is an investment in more concrete and thorough research on the impact of Head Start (both long and short-term). This would require the identification and provision of research funds, the collection of family and teacher feedback, acting on suggestions from the families, and creating a foundation of guaranteed funding to provide continuity, stability and financial security for the program.

\section{Effects of Head Start}

Based on my findings and the research of others, the teachers and directors of programs have been able to identify and see first-hand some of the more immediate impacts of the program on its users. There was consensus among the members of the focus group that the short-term benefits for children involved in the program were obvious. There was however, some uncertainly about the length of time that a child would need to be enrolled in the program to determine if these benefits were permanent. In a working paper, which is currently being written, by members of OCHAP, there is a shift towards using the qualitative experiences of the user at Head Start to raise awareness on the issues and the impacts of Head Start. One of the highlighted cases in this paper was a child whose speech was greatly impaired due to severe tooth decay. The child was treated at CHEO upon examination by a visiting dental hygienist. Thereafter, the child's interest in talking increased and she worked with the speech pathologist at Head Start on catching up for the time lost. This case highlighted the need to address 
all presenting concerns of the child to fully maximize the benefits of their experiences at the Head Start program.

The directors had mixed reactions regarding the impact of Head Start on parents. In the earlier years of Head Start, there was a closer connection between the parents and the program. Although Moy's 2001 survey concluded that parents were generally happy with the services of the program, there was a clear communication gap between the families currently enrolled in the program and the teachers. It is critically important that Head Start programs actively involve the parents in the programs, so that they are both aware of their child's development and actively involved in those activities that will best foster that development. The development of the child is dependent on healthy interactions between the teachers of Head Start and the family as a whole. Programs that employ a child-focused approach in combination with parental support produced the most successful outcomes in terms of child development and academic success (Mc Auley, Pecora, \& Rose, 2006). By attending to the needs of the parents and other significant members of the family, the staff of the Head Start programs can help the families to provide for a more supportive home environment to children and to ensure more continuity of structure between home and care settings (Mc Auley, Pecora, \& Rose, 2006). It is critically important that this component be targeted to ensure greater efforts are directed at strengthening the bond between the program and the parents.

My research suggested that this weakened connection stemmed from limited cultural knowledge about the communities served. When we live and work in 
a community as diverse as Ottawa it is necessary to attain cultural competence and to establish dialogue with those we work with where questions were discussed and community was built. The 2006 census data indicated that the Ottawa-Gatineau area welcomed the fifth largest immigrant populations in 2006. Just over 200000 people settled in this region from various parts of the world including Asia, Africa, the Middle East, the Caribbean and South America. (Statistics-Canada, 2007).

Overall Conclusion

The Head Start programs studied in this research were established in Ottawa in the late 1960 s based on the needs of the community. The program then gained momentum as the Perry Preschool projects and Head Start in the US were gaining wider acceptance. In the earlier years of Head Start (late 1960's and early 1970 s) various pockets across the Ottawa-Carleton Region were pooling resources into a childcare system to meet the needs of families who were unable to afford childcare, but who were in need of support in raising their children. The people involved in grassroots community efforts were the front-runners in moulding the program, but they needed to rely on the funds of the municipal government and private sponsorship as costs and the demand increased to keep the program running. Credit must be given to the ongoing advocacy efforts conducted by OCHAP in championing the cause of families and children who continue to live in poverty. 
While the workers at Head Start programs in Ottawa were doing their best with what they have, I believe that parental involvement should be strengthened as a central focus for future program development. A suggested way would be by placing greater emphasis on recruiting parents as teachers within the centers. Although Head Start may be regarded as providing a respite from childcare for parents living in poverty with few social supports, respite is a small part of Head Start's purpose. More importantly, the program should encourage the presence and attendance of the parents in the childcare provided. When the parents are present the emphasis should not be entirely on teaching them how to be parents and how to manage the poor behaviour of their children. Rather, Head Start program staff need to reach out with a sense of solidarity and respect to recognize the strengths, abilities, and resilience of these parents and their children. Only by building on these strengths can parents be helped to better their living standards and that of their families and ultimately the community. 


\section{References}

Alkens, N., Hulsey, L. K., Molduddin, E., Kopack, A., Takyl-Laryea, A., \& West, J. (2011). Data Tables for Faces 2009 Head Start Children. Families, and Programs: Present and Past Data from Faces Report. Washington: US Department of Health and Human Services.

Ames, L. J., \& Ellsworth , J. (1997). Women Reformed, Women Empowered; Poor mothers and the endangered promise of Head Start. Philadelphia: Temple University Press.

Annavale Nursery School. (2010). Retrieved January 10, 2012, from Ottawa Carleton Head Start Association for Preschools: http://www.ochap.ca/web/annavale.html

Bloomingdale Family Program. (2012). How to Apply. Retrieved May 11, 2012, from The Bloomingdale Family Program: http://uww.bloomingdalefamilyprogram.org/apply.html

Bloomingdale Family Program. (2012). Retrieved March 16, 2012, from http://www.bloomingdalefamilyprogram.org/staff.html

Baines, C. T., Evans, M. P., \& Neysmith, S. M. (1998). Women Caring. Toronto: Oxford University Press.

Beck, J. (1999). How to raise a brighter Child. New York: Pocket Books .

Berenbeim, R. E. (1992). Corporate programs for early education improvement. New York: The Conference Board Inc.

Boykin, W., \& Allen, B. A. (2004). Cultural Integrity and Schooling outcomes of African American Children from Low-Income Backgrounds. In P. B. Pufall, \& R. P. Unsworth, Rethinking Childhood (pp. 104-120). New Jersey: Rutgers University Press.

Brauer, C. M. (1982, Jun). Kennedy, Johnson, and the war on poverty. The Joumal of American History, 69(1), 98-119.

Caputo, R. (2003). Head Start, Other Preschool Programs, Life and success in a youth Cohort. Joumal of Sociology and Social Welfare, 105-121. 
Campaign-2000. (2012, November 21). Govemment of Canada MIA on child . Retrieved February 18, 2013, from Campaign 2000, End Child and Family Poverty in Canada:

http://uww.campaign2000.ca/whatsnew/2012ReportCardPressRelease.pdf

Carniol, B. (2005). Case Critical; Social Services and Social Justice in Canada 5th Edition. Toronto: Between the Lines.

City of Ottawa. (2001-2012). Day Care fee Assistant Program. Retrieved March 08, 2012, from http://unw.ottawa.ca/social_com/daycare/subsidy/index_en.html.

Cohen, A. J. (1996). A brief History of federal financing for child care in the United States. The future of children financing child care, 6(2), 31.

Coleman, J. (1999). Compassion, Solidarity and Empowerment: The ethical contribution of religion in society. In J. J. Stretch, M. Bartlett, W. J. Hutchinson, S. A. Taylor, \& J. Wilson, Raising Our Children out of Poverty (pp. 7-20). New York: The Haworth Pastoral Press.

Connolly, M., \& McKenzie, M. (1999). Effective Participatory Practice. New York: Aldine de Gruyter, Inc.

Cool, J. (2009, February 5th). Child poverty in Canada. Ottawa, Ontario, Canada.

Dobson, S. K., Mackessa, H., Gayle, H., \& Moore, S. (2007). Exploring the impact of Head Start on parents: A pilot Study. Progress in community health partnerships: Research, Education and Action, 133-141.

Dominelli, L., \& McLeod, E. (1989). Feminist Social Work. London: Macmillan Educational Limited.

Gilbert, N. (2008). A mother's Work, how Feminism, the market, and policy shape family Life. Dexter, Michigan: Yale University Press.

Glover, G., Hammel, S., Knapp, J., Jackson-Brown, M., \& Burley, G. (2012). Workers' realities and access to childcare. Ottawa.

Haddow, R. S. (1993). Poverty Reform in Canada 1958-1978. Quebec City: McGill-Queens University Press.

Harden, B. J., Denmark, N., \& Saul, D. (2010). Understanding the needs of staff in Head Start programs: The characteristics, perceptions and experiences of Home visitors. Children and Youth Services Review, 32, 371-379.

Harris Rome, S., \& Slaght, E. F. (1999). Welfare reform and the future of foster children. in J. J. Stretch, M. Bartlett, W. J. Hutchinson, S. A. Talyor, \& J. Wilson, Raising our children out of poverty (pp. 21-36). New York: The Haworth Pastoral Press.

Hick, S. (2006). Social Work in Canada. Toronto: Thompson Educational Publishing Inc.

Hick, S. F., Peters, H. I., Comer, T., \& London, T. (2010). Structural Social Work in action. Toronto: Canadian Scholar Inc.

Hooks, B. (2000). Feminism is for Everybody. Cambridge: South End Press. 
James, A. (2004). An interdisciplinary perspective. In B. P. Pufall, \& P. R. Ainsworth, Rethinking Childhood (pp. 25-37). New Jersey: Rutgers University Press.

Jimeno, C., Chung, P., Bouchard, H., Martinovic, J., \& Urquhart, D. (2010). Poverty Profile of the City of Ottawa based on 2006 Census. Ottawa: The Social Planning Council of Ottawa.

Kail, R., \& Barnfield, A. (2009). Children and their Development. 2007: Pearson Canada Inc.

Kitchen, B., Mitchell, A., Clutterback, P., \& Novick, M. (1991). Unequal futures the legacy of Child Poverty in Canada. Toronto: The Social Planning Council of Metropolitan Toronto.

Klein, B., \& Wekerie, C. (2011). The Value of early childhood education for toddlers and preschoolers: A Neurodevelpomental Approach. Ontario Association of Children's Aid Societies, 2-7.

Knako, S. (2012, May 2). Huff Post New York. Retrieved May 25, 2012, from Bloomberg Budget Brawl:Children's advocate scramble to save New York's State of the Art After school system on the eve of Massive cuts: http://wnw.huffingtonpost.com/2012/05/02/bloombergbudget-after-school-programs-child-care_n_1472589.html

Leira, A. (1992). Welfare States and working mothers, the Scandinavian experience. New York: Cambridge University Press.

Levitt, S. D., \& Dubner, S. J. (2005). Freakonomics. New York: Harper Collins Publishers.

Marlow, C. R. (2011). Research methods for generalist social workers. Belmont, CA: Brooks/Cole Cenage Learning.

Mc Auley, C., Pecora, P. J., \& Rose, W. (2006). Enhancing the well-being of children and families through effective intervention. Philadelphia: Jessica Kinsley Publishers.

Mc Cain , M. N., \& Mustard, F. (1999). Early Years Study, Final Report. Toronto.

Moreau, M., Frosst, S., Frayne, G., Hlywa, M., Leonard, L., \& Rowell, M. (1993). Empowerment II Snapshots of the Structural Approach in action. Ottawa: National Library of Canada.

Moy, S. (2001). OCHAP: Gaps in senvices to families with young children. Ottawa.

Mullaly, B. (2002). Challenging oppression, a critical social work approach. Don Mills: Oxford University Press.

Nauert, R. (2012, 08 23). Junk Food Link to Lower Class, More Screen Time. Retrieved 0824 , 2012, from PsychCentral: http://psychcentral.com/news/2012/08/23/junk-food-linked-tolower-class-more-screen-time/43593.html

Neuman, W. L., \& Kreuger, L. W. (2003). Social Work research methods. Boston: Pearson Educational Inc.

OCHAP. (2006, May 5). OCHAP Mission and Objective. Retrieved November 21, 2011, from Ottawa Carleton Head Start Association for Pre Schools: http:/hwww.ochap.ca/web/mission.html 
OCHAP. (2010, October 4). Ottawa Carleton Headstart Association for Preschools. Retrieved October 4, 2011, from wnw.ochap.ca.

Ottawa Food Bank. (2011, November 25). Retrieved August 10, 2012, from Hunger Count 2011: http://ottawafoodbank.ca/wp-content/uploads/2011/11/HungerCount-2011.pdf.pdf

Padgett, D. K. (1998). Qualitative methods in Social Work research. Thousand Oaks, California: Sage Publication.

Quadagno, J. (1994). The Color of Welfare: how racism undermined the war on poverty. New York: Oxford university Press.

Reynolds, A. J. (2000). Success in early intervention. Lincoln: University of Nebraska Press.

Roach-Pierson, R., \& Griffin-Cohen, M. (1995). Canadian women's issues. Toronto: James Lorimer \& Company Limited Publishers.

Ryan, W. (1976). Blaming the victim. New York: Random House Inc.

Ryerse, C. (1990). Thursday's child; Child poverty in Canada. Ottawa: National Youth in Care Network.

Statistics Canada (2012, June 27). Median total income, by family type, by census metropolitan area. Retrieved February 16, 2013, from Statistics Canada:

http://www.statcan.gc.ca/tables-tableaux/sum-som/101/cst01/famil107a-eng.htm

Statistics Canada. (2007, December 12). Immigrant population by place of birth, by census metropolitan area (2006 Census). Retrieved February 17, 2013, from Statistics Canada: http://www.statcan.gc.ca/tables-tableaux/sum-som/101/cst01/demo35c-eng.htm

Sudbury, J. (1998). Other kinds of Dreams; Black women's organizations and the politics of transformation. New York: Routledge.

Sugar, M. H. (1994). When mothers work who pays? West Port: Greenwood Publishing Company.

Tumer, F. J. (2011). Social Work Treatment. New York: Oxford University Press.

Van de Sande, A., \& Schwart, K. (2011). Research for social justice. Black Point: Fernwood Publishing.

Waring, M. (1988). If Women Counted. New York: Harper Collins Publishers.

Weikart, D. P., Bond, J. T., \& Mc Neil, J. T. (1978). The Ypsilanti Perry Preschool Project: Preschool years and longitudinal results through fourth grade. Ypsilanti: Library of Congress Cataloging in Publication Data.

Weissbourd, R. (1996). The Vulnerable Child. New York: Addison-Wesles publishing Company.

Wood, J. T. (1993). Gendered Lives; communication, gender, and culture. California: Wadsworth Publishing Company. 
Zigler, E., \& Seitz, V. (1982). Head Start as a national laboratory. Annals of the American Academy of Political and Social Science, 81-90.

Zigler, E., \& Valentine, J. (1979). Project Head Start. New York: The Free Press a division of Collier Macmillan Publishers.

\section{Append. 1 -Semi-Structured Interview for Head Start Founders}

1. How long were you employed at Head Start? What jobs/roles did you have while at Head Start? How long were you the Director?

2. What were the sources of funding for your Head Start Program?

3. What were the sources of referral of clients to your agency?

4. What were the information gathering processes at intake?

5. Who made decisions about funding for an individual child?

6. What were the average costs per child per month?

7. Did your Head Start operate with a continuous intake of children, or were there beginnings and ends for programs at set dates?

8. What theories or understandings concerning child development informed and structured Head Start programs?

9. What kinds of programming does Head Start offer to the children?

10. What did a typical day look like?

11. What kinds of lunches and snacks were provided?

12. What was the ratio of children to teachers? 
13. What were the required qualifications for being a Head Start teacher?

14. How did you see the program benefiting the children and their families?

15. How was Head Start similar to and/or different from other early child care programs?

16. What were some of your concerns for the long-term viability of the program?

17. What inspired your interest in a program of this nature?

Append. 2a. -Semi-Structured Interview for Head Start Directors

1. How long have you been employed at Head Start? What jobs/roles have you had since joining Head Start? How long have you been the Director?

2. What are the sources of funding for your Head Start Program? Any fund raising?

3. What are the sources of referral for users of Head Start?

4. Who makes decisions about funding for an individual child?

5. What are the average costs per child per month?

6. Does your Head Start operate with a continuous intake of children, or are there beginnings and endings for programs at set dates?

7. What theories or understandings concerning child development inform and structure Head Start programs?

8. What kind of programming does Head Start offer to the children?

9. What does a typical day look like?

10. What kind of lunches and snacks are provided?

11. What is the ratio of children to teachers?

12. What are the required qualifications for being a Head Start teacher?

13. How do you see the program benefiting the children and their families?

14. How is Head Start similar to and/or different from other early child care programs?

15. What are some of your concerns for the long-term viability of the program?

16. What inspired your interest in a program of this nature? 
17. How is Head Start different to or related to programs like Healthy babies, Healthy Children and success by six?

18. What are the demographic of the children using Head Start?

19. What is the demographic of the teachers in the Head Start classrooms?

20. I looked over the list of requirement for the ideal Head Start Model (append. $2 \mathrm{~b}$ ). What are some of those you have the most difficulties accomplishing and why? (copies of the list will be provided)

Append.2b- The Head Start Model

\begin{tabular}{|c|c|}
\hline Staffing & $\begin{array}{l}\text { - } \text { Qualified staff } \\
\text { - } \text { ECE teachers } \\
\text { - Resource teachers } \\
\text { - Low teacher to child ratio } \\
\text { - Social Work or parent educator }\end{array}$ \\
\hline $\begin{array}{l}\text { Stimulating } \\
\text { Programs }\end{array}$ & $\begin{array}{l}\text { - } \text { Goal oriented curriculum } \\
\text { - } \quad \text { Language-centered program } \\
\text { - } \text { Gross and fine motor skills } \\
\text { - } \text { - Sulti-choice activities } \\
\text { - Outdoor and indoor activities } \\
\text { - } \text { Quiet areas, focus on self esteem } \\
\text { - Gardening area }\end{array}$ \\
\hline $\begin{array}{l}\text { Active Parental } \\
\text { involvement }\end{array}$ & $\begin{array}{l}\text { - } \text { Sitting area for parents } \\
\text { - } \text { Parenting groups } \\
\text { - } \quad \text { Newsletter } \\
\text { - Board Membership }\end{array}$ \\
\hline $\begin{array}{l}\text { Appropriate } \\
\text { Consultations }\end{array}$ & $\begin{array}{l}\text { - Home visits } \\
\text { - Individual program plans } \\
\text { - Speech and language assessments and consultancy } \\
\text { - Consultations with community agencies }\end{array}$ \\
\hline
\end{tabular}




\begin{tabular}{|l|l|}
\hline Special Services & $\begin{array}{l}\text { - Nutritious meals to provide a significant portion of re- } \\
\text { quired daily intake }\end{array}$ \\
& $\begin{array}{l}\text { - Transportation to and from school } \\
\text { - Field trips }\end{array}$ \\
\hline
\end{tabular}




\section{Appendix 3-Ethics Approval

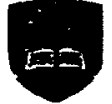 \\ Carleton \\ UNVERESTr \\ Canada's Capltal Untwerelty}

Corteten Un'veraity Resenrch Oulce Reseench Ethics boand.

$5^{\text {th Foor Tory Bulling }}$

1125 colonel By Drive

Ottrume, ON RIS SB6 Canada

Te: 613-520-2517

Fax: 613-520-2521

ethiceseredtion.ca

\section{Ethice Clearance Form}

This is to certify that the Carleton University Research Ethics Board has examined the application for ethical dearance. The REB found the research project to meet approprlate ethical standards as outlined In the Tri-Councll Pollcy Statement: Ethical Conduct for Research Involving Humans and, the Carleton University Poblicles and Procedures for the Ethical Conduct of Research.

$x$ Mew clearence

- Ranewel of original clanrance

Origlasel date of clearance:

Date of clearance

Researcher

Status

Supervisor

Funding status

Project number

Title of project
13 March 2012

Sylvette Errmenth,

M.S.W. ebudent, School of Soclal Work

Profeaser Garald de Montlgmy, School of Social Work

Admintetration

rom-funded

12-1234

An otheographle examination of Head Start Nureary School

Programe in ottama: Pact, present and future

Clearance expires: $31 \mathrm{May} 2013$

All researchere are governed by the following condltions:

Annual Statu: Reports You are required to submit an Annual Status Report to elther renew clearance or dose the file. Falure to submit the Annual Status Report will result in the Immediate suspenston of the project. Funded projects will have accounts suspended until the report is subritted and approved.

Changes to the project: Any changes to the project must be submitted to the Carleton University Research Ethics Board for approval. All changes must be approved prior to the continuance of the research.

Adverse cvents: Should any participant suffer adversely from their participation in the project you are required to report the matter to the Carieton University Research Ethics Board. You must submit a written record of the event and indicate what steps you have taken to resolve the situation.

Suspenoion or termination of clearance: Fallure to conduct the research in accordance with the principles of the Tri-Councll Poficy Statement: Ethical Conduct for Research Involving Humans and the Corteton University Policies and Procedures for the Ethical Conduct of Research may result in the suspension or termination of the research project.

Antonio R. Gualtierl, Chair

Carketon University Research Ethics Board 


\section{Carleton}

School of Social Work

1125 Colond By Drive

Ottowa, ON Canada K1S 586

Tel: (613) 520-5601

Fax: (613) $520-7496$

\section{Append. 4 -Consent Form for the Founder of Head Start}

Title of research project:

An ethnographic examination of Head Start Nursery School Programs in Ottawa: Past, present and future

Date of ethics clearance: To be determined

Ethics Clearance for the Collection of Data Expires: To be determined

I have been provided with information concerning this research project, which is being completed for a MSW thesis by Sylvette Bruneau, who is a Master of Social Work Student from Carleton University, and who is working under the supervision of a Social Work Professor Dr. Gerald de Montigny.

I understand that the research examines the origins of Head Start in the USA, and its adoption and adaptation in Canada with a specific focus on Ottawa. I understand that this interview will explore my understandings, objectives, and knowledge as a former Director of Head Start in order to develop a portrait of the initiation, development, and evolution of Head Start in Ottawa.

I understand that the risks associated with this interview are commensurate with those of any public statements I might make concerning my former work at Head Start, which if deemed inappropriate, unethical, or improper, by any party, could occasion potential loss of reputation, embarrassment and threat to program viability, which could as a result adversely affect myself, employees, or the program.

I understand that a potential benefit of this research is that it might provide an opportunity for a greater scholarly and public attention to the contributions of the Head Start program to at risk, disadvantaged and marginalized children, and their parents.

1 agree to participate in a single interview which is expected to last between forty-five minutes to an hour. The interview will take place in my home or other location convenient for me to meet. The interview will be audio recorded for the purpose of providing for accurate transcription of data.

I understand that by consenting to be interviewed that I do not have anonymity, and that given the small sample size, and the specifics of each Head Start Program, that 
even if I indicate that I wish to have my responses kept confidential that my identity might become known by others.

I understand I will not be asked to share, nor will I share any confidential, personal, or sensitive information about any employees, volunteers, children, or their families involved with Head Start past or present.

During the interview I may refuse to answer any question(s). I may indicate that I wish to have any statement I have made retracted and deleted from the record. I may request ending the interview at any time.

At my request, I will receive an electronic copy of the transcription of our interview.

I may indicate, by voice or e-mail, at any time, up to (one month before the submission of the thesis for examination) that I wish to withdraw from the project, and that the information I provided not be used.

If I am named in the thesis I will be provided with an electronic copy, or hard paper copy (the format will be at my request), of those draft pages of the thesis where $I$ am named and quoted. I can then respond by e-mail or post returning all modification or deletion of attributed materials which will then replace the draft materials.

I understand that digital audio recordings will be produced on a recorder, and transferred to a password protected data stick. Attributed interview segments will be transcribed, as well as non-attributed or anonymous interview segments, although the transcription format for the latter will identify participants by an alphanumeric code, e.g., Founder F-1, F-2, etc.

I understand that the data will be locked in a secure location in the home of the researcher, and that only the thesis supervisor will access to the interview data, in order to allow him to provide instruction concerning transcription protocols. The transcriptions will be shared only with the Supervisor.

I understand that upon submission of the final copy of the thesis that all electronic copies of interview data will be deleted and erased, and any hard copies of transcripts will be destroyed one month following the submission of the final thesis.

I agree to have my name and identity used in the thesis.

Signature Date

I do not agree to have my name and identity used in the thesis, and thus everything I say will be confidential, within the limits specified above.

Signature

Date

Researcher Signature

Date 
I understand that research findings in the form of the final document will be made available to Ottawa Carleton Head Start Association for Pre Schools (OCHAP), after the document has been defended and appropriate modifications made.

\section{(Approval from the Ethic Board will be inserted at this point)}

Should you have concerns regarding this thesis project, you may contact the Carleton University Research Ethics Board.

Chair contact info:

Prof. Antonio Gualtieri, Chair

Carleton University Research Ethics Board

Carleton University

1125 Colonel By Drive

Ottawa, ON

K1S 5B6

Tel: 6135202517

ethics@carleton.ca

Research Supervisor

Signature

Date

Research Student

Signature

Date

Research Supervisor

Gerald de Montigny

Carleton School of Social Work

Gerald demontigny@carleton.ca

Tel: 6135202600 ext. 3658

\author{
Research Student \\ Sylvette Bruneau \\ Carleton School of Social Work \\ sbruneau@connect.carleton.ca
}

Tel:

I, have read the above letter and understand that I am participating in a research project and I voluntarily agree to participate. 


\section{Carleton}

School of Social Work

1125 Colonel By Drive

Ottawa, ON Canada K15 5B6

Tel: 1613$) 520-5601$

Fax: $(613) 520-7496$

\section{Append. 5 -Letter and Consent Form for the Directors of Head Start}

I have been provided with information concerning this research project, which is being completed for a MSW thesis by Sylvette Bruneau, who is a Master of Social Work Student from Carleton University and is working under the supervision of a Social Work Professor Dr. Gerald de Montigny.

I understand that the research examines the origins of Head Start in the USA, and its adoption and adaptation in Canada. I understand that this focus group seeks to envelop a portrait of past and present goals and objectives for head start by eliciting my understandings as Director of Head Start.

I understand that a benefit of this research is that it provides an opportunity for a greater public appreciation of the contributions of the Head Start program and modality to at risk, disadvantaged, and marginalized children and their parents and to the development of best practices models for delivery of such programs.

I understand that the focus group is expected to last between an hour to an hour and a half and will take place in an office at one of the centres. The focus group session will be audio recorded for the purpose of providing for accurate transcription of data.

During the focus group I may refuse to answer any question; I may indicate that I wish to have any statement I have made retracted and deleted from the record; I may request ending the withdrawing from the session at any time.

I understand that by consenting to be a participant in this focus group that I do not have anonymity and confidentiality within the group setting. However, I understand that discussions and transcribed data will be non-attributable i.e. what is said within the session will not be assigned to a specific participant.

I understand that if I request that I will receive an electronic copy of the transcription of the session, and that I may indicate, by voice or e-mail, at any time, up to (one month before the submission of the thesis for examination) that I wish to withdraw from the project, and that the information they provided not be used. During the focus group I will have the option of requesting that specific information or statements be non-attributable.

If I am named in the thesis I will be provided with an electronic copy or hard paper copy (the format will be at my request), of those draft pages of the thesis where I am named and 
quoted. I can then respond by e-mail or post returning all modification or deletion of attributed materials which will then replace the draft materials.

I understand that as a Director of the Head Start program. I will not be asked to share, nor will I share any confidential, personal, or sensitive information.

I understand that digital audio recordings will be produced on a recorder, and transferred to a password protected data stick.

I understand that the data will be locked in a secure location in the home of the researcher, and that only the thesis supervisor will access to the transcribed data, in order to allow him to provide instruction concerning transcription protocols. The transcriptions will be shared only with the Supervisor and that the data will be destroyed one month following the submission of the final thesis.

I agree to have my name and identity used in the thesis.

Signature

Date

I do not agree to have my name and identity used in the thesis, and thus everything I say will be anonymous

Signature Date

Researcher Signature Date

I understand that research findings in the form of the final document will be made available to Ottawa Carleton Head Start Association for Pre Schools (OCHAP), after the document has been defended and appropriate modifications made.

(Approval from the Ethic Board will be inserted at this point)

Should you have concerns regarding this thesis project, you may contact the Carleton University Research Ethics Board.

Chair contact info:

Prof. Antonio Gualtieri, Chair

Carleton University Research Ethics Board

Carleton University

1125 Colonel By Drive

Ottawa, ON

K1S 5B6 
Tel: 6135202517

ethics@carleton.ca

Research Supervisor

Signature

Date

Research Student

Signature

Date

Research Supervisor

Research Student

Gerald de Montigny

Sylvette Bruneau

Carleton School of Social Work

Carleton School of Social Work

Gerald demontigny@carleton.ca

sbruneau@connect.carleton.ca

Tel: $6135202600 \quad$ ext. 3658

Tel:

I, have read the above letter and understand that I am participating in a research project and I voluntarily agree to participate. 